\title{
11
}

\section{Dating painted Panel E1 at Nawarla Gabarnmang, central-western Arnhem Land plateau}

\author{
Bruno David, Jean-Jacques Delannoy, Robert Gunn, Emilie Chalmin, \\ Géraldine Castets, Fiona Petchey, Ken Aplin, Magen 0'Farrell, \\ Ian Moffat, Jerome Mialanes, Jean-Michel Geneste, Bryce Barker, \\ Benjamin Sadier, Margaret Katherine, Meropi Manataki and \\ Ursula Pietrzak
}

\section{Introduction}

The southern Arnhem Land plateau contains a rich mosaic of thousands of rock art sites located in outcrops of Proterozoic Marlgowa Sandstone of the Kombolgie formation (Carson et al. 1999) (Figure 11.1). Within this region in Jawoyn Country can be found Nawarla Gabarnmang, an impressive rockshelter exhibiting a gridded network of pillars that supports a thick ceiling of $10 \mathrm{~cm}$ to $40 \mathrm{~cm}$ thick cross-beds of hard sandstone and quartzite (Figures 11.2 and 11.3; see also Chapter 10). The inter-layer joints and fissures between these compact and poorly soluble quartz-rich sandstones and quartzites have witnessed geologically slow dissolution of the bedrock, resulting in a hollowing out of the rock in a process known as 'ghost rock' formation or 'phantomisation' (Quinif 2010), a particular cave-forming process causing the regular gridshaped structure of underground cavities and pillars (for details of site formation processes, see Chapter 13).

The remnant pillars supporting ceiling rock strata at Nawarla Gabarnmang are an anthropic cave structure (Delannoy et al. 2013; see Chapter 10): in addition to the slow geological dissolution of the rock along layer planes and fissure lines, people have also entirely or partially removed individual pillars, and possibly ceiling strata, over a period commencing sometime after the site was first occupied around 50,000 years ago (e.g. David et al. 2011, completed manuscript). What catches one's attention at Nawarla Gabarnmang are the voids between the pillars, typically c. 1-2 $\mathrm{m}$ apart in the southwestern corner of the site, but more than $8 \mathrm{~m}$ apart in the centraleastern portion. In that noticeably more open central-eastern area, a large, sub-horizontal and flat ceiling is supported by some 20 sparsely distributed pillars. Here, as in most other parts of the site, the floor of the sheltered area is generally flat and sub-horizontal, consisting of ashy sand with sparsely scattered, relatively small blocks of rock originating from the ceiling but not in their original fallen positions (these blocks have all, without exception, been moved by people). Within the fill across the site are rich archaeological deposits including stone artefacts, ochre pieces and animal bones, as revealed in the archaeological excavations (David et al. 2011; 
Geneste et al. 2012). What we see today in the shelter are the results of tens of thousands of years of human occupation, modification of rock surfaces and site use that express well the notion of 'dwelling' and 'inhabitation' (e.g. David et al. 2013, 2014; Delannoy et al. 2013; Geneste et al. 2010; cf. Ingold 2000; Thomas 2008).

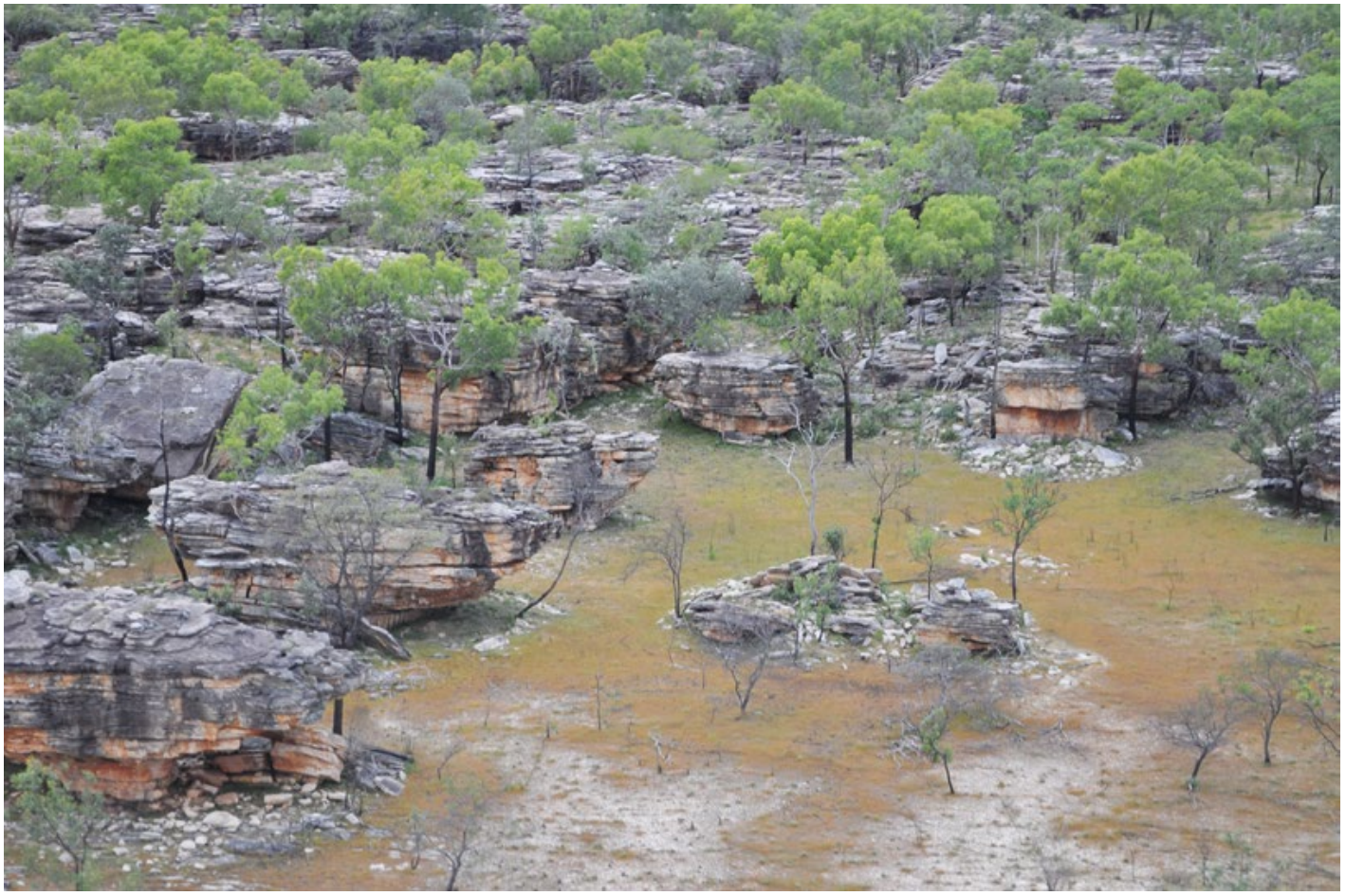

Figure 11.1 Detail of the vast rockshelter landscape of the central-western Arnhem Land plateau.

Source: Photograph by Bruno David.

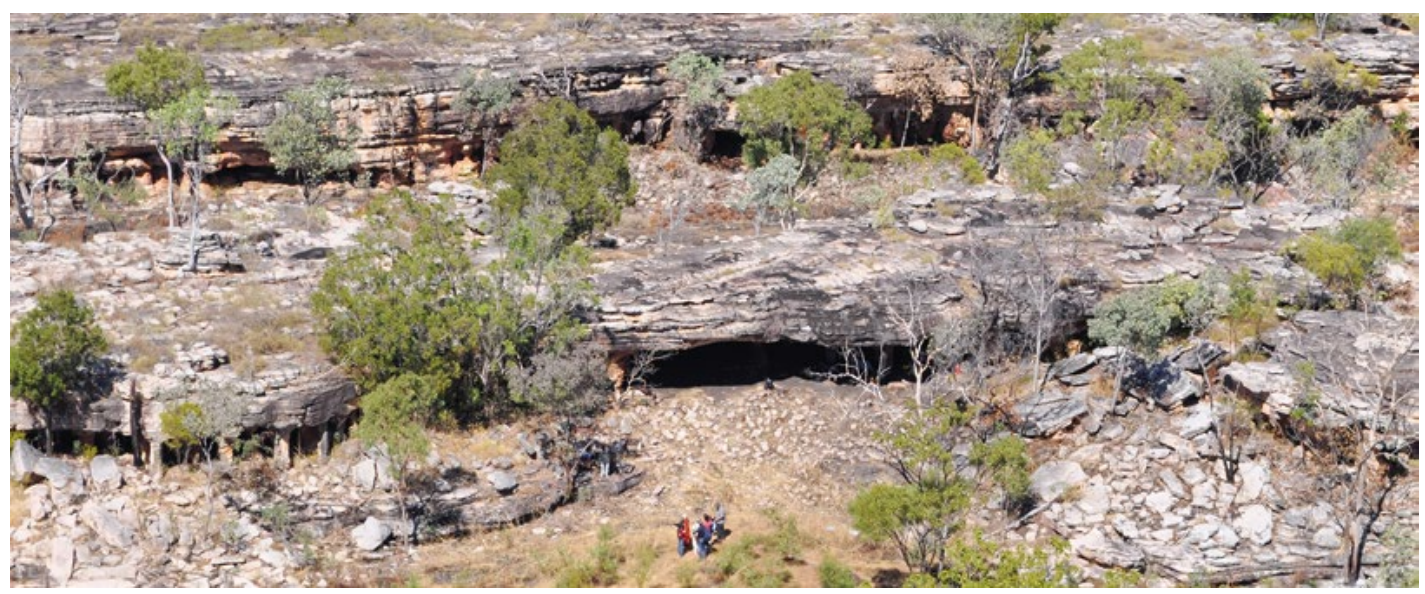

Figure 11.2 Nawarla Gabarnmang, northern entrance.

Source: Photograph by Bruno David. 


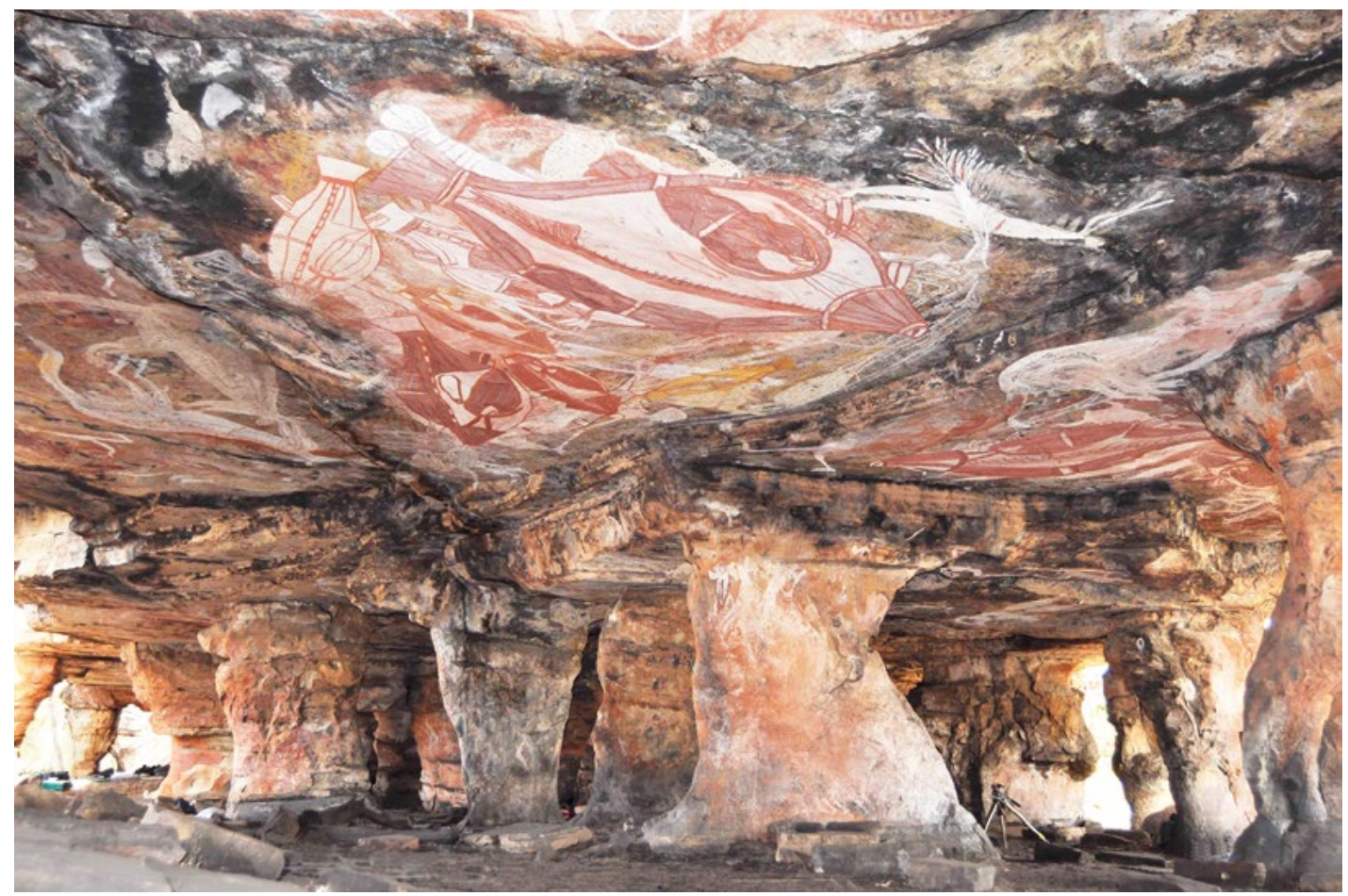

Figure 11.3 Inside Nawarla Gabarnmang, showing pillared site structure.

Source: Photograph by Jean-Jacques Delannoy.

Nawarla Gabarnmang is of special interest for rock art research because it has a rich and especially well preserved record of paintings under its well-protected overhang and, to a lesser extent, on its rock pillars (e.g. Figure 11.3). This art is, in some parts of the site, represented by expansive and overlapping concentrations of paintings (with minor quantities of other kinds of artworks also being present, such as cupules, beeswax designs and stencils). Elsewhere in the shelter, more or less discrete art panels usually have multiple and complex patterns of superimposition.

Gunn (2016) has divided the shelter's ceiling into 41 sections with pigment art (Figure 11.4), each section representing a more or less spatially discrete area of art. A total of 1391 images have been recorded in up to 49 layers of superimposition from the ceiling alone. The area reported in this chapter is Panel E1, located immediately above archaeological excavation Square P (Figures 11.4 and 11.5). While the complex superimpositions in Panel E1 reveal a chronological sequence of painted images, detailed three-dimensional (3-D) laser mapping of the site, geomorphological investigations and excavation of Square P have revealed surface and in situ buried information that individually and together enable us to understand better the ages of these sequential layers of artworks on the ceiling above.

The aim of this chapter is to cross-correlate information obtained from the painted ceiling at Panel E1 with geomorphological details and archaeological evidence buried immediately below the art panel in Square P. In this way, the information immanent in the rock art and in the strata below it are combined into an integrated understanding, in a way rarely attempted when studying Australian rock art. 


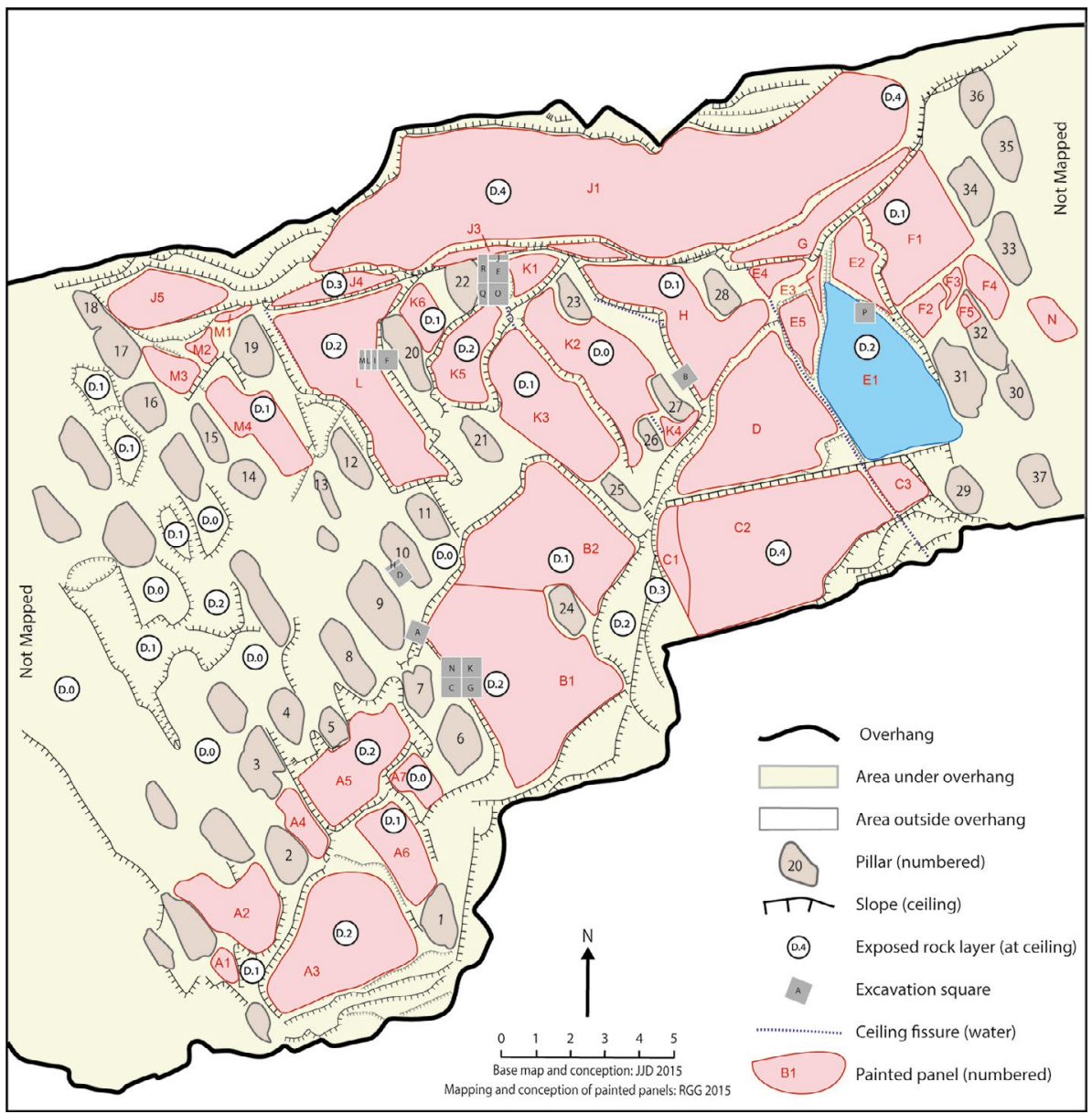

Figure 11.4 Map of ceiling of Nawarla Gabarnmang, showing location of Panel E1 relative to other ceiling art panels and excavation squares.

Note that the pillars are shown where they meet the ceiling, whereas the excavation squares are at ground level. Source: Illustration by Jean-Jacques Delannoy, Robert Gunn and Kara Rasmanis.

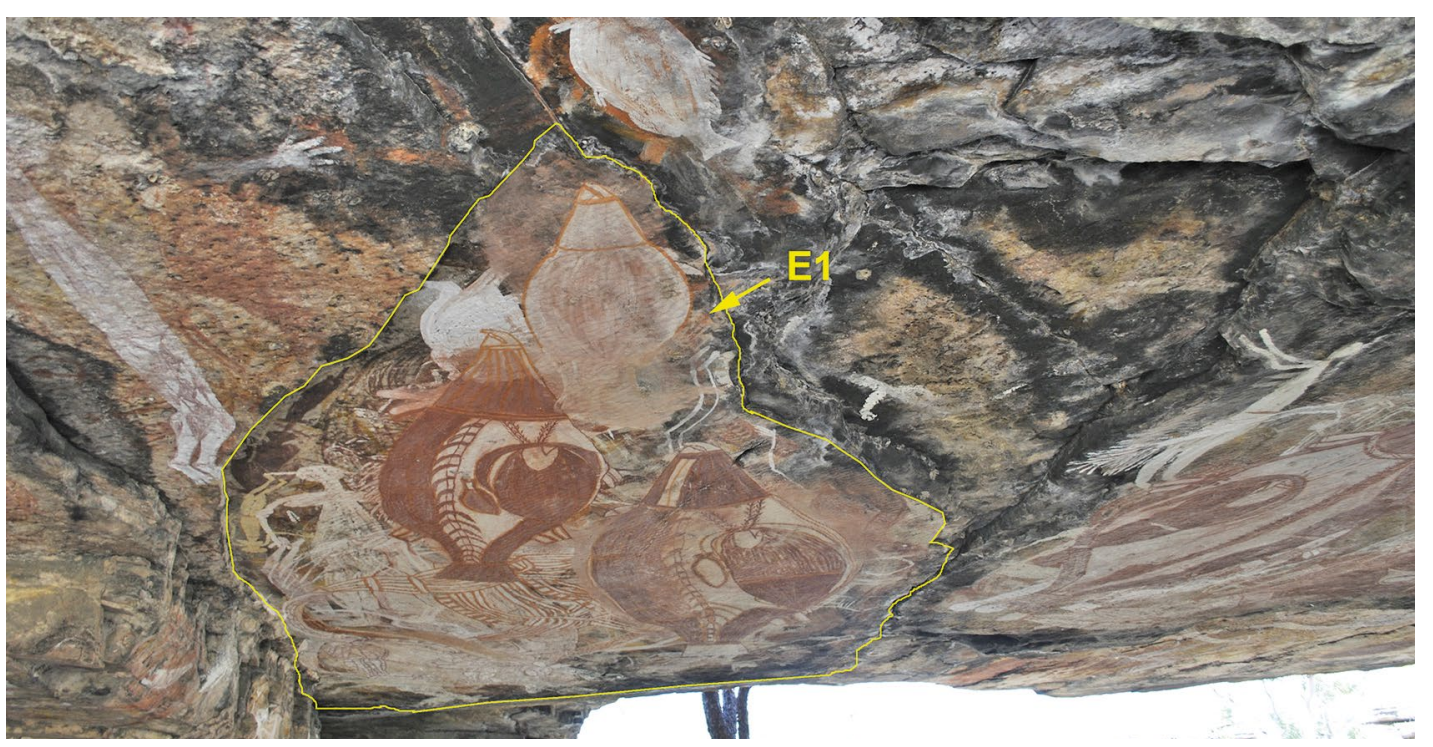

Figure 11.5 Location of Panel E1 within the centre-eastern ceiling.

Source: Photograph by Robert Gunn. 


\section{Panel E1}

Panel E1 is large, covering a roughly triangular area $5.4 \times 2.4 \mathrm{~m}$ in maximum dimensions. It is located in the central-eastern side of the shelter, in a part of the site where there is maximum spacing between pillars. The surface of the ceiling at Panel E1 is flat and sub-horizontal, exhibiting small and shallow ripple marks that provide minor rounded texture. Eighty-two painted or stencilled images are present on this panel, mostly concentrated towards its centre, with extensive superimpositioning virtually obliterating the central motifs of the underlying and therefore older layers (Tables 11.1-11.3; Figures 11.6 and 11.7).

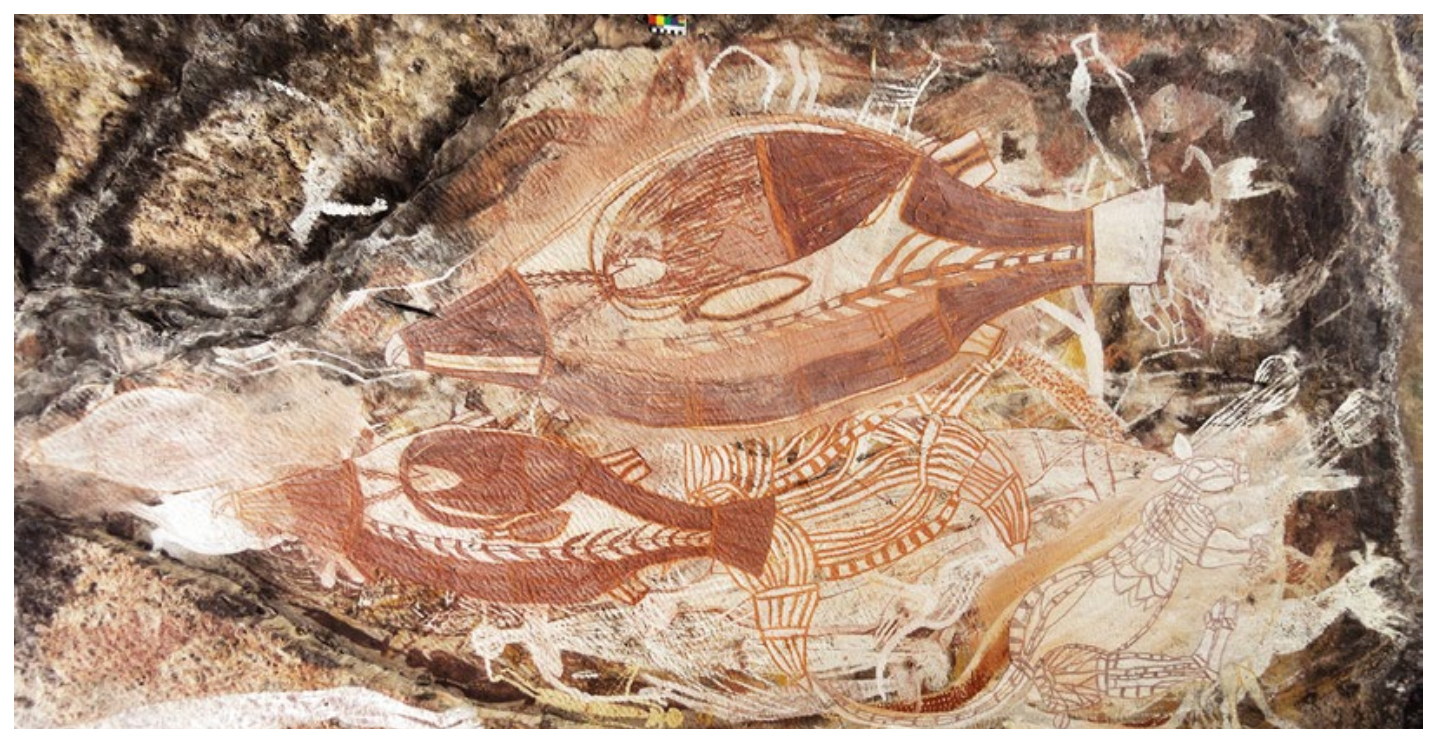

Figure 11.6 Panel E1.

Source: Photograph by Robert Gunn.

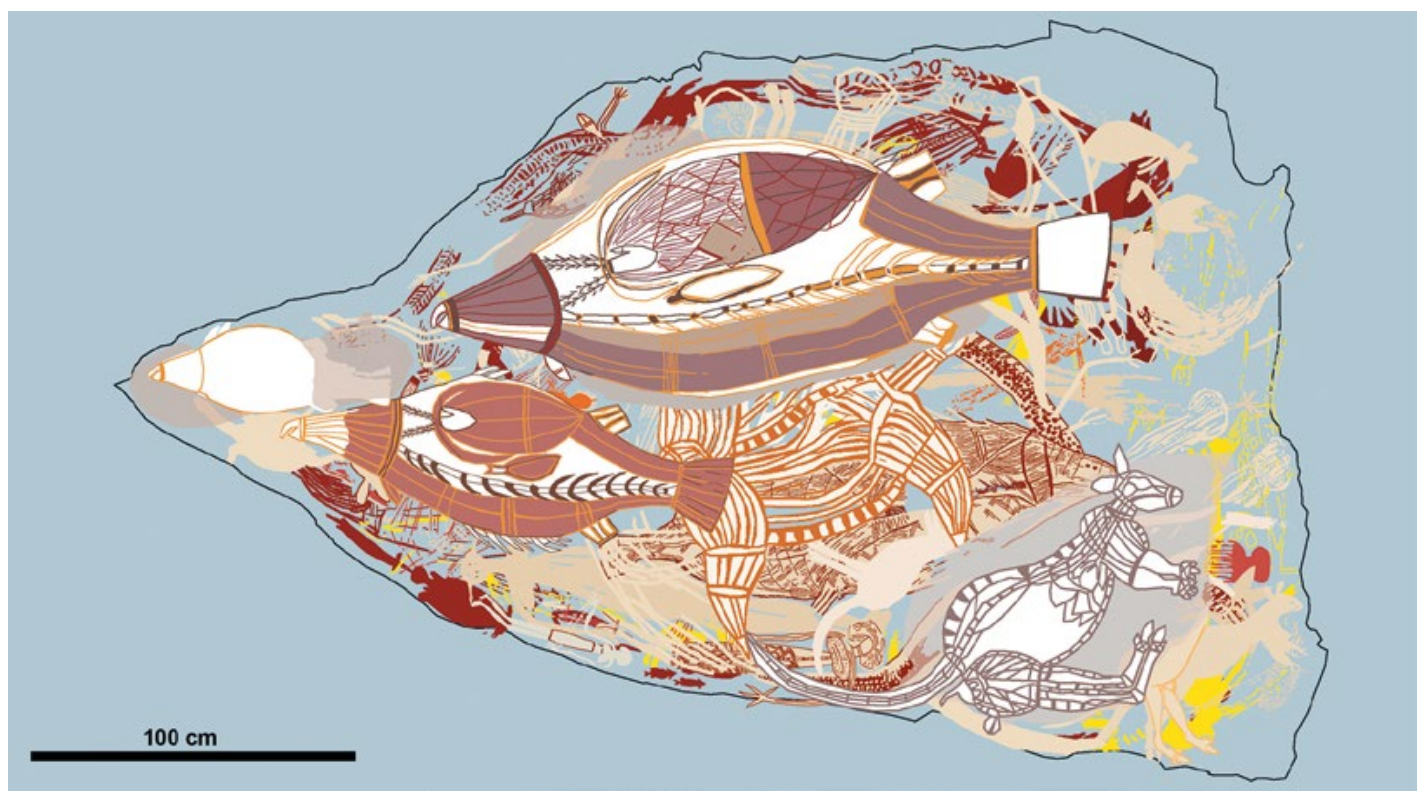

Figure 11.7 Photo-tracing of Panel E1.

The images are drawn in selected standardised colours that do not equate precisely with the hues of the original images. Here, as in the other photo-tracings presented in this chapter, a grey background (Pantone Cool Grey 9 C) was selected to provide good contrast for the overlying art colours.

Source: Illustration by Robert Gunn. 
In order to clarify patterns of superimposition across the whole of the panel, a Harris Matrix was constructed, incorporating all of the art present in Panel E1. The Harris Matrix approach, originally created to describe complex archaeological stratigraphies in intricate urban sites (Harris 1989; Russell 2012), was first used for rock art in western Arnhem Land (Chippindale and Taçon 1993). It models the relative superimposition of strata across space, in this case involving the micro-strata of superimposing artworks spread across the panel. The completed Harris Matrix depicts the minimum number of paint layers required to account for all the art and their superimpositions in Panel E1, as generated from the sum of individual superimpositions (Figure 11.8).

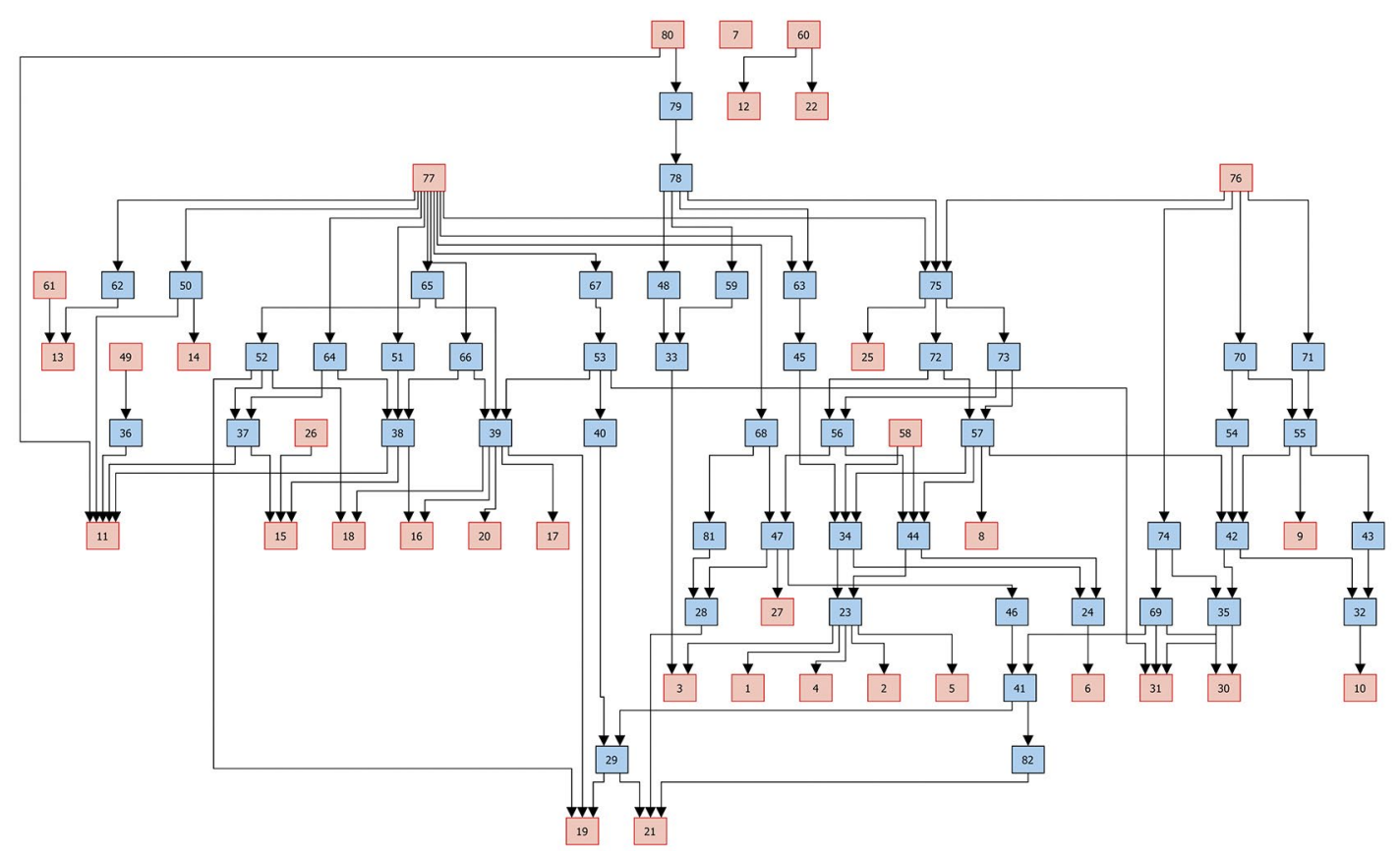

Figure 11.8 Harris Matrix showing pattern of superimpositions for all 82 images of Panel E1.

Red squares indicate images at the beginning or end of a sequence of superimpositions, and singular images not involved in superimpositions. Blue squares indicate images within a sequence of superimpositions (see Harris 1989; Russell 2012).

Note: To magnify the diagram please see the PDF version at: press.anu.edu.au

Source: Illustration by Robert Gunn.

The systematic computation integrating all the cases of superimposition in Panel E1 identifies at least 15 layers of superimposition involving all but one of its 82 images. That lone image (Image \#7) was assigned to Layer 13 on the basis of similarities in motif type, colour, size and preservation relative to adjacent Images \#6 and \#8. All 15 layers, numbered from the top down as Layers $1-15$, were grouped into six chronological phases, numbered from the bottom up as Phases I-VI (Figure 11.9):

- Phase I is made up of Layers 14 and 15: This earliest phase consists of 21 images in red in at least two separate layers. Of note is the presence of basic X-ray features in a monochrome red fish (Image \#15; with stylised backbone and ribs depicted) and a long snake (Image \#11; with backbone, ribs and eggs depicted) (Figure 11.10).

- Phase II is Layer 13: This layer consists of 12 yellow paintings, with only one simple design being clear enough to identify to motif type (Figure 11.11).

- Phase III is Layer 12: A layer of four red paintings also cannot be identified to motif type (Figure 11.11). 
- Phase IV is made up of Layers 5-11: The 39 images from this phase come from six distinct layers dominated by paintings in monochrome white and bichrome white and red (Figures 11.12-11.14). Within this phase, Layer 5 has two anomalous orange anthropomorphs, one of which (Image \#46) has a white headdress. The white monochrome and bichrome with basal white motifs do not occur as separate, discrete layers, suggesting that on this panel they are contemporaneous.

- Phase V is Layer 4: A single bichrome turtle motif in white and orange. This motif is distinctly different from all underlying or overlying motifs (Figure 11.14).

- Phase VI is made up of Layers 1-3: This most recent phase, which contains five images, shows a distinct change in the art towards larger and more visually dramatic images (Figure 11.15).

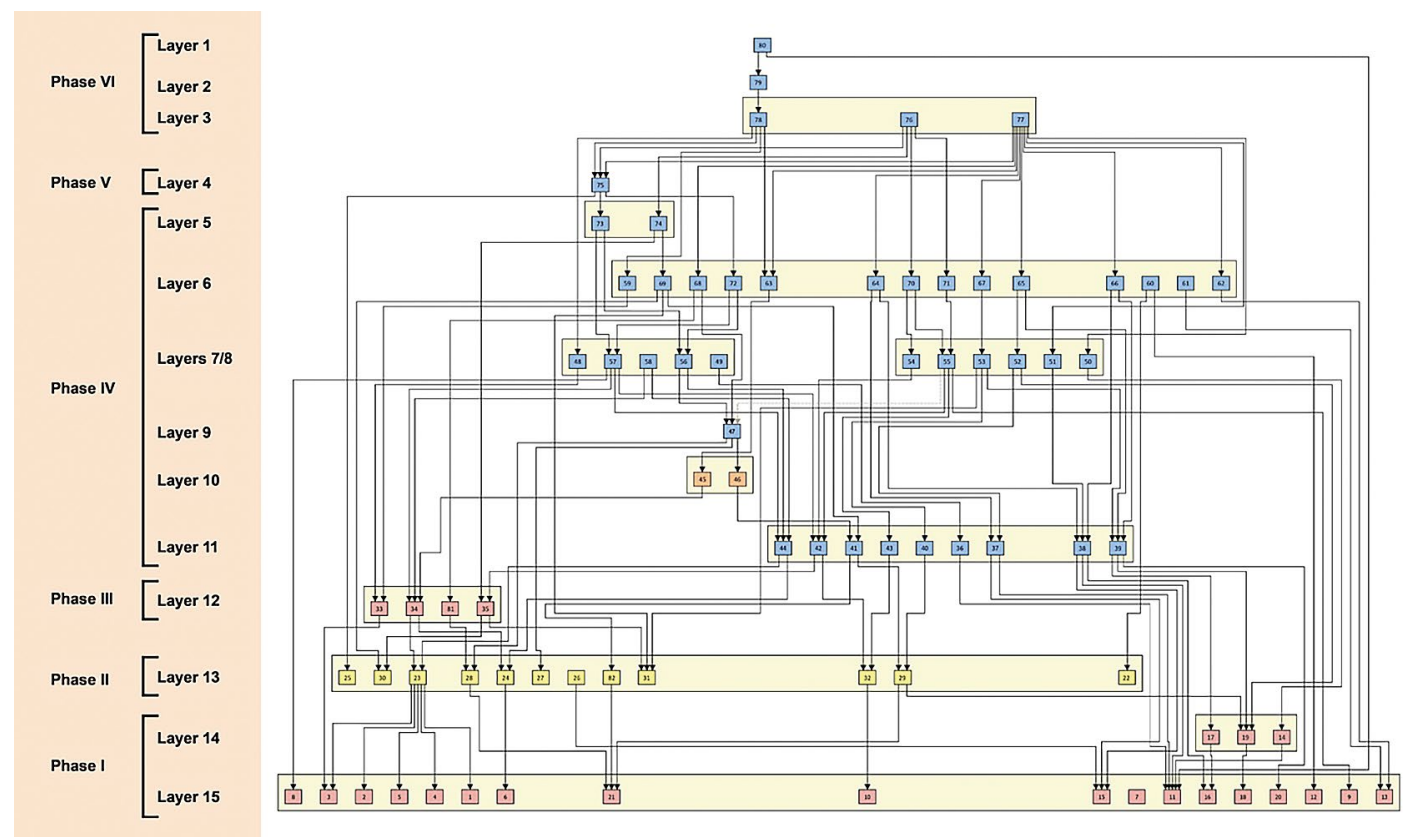

Figure 11.9 Interpretation of the Panel E1 Harris Matrix, with phases indicated.

Coloured squares indicate the principal colour of the image (in polychrome works, this is the underlying colour and usually the most abundant colour in that image, as in an X-ray image where the underlying colour forms a solid silhouette onto which lines in other colours are superimposed): blue = white, red = red, yellow = yellow, orange = orange (see Harris 1989; Russell 2012).

Note: To magnify the diagram please see the PDF version at: press.anu.edu.au

Source: Illustration by Robert Gunn.

Most of the larger motifs occur towards the central parts of the panel. However, a large snake (Image \#11) from the earliest Phase I (Layer 15) was positioned to curve around the panel's western edge (Figure 11.10). No consistency has been noted in the alignment of images relative to each other or to any other reference point. Unlike a vertical panel, this near-horizontal surface seems to have no top or bottom, and there is no 'right way up' or 'upside down' for the figures on it.

X-ray features occur among the lowermost (i.e. oldest) layers of Panel E1. This was unexpected, as elsewhere at Nawarla Gabarnmang (e.g. on Panel D) X-ray features occur only in the more recent art (Gunn 2016). The two X-ray motifs in the lowermost Layer 15 (Phase I) of Panel E1 are both in monochrome red: a fish (Image \#15) with stylised backbone and ribs; and the large red snake mentioned above (Image \#11) with backbone, ribs and eggs (Figures 11.10 and 11.16). 


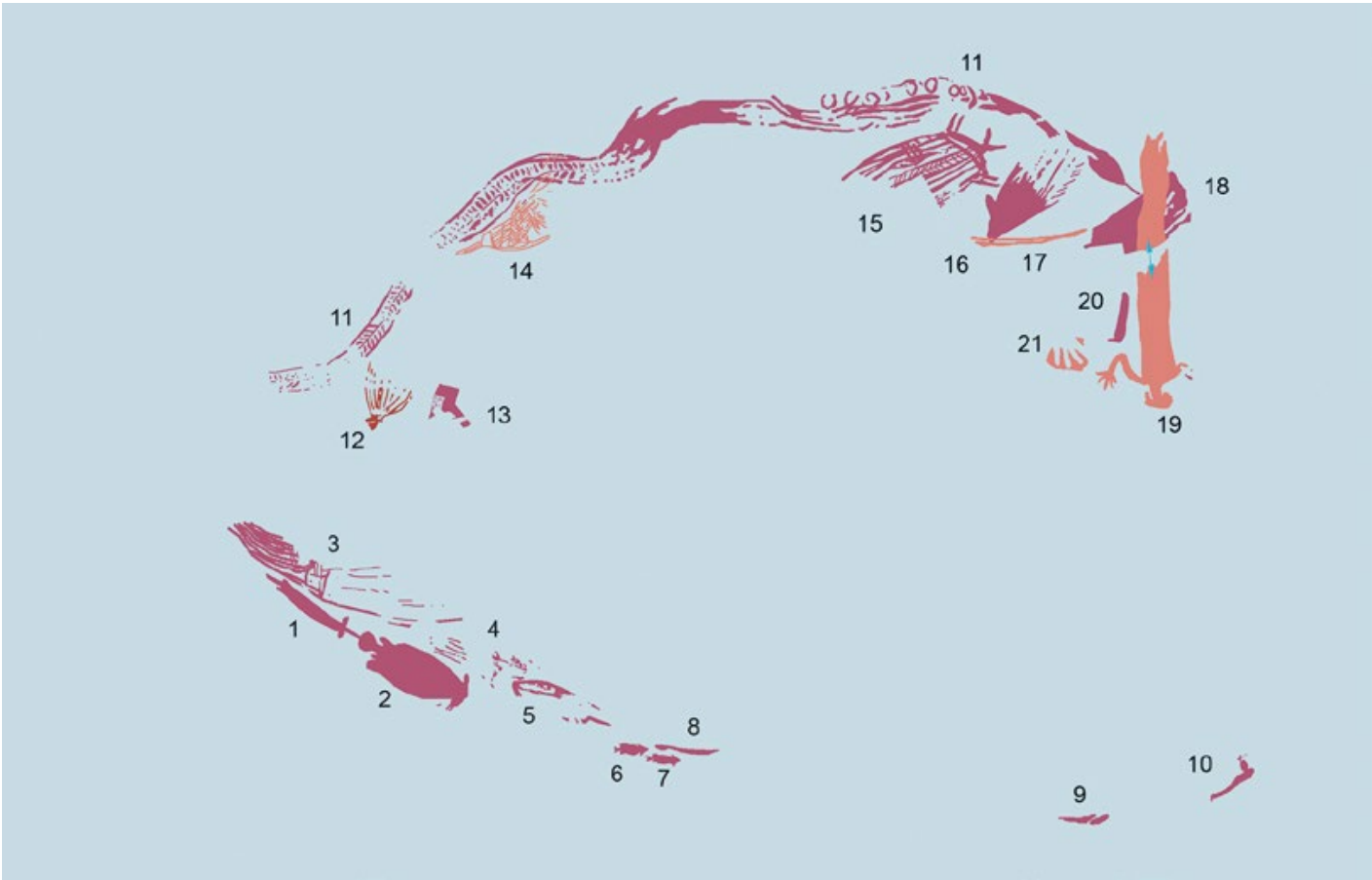

Figure 11.10 Phase I images (Layers 14 and 15), Panel E1.

Source: Illustration by Robert Gunn.

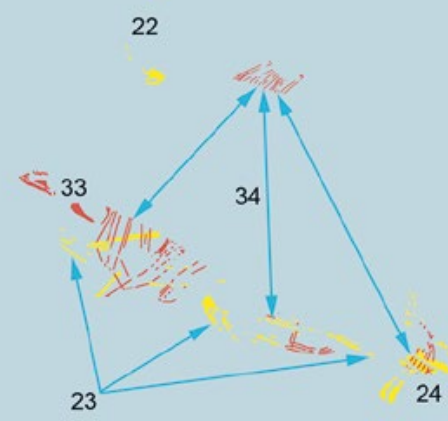

25

$28 \quad 82$

29

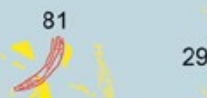

31

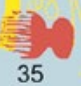

27

Figure 11.11 Phase II images (yellow = Layer 13) and Phase III images (red = Layer 12), Panel E1. Source: Illustration by Robert Gunn. 


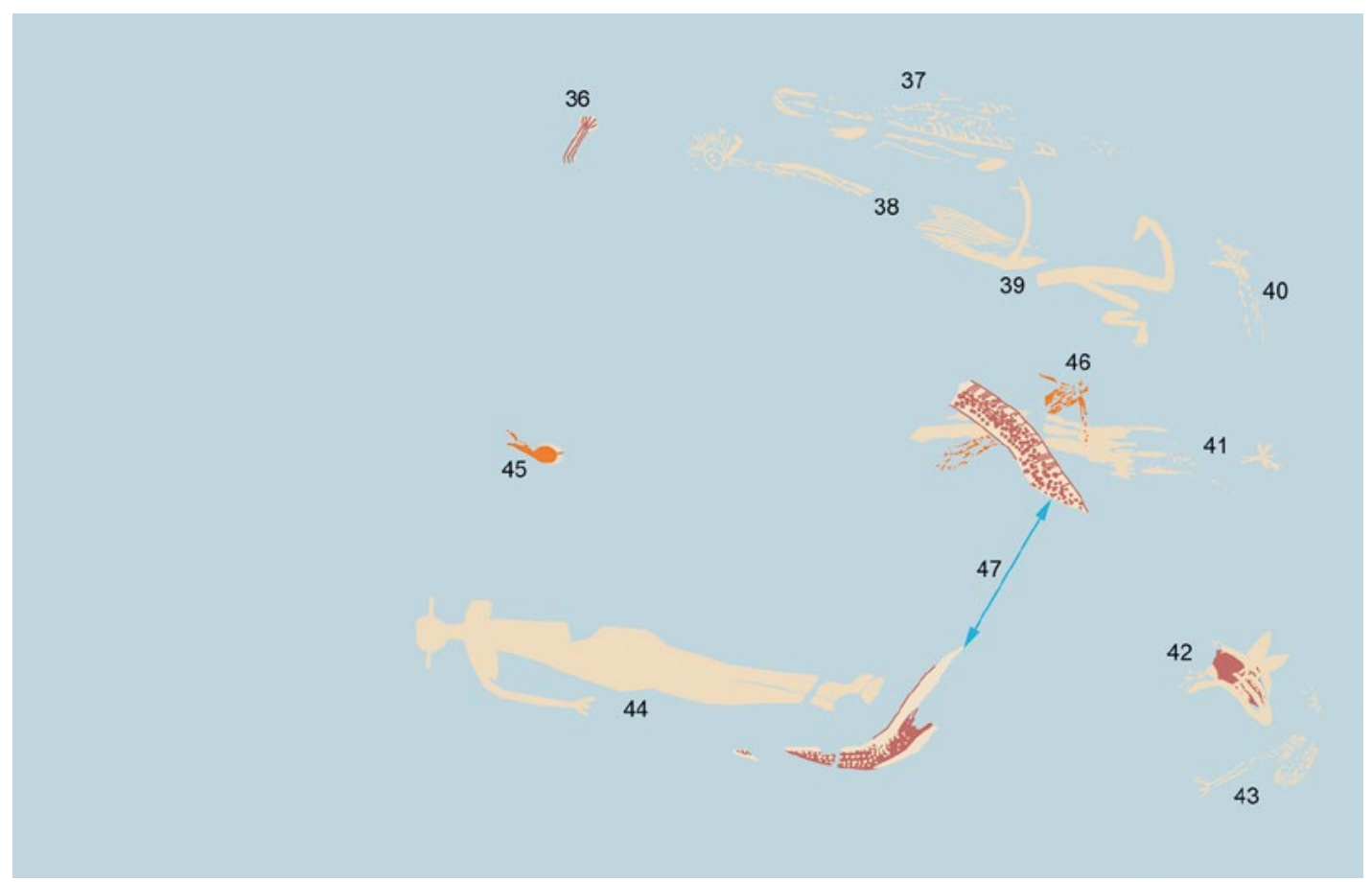

Figure 11.12 Phase IV images (Layers 9-11), Panel E1.

Source: Illustration by Robert Gunn.

49

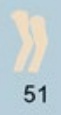

52

50

51

53

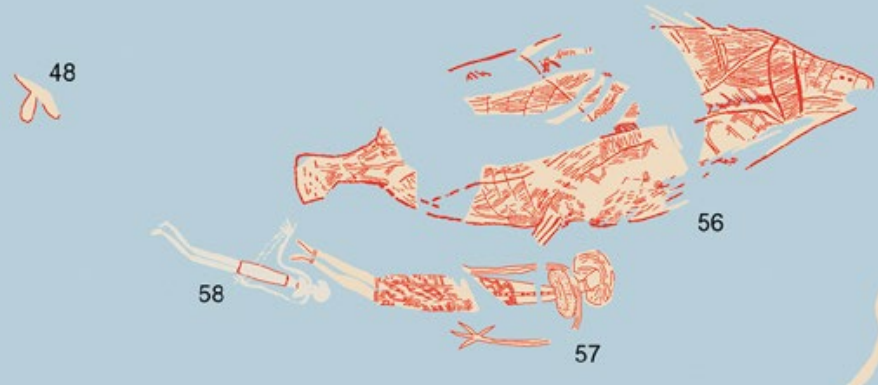

54

Figure 11.13 Phase IV images (Layers 7 and 8), Panel E1.

Source: Illustration by Robert Gunn. 


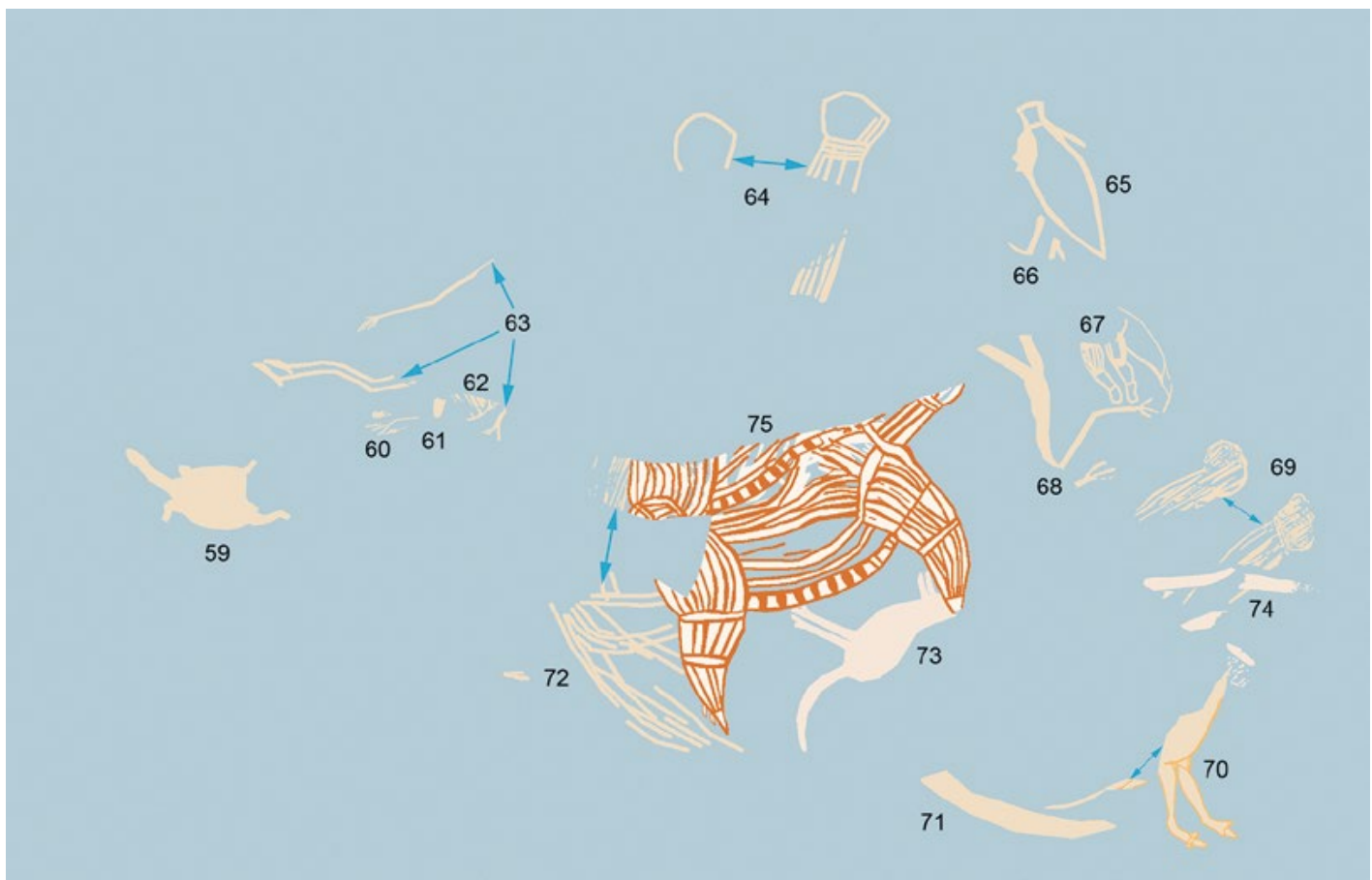

Figure 11.14 Phase IV images \#59-\#74 (Layers 5-6) and Phase V image \#75 (Layer 4), Panel E1. Source: Illustration by Robert Gunn.

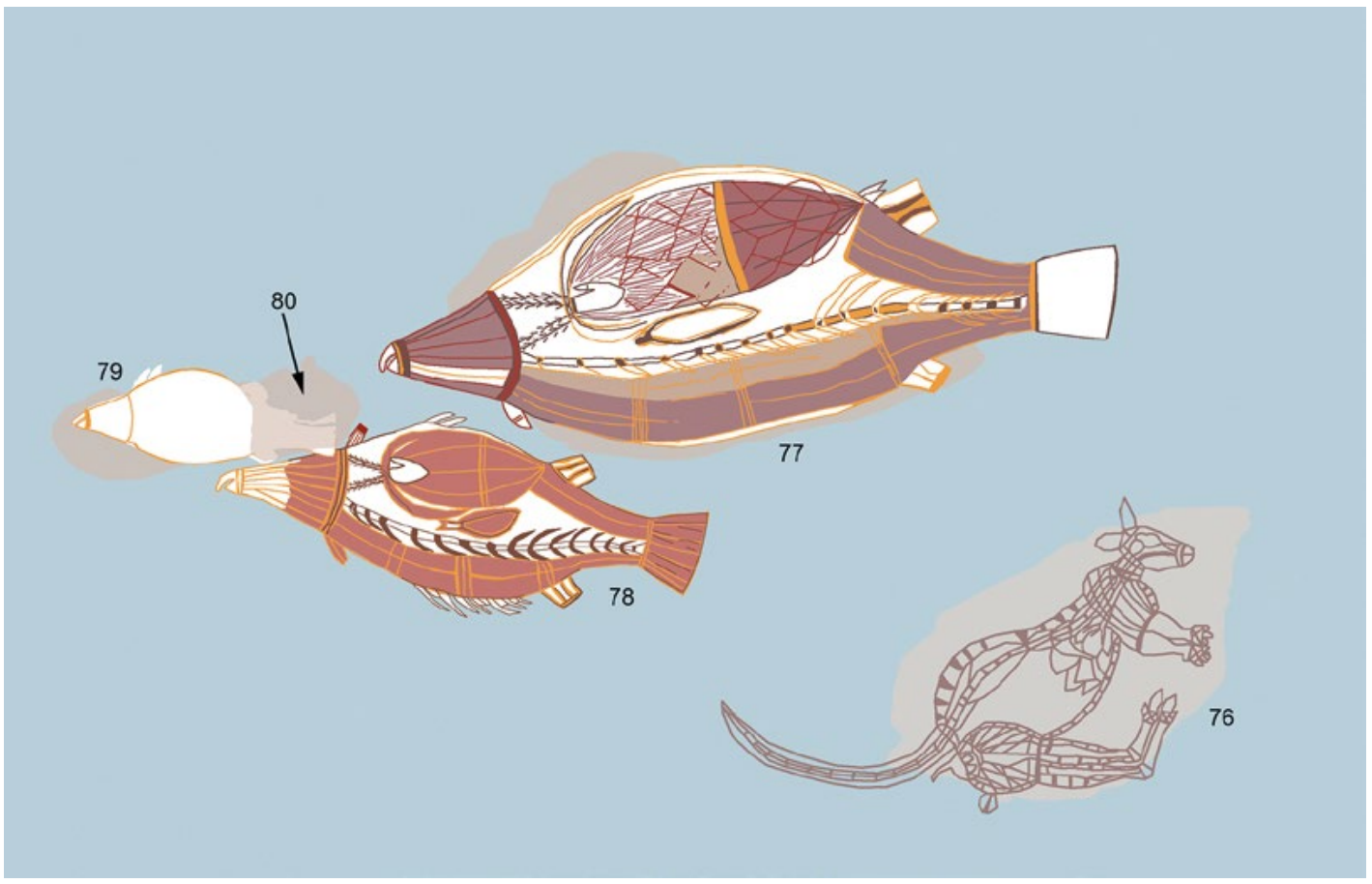

Figure 11.15 Phase VI images (Layers 1-3), Panel E1.

Source: Illustration by Robert Gunn. 


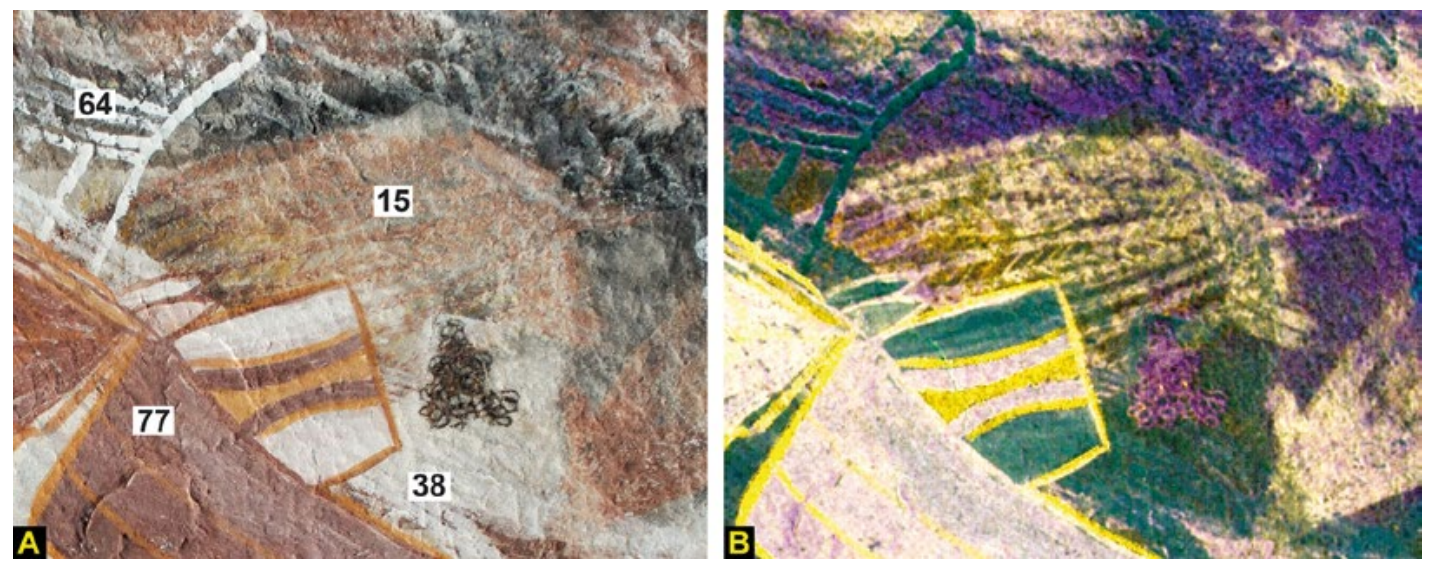

Figure 11.16 Details of monochrome X-ray fish Image \#15.

A: Original photograph. B: Digitally enhanced photograph using DStretch_labi10. Source: Photographs and enhancement by Robert Gunn.

As noted above, the white monochrome and bichrome with basal white paintings occur within the same phase, suggesting that they are contemporaneous. The bichrome motifs include two 'Jawoyn Lady' paintings (Images \#57 and \#58) and a large fish with patterned infill (Image \#56) (Figures 11.13 and 11.17).

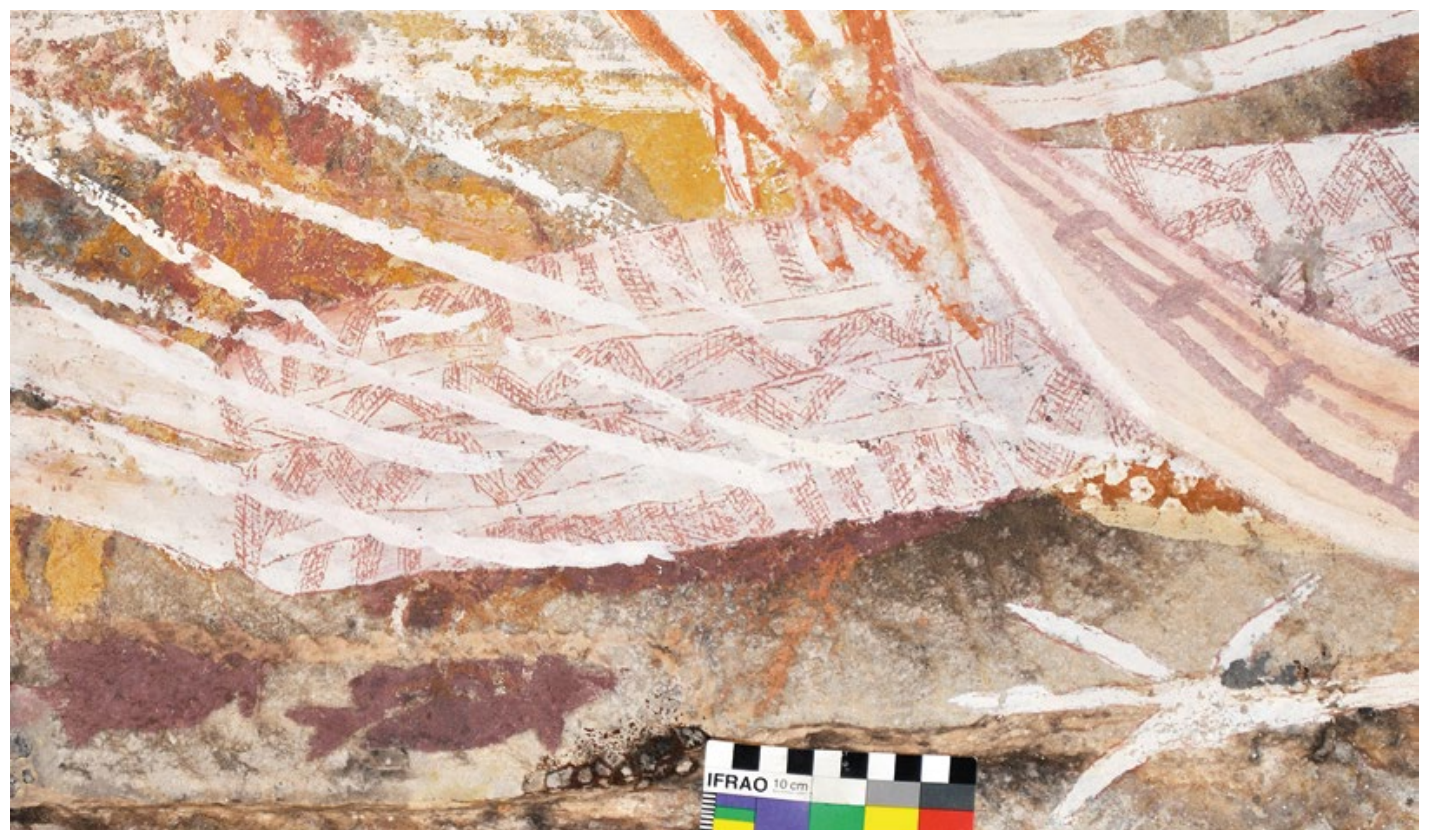

Figure 11.17 Details of body decoration on 'Jawoyn Lady' Image \#57.

Source: Photograph by Robert Gunn.

The uppermost, most recent paintings in the superimpositions show a distinct change in the art towards larger and more visually dramatic images. The lowermost of these impressively large images is a turtle (Image \#75; Figure 11.18) painted in 'Bula style'. Bula art is a style of painting relating to the ethnographic period and restricted to Jawoyn Country, defined by solid white silhouettes with bold red outline and infill line work (cf. Gunn 1992). Above the Bula-style turtle of Layer 4 in Panel E1 is an unusual form of X-ray macropod (Image \#76; Figure 11.19) and two large polychrome X-ray barramundi (Image \#77 and Image \#78; Figures 11.20 and 11.21), each of Layer 3; both barramundi have been later partially retouched on several occasions. 
The most recent image on Panel E1 is a barramundi that appears to have been only partially completed (Image \#79; Figure 11.22). It was painted on a prepared 'surface-smear' of pink paint (probably a blend of an applied white mixing with an existing red image). Subsequently, the barramundi (Image \#79) was partly over-painted by an off-white smeared area (Image \#80). Similarly, Images \#76 and \#77 were also painted over prepared surfaces. Ethnographically, Elkin (1952:245) reported the practice in Jawoyn Country of erasing a deceased person's painting by relatives smearing it with red ochre and over-painting another picture, usually a malindji (spirit figure) representing the deceased's spirit. He gives no actual examples of this practice, and no cases of smearing and over-painting with a spirit figure have been located in the recent extensive site recording in Jawoyn Country. Apart from these examples on Panel E1, smearing has only been recorded at the nearby shelter of Dalakngalarr (see Chapter 13). Whether the underlying smear was a preparation for making the over-painted image is unclear. Certainly, the practice of smearing was uncommon in Jawoyn Country.

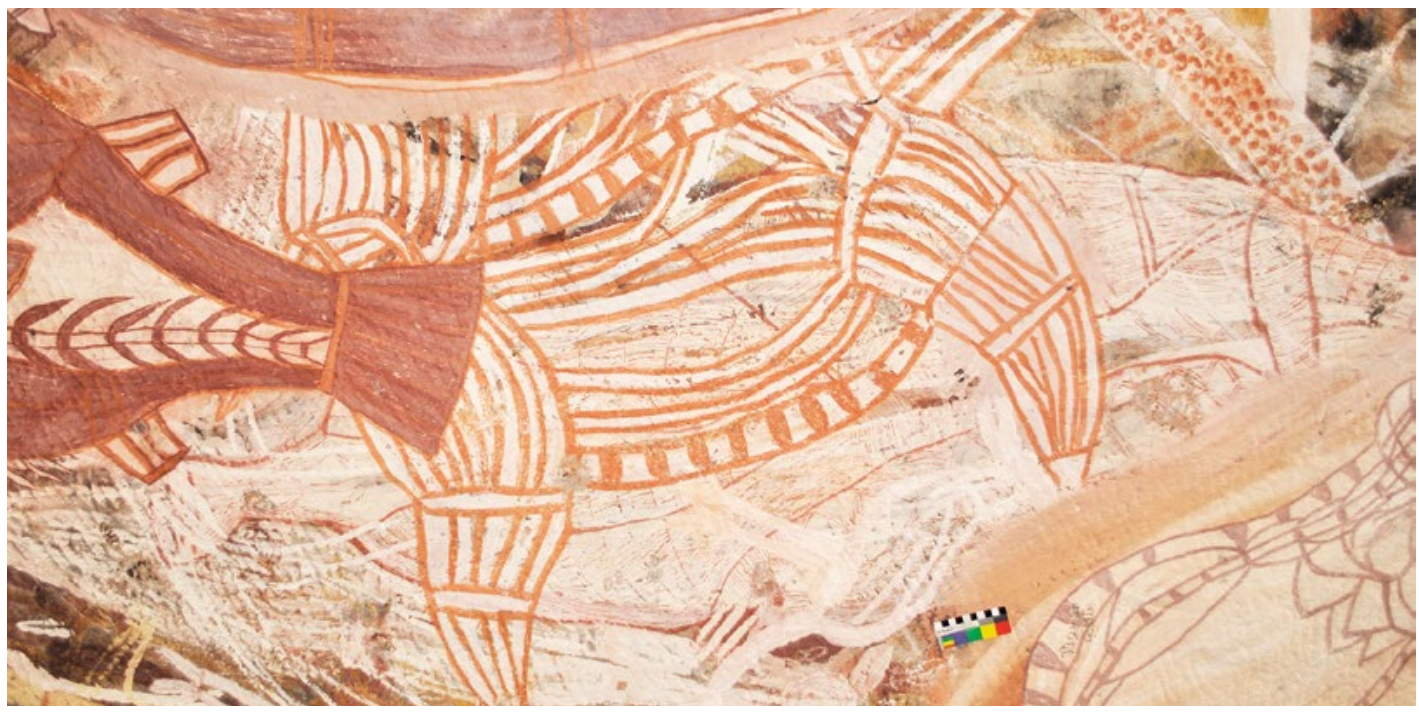

Figure 11.18 Bula-style turtle, Image \#75.

Source: Photograph by Robert Gunn.

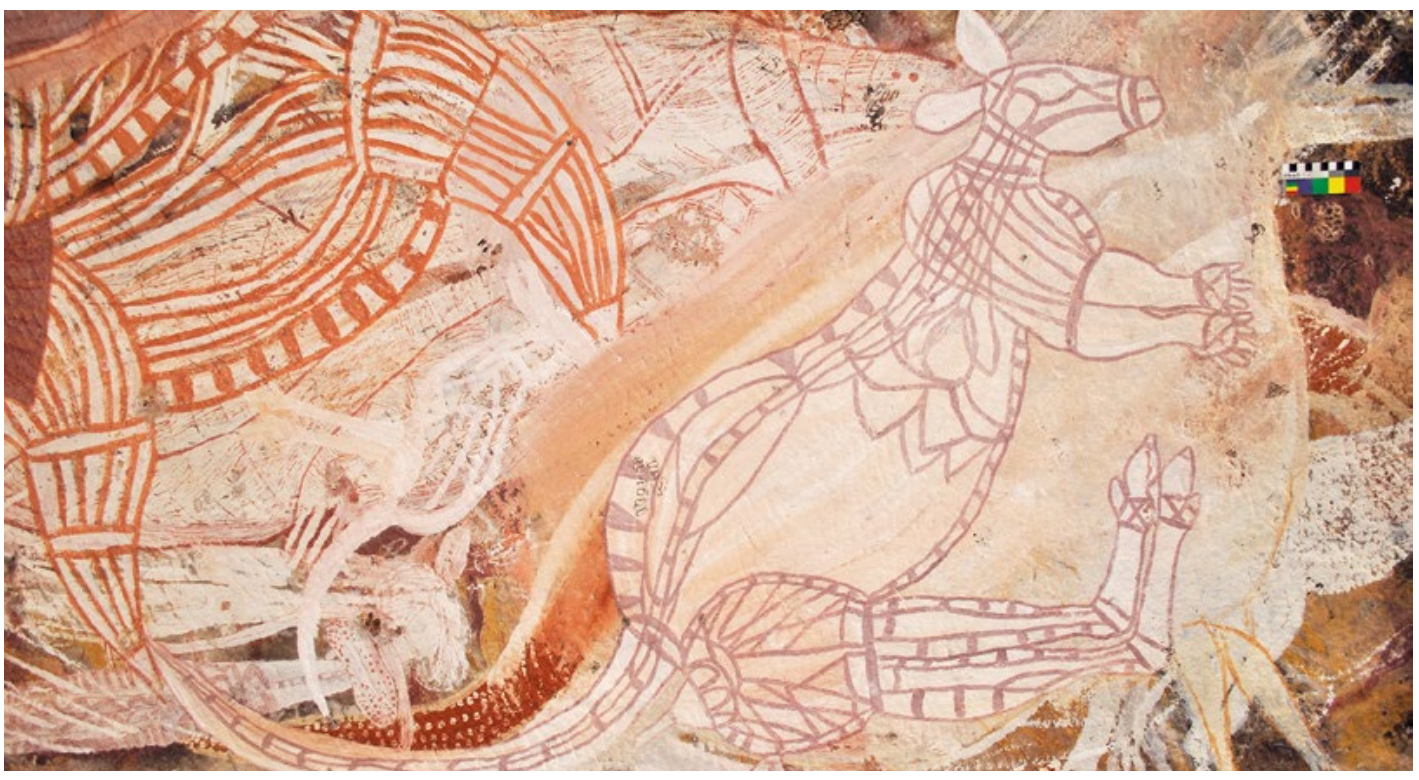

Figure 11.19 Macropod Image \#76 in a unique X-ray style variation.

Source: Photograph by Robert Gunn. 


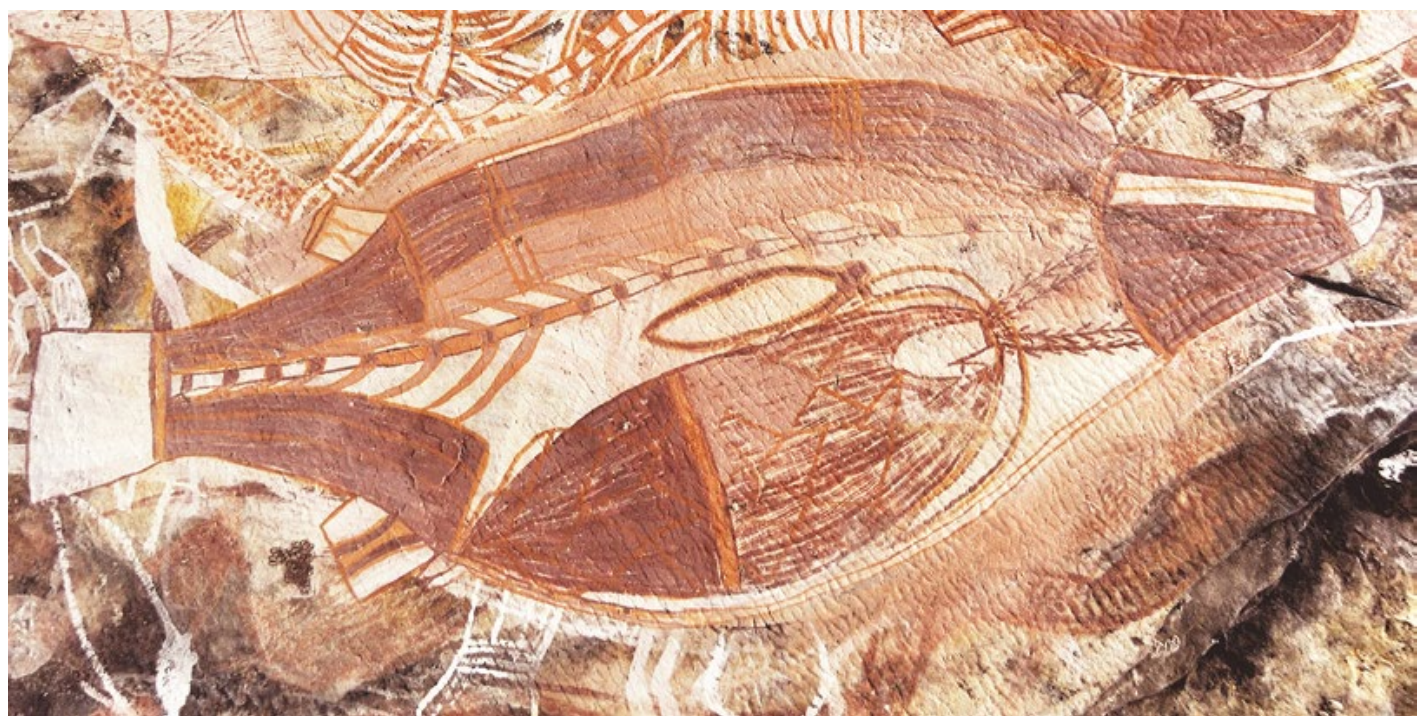

Figure 11.20 Large X-ray barramundi Image \#77.

Source: Photograph by Robert Gunn.

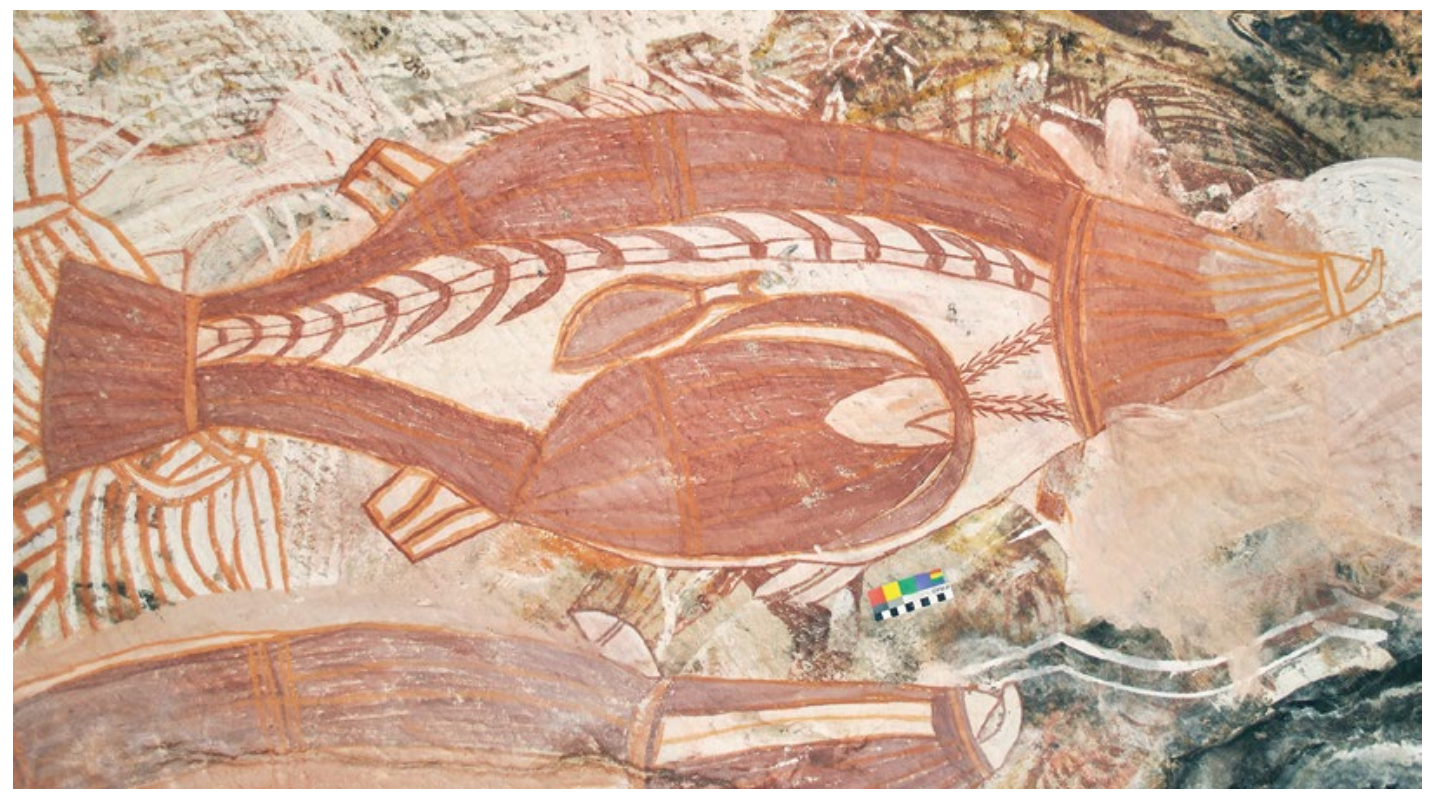

Figure $11.21 \mathrm{X}$-ray barramundi Image \#78.

Source: Photograph by Robert Gunn.

In the overall sequence, there is a change in colour from red to yellow to white and polychrome with basal white. Gunn et al. (2012) proposed that the turtle motif (Image \#75) of Panel E1 has stylistic connections - similarities in colour, size, form and visual impact - to paintings relating to the apocalyptic Bula cult of ethnographic times (cf. Gunn 1992), suggesting a past association between Nawarla Gabarnmang and that religious cult. The Bula cult incorporated restricted rock art and non-rock art sites across a small area in northern Jawoyn Country, some $30 \mathrm{~km}$ southwest of Nawarla Gabarnmang. The subsequent partial over-painting of the Bula-style turtle on Panel E1 was seen by a senior Jawoyn man, Peter Bolgay (pers. comm. to Robert Gunn 2006), as indicating a change in the function of the site, shifting away from an association with the Bula cult to becoming a place where visitors from the north of the plateau would camp while attending ceremonies with Jawoyn (Gunn et al. 2012). 


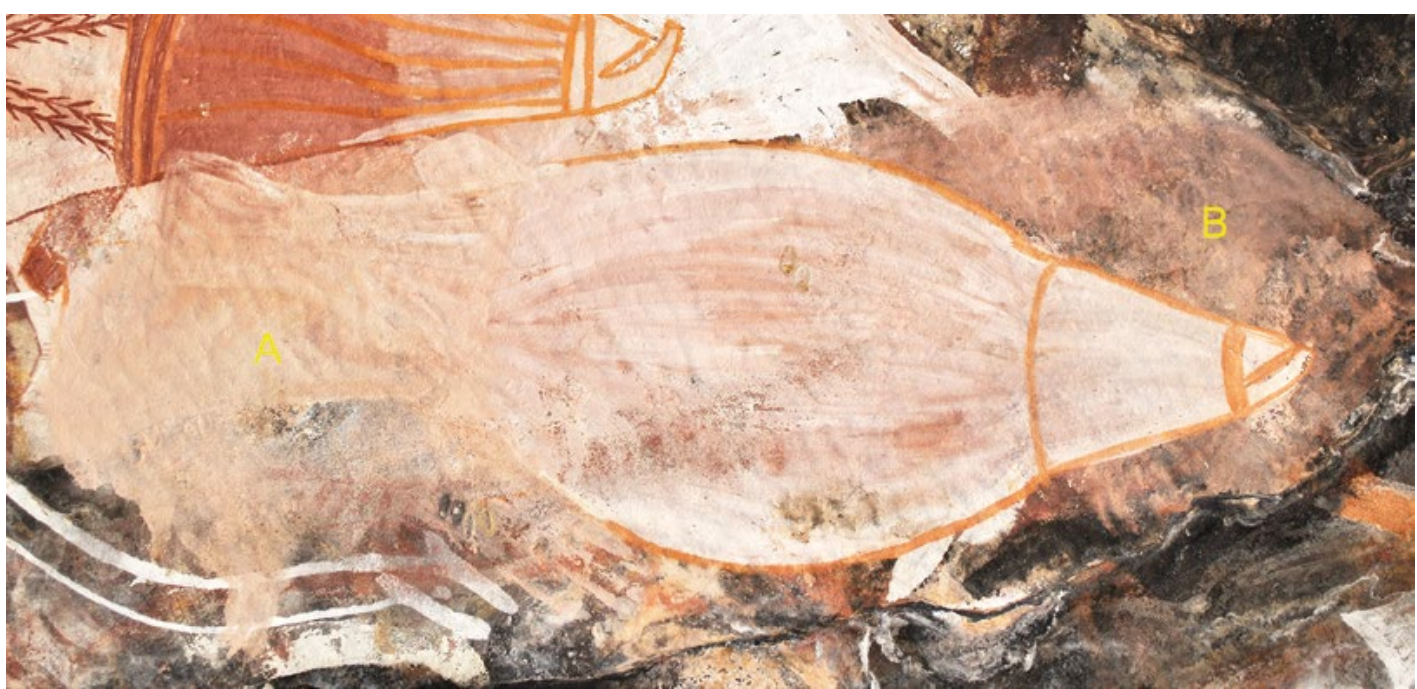

Figure 11.22 Image \#79 painted on a smeared background (B) and subsequently partially overpainted by a second smear (A).

Source: Photograph by Robert Gunn.

The quality and proficiency of the brushwork on Panel E1 also changes noticeably over time. Earlier paintings more often incorporate fine-line brushwork, occasionally also broad brushwork. More recent paintings generally have broader line works, and even their finer details are applied somewhat more coarsely than are the earlier line infills (Figures 11.23 and 11.24). Further evidence for this change in conventions is the later partial re-decoration of Image \#77, where an orange mesh design uncomfortably overlies the brown gut pattern beneath, and a partial purple infill of this mesh design has not been confined to the mesh compartments (Figure 11.25).

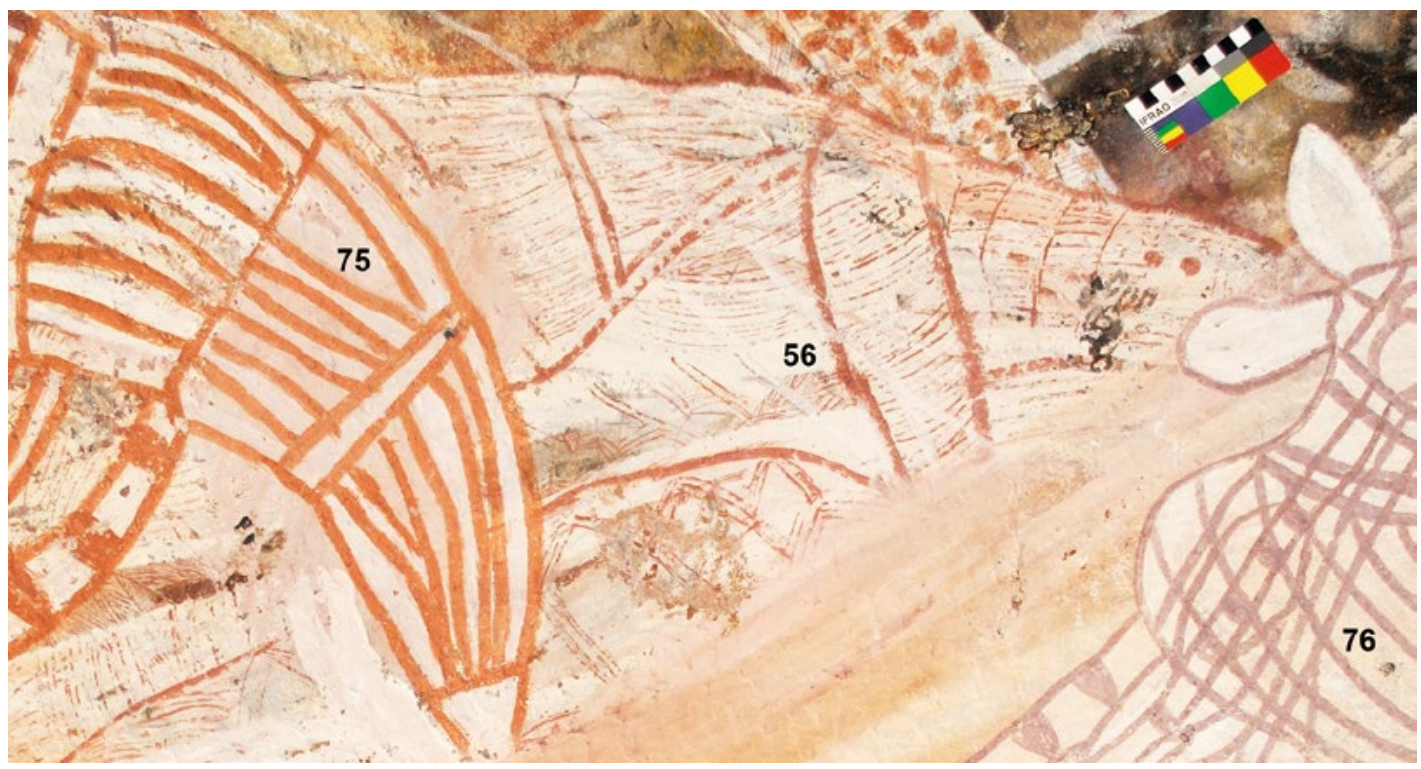

Figure 11.23 Contrasting the differences in brushwork between the underlying (older) fine and overlying (more recent) broad lines of Images \#56, \#75 and \#76.

Source: Photograph by Robert Gunn. 


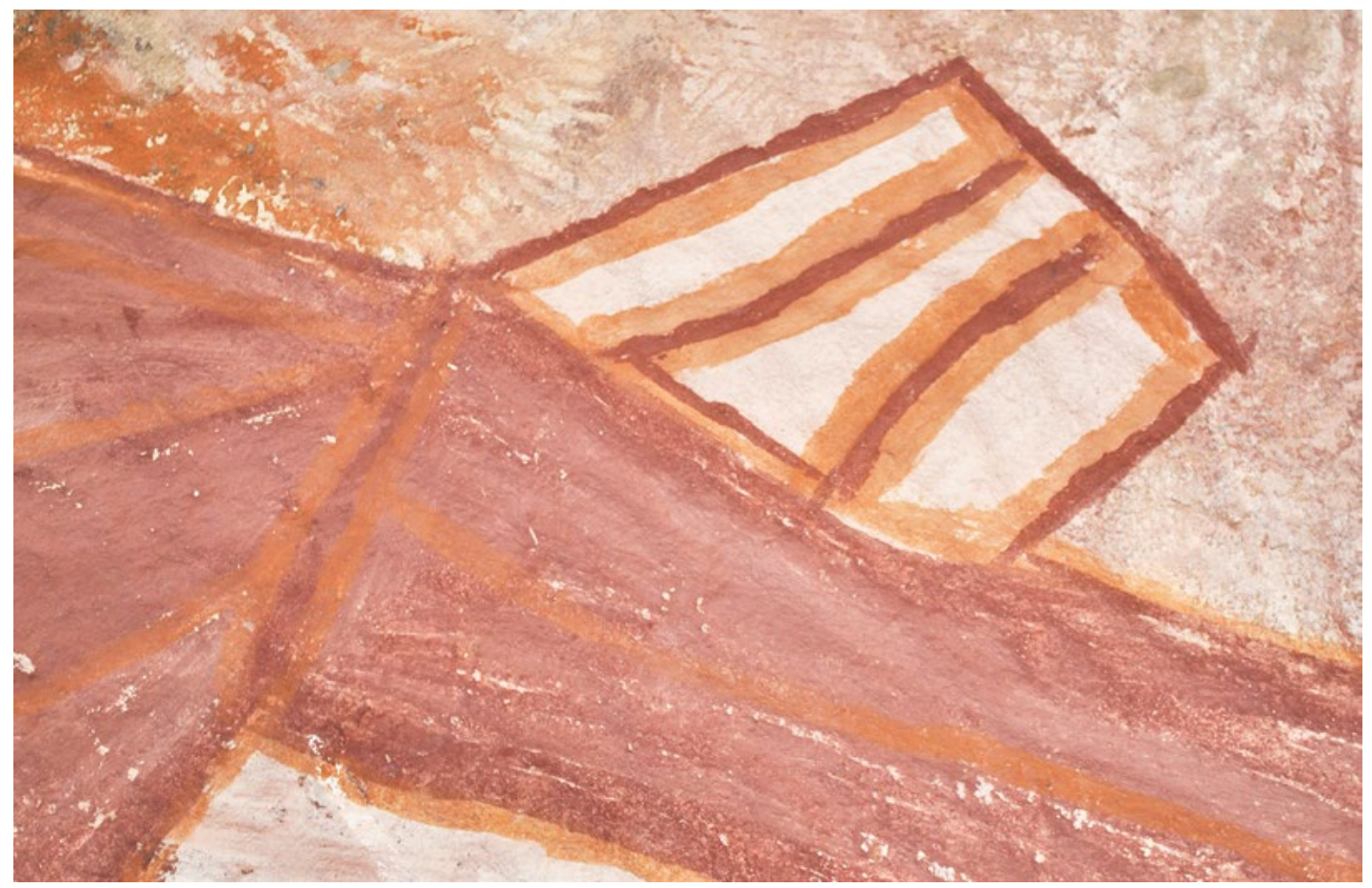

Figure 11.24 Detail of painting quality of Image \#78.

Source: Photograph by Robert Gunn.

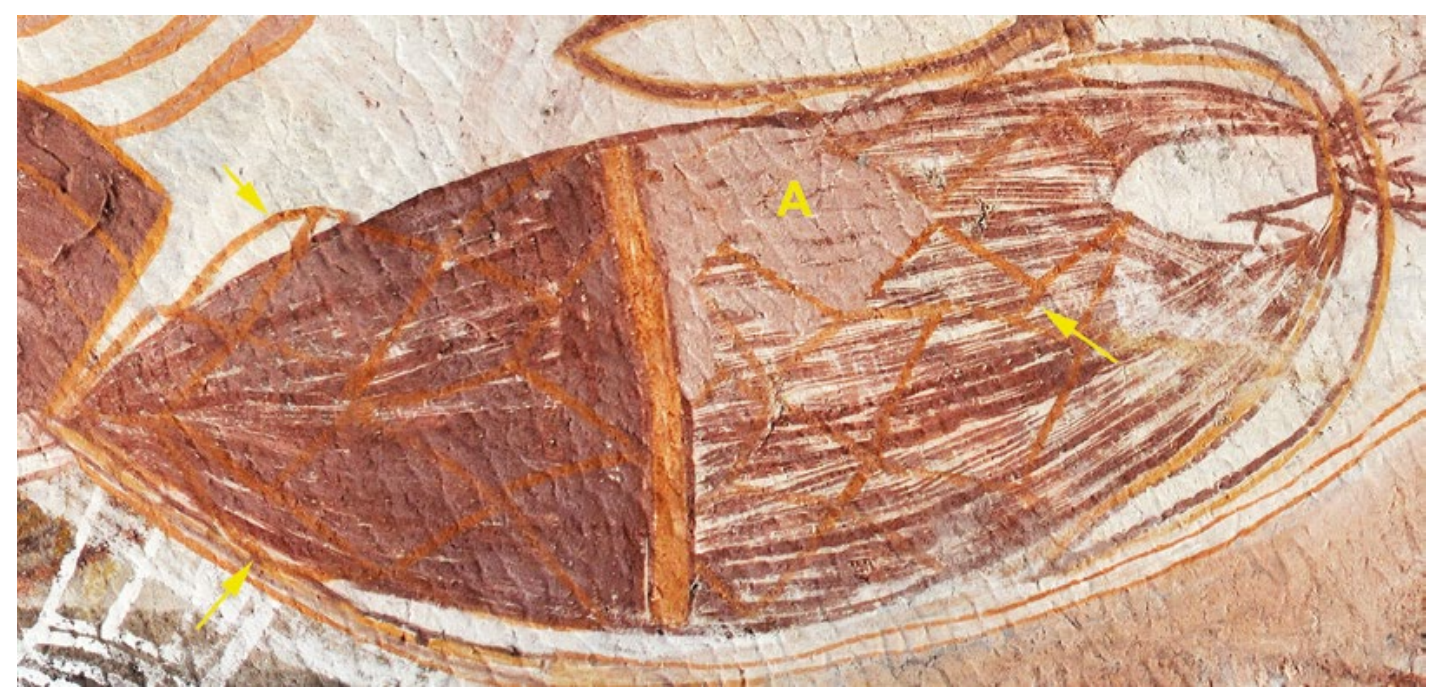

Figure 11.25 Detail of retouching over the stomach pattern of Image \#77. A = purple over-paint; arrows highlight underlying orange mesh pattern.

Source: Photograph by Robert Gunn.

The huge barramundi (Image \#77), $239 \mathrm{~cm}$ long $\times 86 \mathrm{~cm}$ wide, is the largest polychrome X-ray fish at Nawarla Gabarnmang (Figure 11.20; at $171 \times 73 \mathrm{~cm}$, the other painted barramundi on Panel E1 (Image \#78; Figure 11.21) is the fourth largest). Other large X-ray barramundi occur on Panels D and H, 2 m and $3 \mathrm{~m}$ away respectively (see Figure 11.4). 


\begin{tabular}{|c|c|c|c|c|c|c|c|c|c|c|c|c|c|c|c|c|c|c|c|c|c|c|c|c|c|}
\hline \multirow{2}{*}{$\stackrel{ \pm}{\sim}$} & Width $(\mathrm{cm})$ & เn & $\simeq$ & & & & & 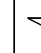 & 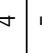 & \llcorner & & & & & & & & & & & & & & & \\
\hline & Length $(\mathrm{cm})$ & $\stackrel{\infty}{m}$ & $\underset{\sim}{\infty}$ & & & & & $\stackrel{n}{r}$ & $n$ & $a$ & & & & & & & & & & & & & & & \\
\hline \multirow{5}{*}{ 을 } & Excellent & & & & & & & & & & & & & & & & & & & & & & & & \\
\hline & Good & $>$ & $>$ & & & & $>$ & $>$ & $>$ & & & & & & & & & & & & & & & & \\
\hline & Fair & & & & & & & & & & & & & & & $>$ & $>$ & & & & $>$ & & & & \\
\hline & Poor & & & & & & & & & & & & $>$ & $>$ & $>$ & & & $>$ & $>$ & & & & $>$ & & \\
\hline & Very poor & & & $>$ & $>$ & $>$ & & & & $>$ & $>$ & $>$ & & & & & & & & $>$ & & $>$ & & $>$ & $>$ \\
\hline \multicolumn{2}{|l|}{ 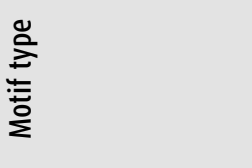 } & $\stackrel{\underline{E}}{\underline{=}}$ & $\stackrel{\underline{E}}{\cong}$ & $\sim$ & $\sim$. & $\sim$ & $\stackrel{5}{.5}$ & & $\underline{\underline{\underline{E}}}$ & $\sim$ & $\sim$ & $\sim$ & 峁 & $\sim$. & $\sim$ & $\sim$ & $\stackrel{气=}{\cong}$ & $\stackrel{气=}{\cong}$ & $\sim$ & $\sim$ & 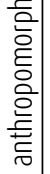 & $\sim$ & $\begin{array}{l}\text { 듣 } \\
\text { 든 } \\
\text { 론 }\end{array}$ & $\sim$. & $\sim$ \\
\hline & Fragment & & & & $>$ & $>$ & & & & & & & & & & & & & $>$ & & & & & & \\
\hline & Pigment trace & & & & & & & & & $>$ & $>$ & $>$ & & & & & & & & & & & & $>$ & \\
\hline & Hand stencil & & & & & & & & & & & & & & & & & & & & & & $>$ & & \\
\hline & X-ray & & & & & & & & & & & & & & & & $>$ & & & & & & & & \\
\hline E్ & Infill & & & $>$ & & & & & & & & & $>$ & $>$ & & $>$ & & & & & & & & & \\
\hline & Outline & & & $>$ & & & & & & & & & $>$ & $>$ & & $>$ & & & & & & & & & \\
\hline & Solid + linear & & & & & & & & & & & & & & & & & & & & & & & & \\
\hline & Solid & $>$ & $>$ & & & & $>$ & $y$ & $>$ & & & & & & $>$ & & & $>$ & & $>$ & $>$ & $>$ & & & \\
\hline & Linear & & & & & & & & & & & & & & & & & & & & & & & & $>$ \\
\hline \multirow{11}{*}{ 흥 } & $\begin{array}{l}\text { White + red + } \\
\text { orange + purple }\end{array}$ & & & & & & & & & & & & & & & & & & & & & & & & \\
\hline & Cream + red & & & & & & & & & & & & & & & & & & & & & & & & \\
\hline & White + purple & & & & & & & & & & & & & & & & & & & & & & & & \\
\hline & White + orange & & & & & & & & & & & & & & & & & & & & & & & & \\
\hline & Orange + white & & & & & & & & & & & & & & & & & & & & & & & & \\
\hline & White + red & & & & & & & & & & & & & & & & & & & & & & & & \\
\hline & Orange & & & & & & & & & & & & & & & & & & & & & & & & \\
\hline & White & & & & & & & & & & & & & & & & & & & & & & & & \\
\hline & Cream & & & & & & & & & & & & & & & & & & & & & & & & \\
\hline & Yellow & & & & & & & & & & & & & & & & & & & & & & & $>$ & $>$ \\
\hline & Red & $>$ & $>$ & $>$ & $>$ & $>$ & 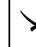 & $y$ & $>$ & $>$ & $>$ & $>$ & $>$ & $>$ & $>$ & $>$ & $>$ & $>$ & $>$ & $>$ & $>$ & $>$ & $>$ & & \\
\hline \multirow{2}{*}{ 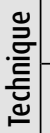 } & Stencil & & & & & & & & & & & & & & & & & & & & & & $>$ & & \\
\hline & Painting & $>$ & $>$ & $>$ & $>$ & $>$ & 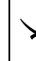 & 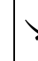 & $>$ & $>$ & $>$ & $>$ & $>$ & $>$ & $>$ & $>$ & $>$ & $>$ & $>$ & $>$ & $>$ & $>$ & & $>$ & $>$ \\
\hline \multicolumn{2}{|c|}{ 莺 } & - & $\sim$ & $m$ & $\nabla$ & in & $\checkmark$ & $r$ & - & $\infty$ & $a$ & 이 & $\mp$ & $\simeq$ & $m$ & $\Xi$ & $\stackrel{ }{\leftarrow}$ & $\div$ & $\approx$ & $\stackrel{\infty}{\leftarrow}$ & $a$ & 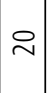 & $\bar{\sim}$ & $\approx$ & $\approx$ \\
\hline
\end{tabular}




\begin{tabular}{|c|c|c|c|c|c|c|c|c|c|c|c|c|c|c|c|c|c|c|c|c|c|c|c|c|c|c|}
\hline \multirow{2}{*}{$\stackrel{\tilde{*}}{\sim}$} & Width $(\mathrm{cm})$ & & & & & & & & & & & & & & & & & & & & & 유 & Ln & & & \\
\hline & Length $(\mathrm{cm})$ & & & & & & & & & & & & & & & & & & & & & 出 & 奥 & & & \\
\hline \multirow{5}{*}{ 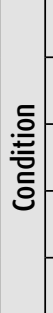 } & Excellent & & & & & & & & & & & & & & & & & & & & & & & & & \\
\hline & Good & & & & & & & & & & & & & & & & & & & & & & & & & \\
\hline & Fair & & & & & & & & & & & & & & & & & & & & & & $>$ & & & $>$ \\
\hline & Poor & & & & & & & $>$ & $>$ & $Y$ & $>$ & & & $>$ & & & $>$ & $>$ & & & $>$ & $>$ & & $>$ & & \\
\hline & Very poor & $>$ & $>$ & $>$ & $>$ & $>$ & $>$ & & 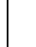 & & & $>$ & $>$ & & $>$ & $>$ & & & $>$ & $>$ & & & & & $>$ & \\
\hline \multicolumn{2}{|l|}{ 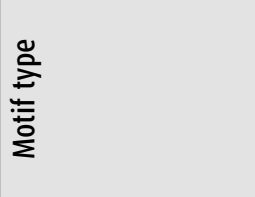 } & $\sim$ & $\sim$ & $\sim$. & $\sim$. & $\sim$. & $\sim$. & $\sim$ & 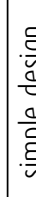 & s. & & $\sim$ & $\sim$ & 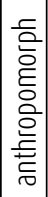 & 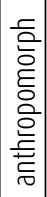 & $\underline{\underline{\underline{E}}}$ & 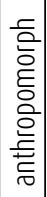 & 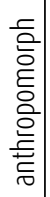 & $\sim$ & $\sim$ & 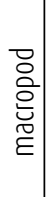 & 宅 & 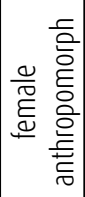 & 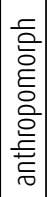 & 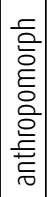 & \\
\hline \multirow{9}{*}{ 톤 } & Fragment & $>$ & & & & & $>$ & & & & & & & & & & & & $>$ & $>$ & & & & & & \\
\hline & Pigment trace & & $>$ & & $>$ & $>$ & & & & & & & & & & & & & & & & & & & & \\
\hline & Hand stencil & & & & & & & & & & & & & & & & & & & & & & & & & \\
\hline & X-гау & & & & & & & & & & & & & & & & & & & & & & & & & \\
\hline & Infill & & & $>$ & & & & & $>$ & & & & $>$ & $>$ & $>$ & $>$ & $>$ & & & & $>$ & & & & & $>$ \\
\hline & Outline & & & $>$ & & & & & $>$ & & & & $>$ & $>$ & $>$ & $>$ & $>$ & & & & $>$ & & & & & $>$ \\
\hline & Solid + linear & & & & & & & & & & & & & & & & & & & & & & & & & \\
\hline & Solid & & & & & & & $>$ & & $y$ & $>$ & $>$ & & $>$ & 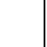 & & & $>$ & & & & $>$ & $>$ & $>$ & $>$ & \\
\hline & Linear & & & & & & & & & & & & & & & & & & & & & $>$ & $>$ & $>$ & $>$ & \\
\hline \multirow{11}{*}{ 흥 } & $\begin{array}{c}\text { White + red + } \\
\text { orange + purple }\end{array}$ & & & & & & & & & & & & & & & & & & & & & & & & & \\
\hline & Cream + red & & & & & & & & & & & & & & & & & & & & & & & & & \\
\hline & White + purple & & & & & & & & & & & & & & & & & & & & & & & & & \\
\hline & White + orange & & & & & & & & & & & & & & & & & & & & & & & & & \\
\hline & Orange + white & & & & & & & & & & & & & & & & & & & & & & & $>$ & & \\
\hline & White + red & & & & & & & & & & & & & & $>$ & & & & & & $>$ & & & & & $>$ \\
\hline & Orange & & & & & & & & & & & & & & & & & & & & & & & & $>$ & \\
\hline & White & & & & & & & & & & & & & & & $>$ & $>$ & $>$ & $>$ & $>$ & & $>$ & $>$ & & & \\
\hline & Cream & & & & & & & & & & & & & & & & & & & & & & & & & \\
\hline & Yellow & $>$ & $>$ & $>$ & $>$ & $>$ & $>$ & $>$ & $>$ & 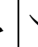 & $>$ & & & & & & & & & & & & & & & \\
\hline & Red & & & & & & & & & & & $>$ & $>$ & $>$ & & & & & & & & & & & & \\
\hline \multirow{2}{*}{ 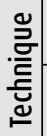 } & Stencil & & & & & & & & & & & & & & & & & & & & & & & & & \\
\hline & Painting & $>$ & $>$ & $>$ & $>$ & $>$ & $>$ & $>$ & $>$ & 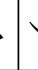 & $>$ & $>$ & $>$ & $>$ & $>$ & $>$ & $>$ & $>$ & $>$ & $>$ & $>$ & $>$ & $>$ & $>$ & $>$ & \rangle \\
\hline \multicolumn{2}{|c|}{ 莺 \# } & む & $\stackrel{\llcorner}{\sim}$ & $\stackrel{\sim}{\sim}$ & $\approx$ & $\stackrel{\infty}{\sim}$ & సิ & $\stackrel{\rho}{\rho}$ & $\bar{m}$ & $5 ?$ & ñ & $m$ & $\vec{m}$ & $\stackrel{m}{m}$ & $\stackrel{m}{m}$ & $\hat{m}$ & $\stackrel{\infty}{m}$ & ळे & 앙 & $\tau$ & $\mathscr{F}$ & $\mathscr{\vartheta}$ & ঔ & 饮 & 8 & F \\
\hline
\end{tabular}




\begin{tabular}{|c|c|c|c|c|c|c|c|c|c|c|c|c|c|c|c|c|c|c|c|c|c|c|c|c|c|}
\hline \multirow{2}{*}{$\stackrel{\Perp}{\sim}$} & Width $(\mathrm{cm})$ & & & & & & & & & ตn & ถn & $\bar{m}$ & $\lesssim$ & $\stackrel{\sim}{\sim}$ & & & & & & $\approx$ & & & & & \\
\hline & Length $(\mathrm{cm})$ & & & & & & & & & 읃 & $\infty$ & 능 & in & 뉴 & & & & & & 윰 & & & & & \\
\hline \multirow{5}{*}{ 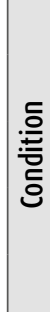 } & Excellent & & & & & & & & & & & & & & & & & & & & & & & & \\
\hline & Good & & & & & & & & & & & & $>$ & & & & & & & $>$ & & & & & \\
\hline & Fair & & & & & & $>$ & $>$ & & & $>$ & $>$ & & $>$ & & & & $>$ & & & & & & & \\
\hline & Poor & & & & & $>$ & & & $>$ & $>$ & & & & & & & & & $>$ & & & $>$ & $>$ & $>$ & $>$ \\
\hline & Very poor & $>$ & $y$ & 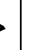 & $>$ & & & & & & & & & & $>$ & $>$ & $>$ & & & & $>$ & & & & \\
\hline \multicolumn{2}{|l|}{ 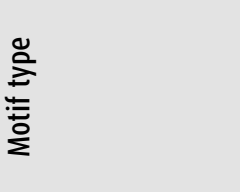 } & $\begin{array}{l}\text { 을 } \\
\text { ठ․ㅡ } \\
\text { है }\end{array}$ & ? & - & $\sim$ & $\sim$ & Е్ & $\sim$ & $\sim$ & 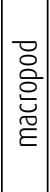 & $\stackrel{\underline{\underline{E}}}{\underline{=}}$ & 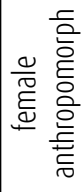 & 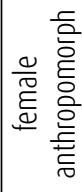 & $\frac{\varrho}{\Xi}$ & $\sim$ & $\sim$ & $\sim$ & 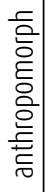 & $\sim$. & $\underline{E}$ & $\sim$ & 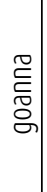 & 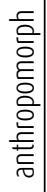 & $\sim$ & 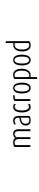 \\
\hline \multirow{9}{*}{ 톤 } & Fragment & & $Y$ & 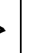 & $>$ & $>$ & & & $>$ & & & & & & $>$ & $>$ & $>$ & & & & $>$ & & & & \\
\hline & Pigment trace & & & & & & & & & & & & & & & & & & & & & & & & \\
\hline & Hand stencil & & & & & & & & & & & & & & & & & & & & & & & & \\
\hline & X-гау & & & & & & & & & & & & & & & & & & & & & & & & \\
\hline & Infill & & & & & & & & & & $>$ & $>$ & $>$ & & & & & & $>$ & $>$ & & $>$ & & $>$ & $>$ \\
\hline & Outline & $>$ & & & & & & & & & $>$ & $>$ & $>$ & & & & & & $>$ & $>$ & & $>$ & & $>$ & $>$ \\
\hline & Solid + linear & & & & & & & & & & & & & & & & & & & & & & & & \\
\hline & Solid & $>$ & & & & & $>$ & $>$ & & $>$ & $>$ & $>$ & $>$ & $>$ & & & & & & & & & $>$ & & $>$ \\
\hline & Linear & & & & & & $>$ & $>$ & & & & & & & & & & $>$ & & & & & $>$ & & \\
\hline \multirow{11}{*}{ 흥 } & $\begin{array}{l}\text { White + red + } \\
\text { orange + purpl }\end{array}$ & & & & & & & & & & & & & & & & & & & & & & & & \\
\hline & Cream + red & & & & & & & & & & & & $>$ & & & & & & & & & & & & \\
\hline & White + purpl & & & & & & & & & & & & & & & & & & & & & & & & \\
\hline & White + orang & & & & & & & & & & & & & & & & & & & & & & & & $>$ \\
\hline & Orange + whit & & & & & & & & & & & & & & & & & & & & & & & & \\
\hline & White + red & $>$ & $y$ & $>$ & & & & & & & $>$ & $>$ & & & & & & & & & & & & & \\
\hline & 0range & & & & & & & & & & & & & & & & & & & & & & & & \\
\hline & White & & & & $>$ & $>$ & $>$ & $>$ & $>$ & $>$ & & & & $>$ & $>$ & $>$ & $>$ & $>$ & $>$ & $>$ & $>$ & $>$ & $>$ & $>$ & \\
\hline & Cream & & & & & & & & & & & & & & & & & & & & & & & & \\
\hline & Yellow & & & & & & & & & & & & & & & & & & & & & & & & \\
\hline & Red & & & & & & & & & & & & & & & & & & & & & & & & \\
\hline \multirow{2}{*}{ 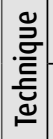 } & Stencil & & & & & & & & & & & & & & & & & & & & & & & & \\
\hline & Painting & $>$ & Y & $>$ & $>$ & $>$ & $>$ & $>$ & $>$ & $>$ & $>$ & $>$ & $>$ & $>$ & $>$ & $>$ & $>$ & $>$ & $>$ & $>$ & $>$ & $>$ & $>$ & $>$ & $>$ \\
\hline \multicolumn{2}{|c|}{ 莺 \# } & $\stackrel{\infty}{\forall}$ & 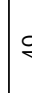 & 字 & 유 & โn & กี & 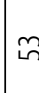 & เै & 는 & 㶽 & in & $\stackrel{\infty}{\sim}$ & ติ & 8 & $\overline{6}$ & $\widetilde{\sigma}$ & $\tilde{b}$ & వे & 约 & $\bullet$ & $\hat{\sigma}$ & $\infty$ & 6 & 요 \\
\hline
\end{tabular}




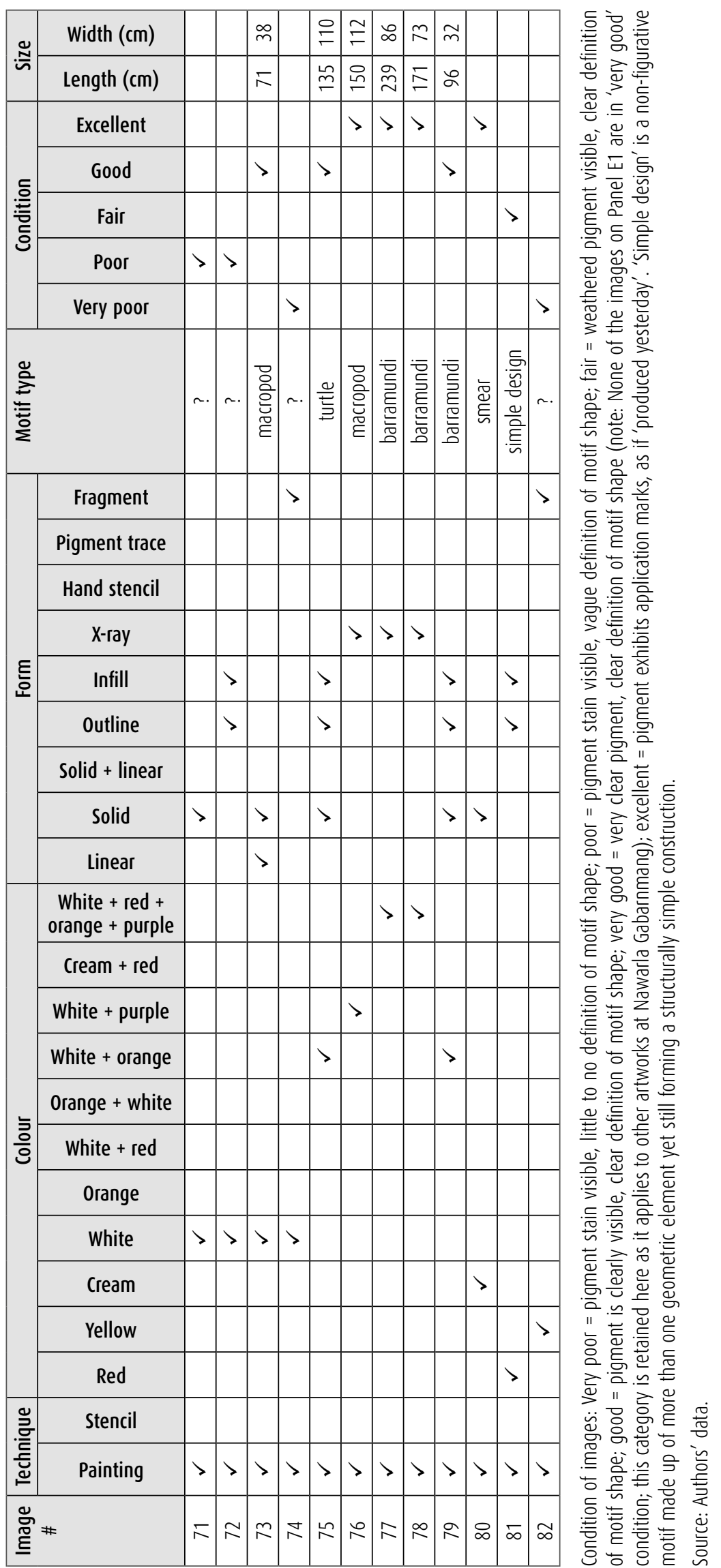


Table 11.2 Panel E1: Superimpositions.

\begin{tabular}{|l|l|}
\hline Image \# & Underlying images \\
\hline 16 & $(16: 17$ unclear $)$ \\
\hline 17 & $(16: 17$ unclear $)$ \\
\hline 18 & $(18: 19$ unclear $)$ \\
\hline 19 & $(18: 19$ unclear $)$ \\
\hline 23 & $1,2,3,4,5$ \\
\hline 24 & 6 \\
\hline 26 & 15 \\
\hline 28 & 21 \\
\hline 29 & 19,21 \\
\hline 32 & 10 \\
\hline 33 & 3 \\
\hline 34 & $1,2,4,5,23,24$ \\
\hline 35 & 30,31 \\
\hline 36 & 11 \\
\hline 37 & 11,15 \\
\hline 38 & $11,15,16$ (38:39 unclear) \\
\hline 39 & $16,17,18,19,20$ (38:39 unclear) \\
\hline 40 & 29 \\
\hline 41 & 29,82 \\
\hline 42 & $30,31,32,35$ \\
\hline 43 & 32 \\
\hline 44 & $2,3,4,5,23,24$ \\
\hline 45 & 34 \\
\hline 46 & 41,82 \\
\hline 47 & $27,28,41,46$ \\
\hline 48 & 3,33 \\
\hline 49 & 11,36 \\
\hline 50 & 11,14 \\
\hline 51 & 11,38 \\
\hline 52 & $11,18,19,37$ \\
\hline 53 & $19,29,31,39,40$ \\
\hline 54 & 30,42 \\
\hline
\end{tabular}

\begin{tabular}{|c|c|}
\hline Image \# & Underlying images \\
\hline 55 & $9,10,32,42,43$ \\
\hline 56 & $44,46,47$ \\
\hline 57 & $5,8,23,24,34,44,47$ \\
\hline 58 & $2,5,23,34,44$ \\
\hline 59 & 3,33 \\
\hline 60 & 12,22 \\
\hline 61 & 13 \\
\hline 62 & 13 \\
\hline 63 & 34,45 \\
\hline 64 & $11,15,37,38$ \\
\hline 65 & $11,16,17,18,37,39,52$ \\
\hline 66 & $16,17,38,39$ \\
\hline 67 & $19,20,21,29,39,53$ \\
\hline 68 & $19,28,29,41,46,47,81$ \\
\hline 69 & $29,30,31,41$ \\
\hline 70 & $32,42,54,55$ \\
\hline 71 & $9,32,55$ \\
\hline 72 & $8,23,24,34,44,56,57$ \\
\hline 73 & $44,47,56,57$ \\
\hline 74 & $30,31,35,69$ \\
\hline 75 & $24,25,41,44,47,56,57,72,73$ \\
\hline 76 & $\begin{array}{l}30,32,35,44,47,54,55,56,57,69,70, \\
71,72,73,74,75\end{array}$ \\
\hline 77 & $\begin{array}{l}13,15,17,18,20,21,25,28,34,38,39, \\
47,50,51,62,63,64,65,66,67,68,72, \\
75,81\end{array}$ \\
\hline 78 & $3,23,33,34,44,48,56,59,63,72,75$ \\
\hline 79 & 78 \\
\hline 80 & $11,63,79$ \\
\hline 81 & 21,28 \\
\hline 82 & 21 \\
\hline
\end{tabular}

Source: Authors' data.

Table 11.3 Panel E1: Summary of the art phases.

\begin{tabular}{|l|l|l|l|l|l|}
\hline Phase & Number of layers & Number of images & Major colours & Major conventions & Major motif classes \\
\hline VI & 3 & 5 & polychrome & X-ray & fish, macropod \\
\hline V & 1 & 1 & white+orange & solid+outline+infill & reptile \\
\hline IV & 7 & 39 & white, white+red & $\begin{array}{l}\text { solid, } \\
\text { solid+outline+infill }\end{array}$ & $\begin{array}{l}\text { macropods, fish, } \\
\text { reptile, anthropomorph, bird }\end{array}$ \\
\hline III & 1 & 4 & red & outline+striped infill & unknown \\
\hline II & 1 & 12 & yellow & solid, outline & complex abstract design \\
\hline I & 2 & 21 & red & solid, outline+infill & reptile, fish \\
\hline
\end{tabular}

Source: Authors' data. 


\section{Excavation Square $\mathbf{P}$}

In May 2012, we excavated a small, $50 \times 50 \mathrm{~cm}$ square immediately beneath Panel E1 (Figures 11.4 and 11.26). Our aims were threefold:

- To find and date any (now dried) drops of paint that may have fallen onto then-floor surfaces at the time of painting, thereby dating immediately overhanging paintings in those colours.

- To find and date fragments of pigment that fell from the overlying ceiling paintings, thereby giving minimum ages for those paintings.

- To date when the Panel E1 ceiling surface was created, by finding and dating buried slabs of rock from the previous ceiling rock stratum before the current one was painted, thereby giving a maximum age for the painted Panel E1.

Square $\mathrm{P}$ was excavated in 23 artificial Excavation Units (XU) following the stratigraphy (Table 11.4). Individual XUs averaged $1.3 \pm 0.3 \mathrm{~cm}$ in thickness. Excavation proceeded to a maximum $29 \mathrm{~cm}$ depth when a hard and continuous flat rock surface was reached. That rock surface is not the bedrock, but a layer of rock that fell from the ceiling (see below) in the process creating the current and subsequently painted ceiling rock surface of Panel E1 (Figure 11.27).

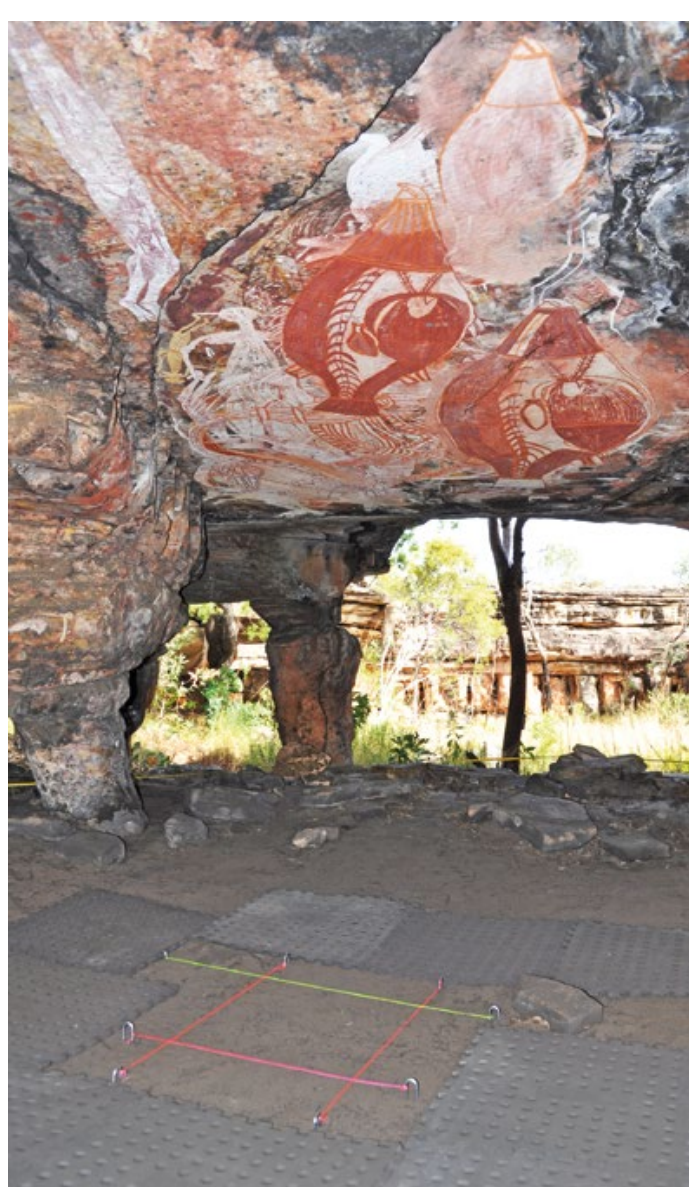

Figure 11.26 Square $P$ before excavation, below painted Panel E1.

Source: Photograph by Bruno David.

Table 11.4 Square P: Details of Excavation Units.

\begin{tabular}{|c|c|c|c|c|c|c|c|c|}
\hline XU & SU & $\begin{array}{l}\text { Mean depth } \\
\text { at top }(\mathrm{cm})\end{array}$ & $\begin{array}{c}\text { Mean depth at } \\
\text { centre }(\mathrm{cm})\end{array}$ & $\begin{array}{c}\text { Mean depth at } \\
\text { base }(\mathrm{cm})\end{array}$ & $\begin{array}{l}\text { Mean thickness } \\
(\mathrm{cm})\end{array}$ & $\begin{array}{l}\text { Area } \\
\left(\mathrm{m}^{2}\right)\end{array}$ & $\begin{array}{l}\text { Weight } \\
(\mathrm{kg})\end{array}$ & $\begin{array}{l}\text { Volume } \\
\text { (litres) }\end{array}$ \\
\hline 1 & $1 a+1 b$ & 0.0 & 1.0 & 2.0 & 2.0 & 0.25 & 4.4 & 3.0 \\
\hline 2 & $1 a+1 b$ & 2.0 & 2.6 & 3.1 & 1.1 & 0.25 & 4.6 & 3.0 \\
\hline 3 & $1 b+2$ & 3.1 & 3.8 & 4.5 & 1.4 & 0.25 & 5.9 & 4.5 \\
\hline 4 & $1 b+2$ & 4.5 & 5.1 & 5.6 & 1.1 & 0.25 & 4.3 & 2.5 \\
\hline 5 & $1 b+2$ & 5.6 & 6.3 & 6.9 & 1.3 & 0.25 & 4.7 & 4.0 \\
\hline 6 & $1 b+2$ & 6.9 & 7.6 & 8.3 & 1.4 & 0.25 & 4.6 & 4.0 \\
\hline 7 & 2 & 8.3 & 9.0 & 9.7 & 1.4 & 0.25 & 5.4 & 4.5 \\
\hline 8 & $2+3 a$ & 9.7 & 10.5 & 11.3 & 1.6 & 0.25 & 5.4 & 5.0 \\
\hline 9 & $2+3 a$ & 11.3 & 12.0 & 12.7 & 1.4 & 0.25 & 4.3 & 3.0 \\
\hline 10 & $2+3 a$ & 12.7 & 13.6 & 14.5 & 1.8 & 0.25 & 6.0 & 5.5 \\
\hline 11 & $2+3 a$ & 14.5 & 15.2 & 15.9 & 1.4 & 0.25 & 4.8 & 4.0 \\
\hline 12 & $2+3 a$ & 15.9 & 16.5 & 17.1 & 1.2 & 0.25 & 4.6 & 3.5 \\
\hline 13 & $2+3 a$ & 17.1 & 17.8 & 18.4 & 1.3 & 0.25 & 4.5 & 4.0 \\
\hline 14 & $3 a$ & 18.4 & 19.3 & 19.7 & 1.3 & 0.25 & 3.3 & 2.5 \\
\hline
\end{tabular}




\begin{tabular}{|c|c|c|c|c|c|c|c|c|}
\hline$X U$ & SU & $\begin{array}{l}\text { Mean depth } \\
\text { at top }(\mathrm{cm})\end{array}$ & $\begin{array}{c}\text { Mean depth at } \\
\text { centre }(\mathrm{cm})\end{array}$ & $\begin{array}{c}\text { Mean depth at } \\
\text { base }(\mathrm{cm})\end{array}$ & $\begin{array}{l}\text { Mean thickness } \\
(\mathrm{cm})\end{array}$ & $\begin{array}{l}\text { Area } \\
\left(\mathrm{m}^{2}\right)\end{array}$ & $\begin{array}{l}\text { Weight } \\
(\mathrm{kg})\end{array}$ & $\begin{array}{l}\text { Volume } \\
\text { (litres) }\end{array}$ \\
\hline 15 & $3 a$ & 19.7 & 20.3 & 20.8 & 1.1 & 0.25 & 3.7 & 3.0 \\
\hline 16 & $3 a$ & 20.8 & 21.3 & 21.8 & 1.0 & 0.25 & 2.8 & 2.5 \\
\hline 17 & $3 a$ & 21.8 & 22.5 & 23.2 & 1.4 & 0.25 & 4.3 & 4.0 \\
\hline 18 & $3 a$ & 23.2 & 23.7 & 24.1 & 0.9 & 0.25 & 3.4 & 3.0 \\
\hline 19 & $3 a+3 b$ & 24.1 & 24.7 & 25.2 & 1.1 & 0.25 & 3.6 & 3.0 \\
\hline 20 & $3 a+3 b$ & 25.2 & 25.9 & 26.6 & 1.4 & 0.25 & 5.1 & 4.5 \\
\hline 21 & $3 a+3 b$ & 26.6 & 27.3 & 28.0 & 1.4 & 0.25 & 4.9 & 4.0 \\
\hline 22 & $3 a+3 b$ & 28.0 & 28.4 & 28.7 & 0.7 & 0.23 & 2.3 & 1.0 \\
\hline 23 & $3 a+3 b$ & 28.7 & 28.9 & 29.1 & 0.4 & 0.05 & 0.5 & $<0.5$ \\
\hline Total & & & & & $1.3 \pm 0.3$ & & 97.4 & 78.0 \\
\hline
\end{tabular}

SU numbers in bold contribute most to that XU's sediments.

Source: Authors' data.

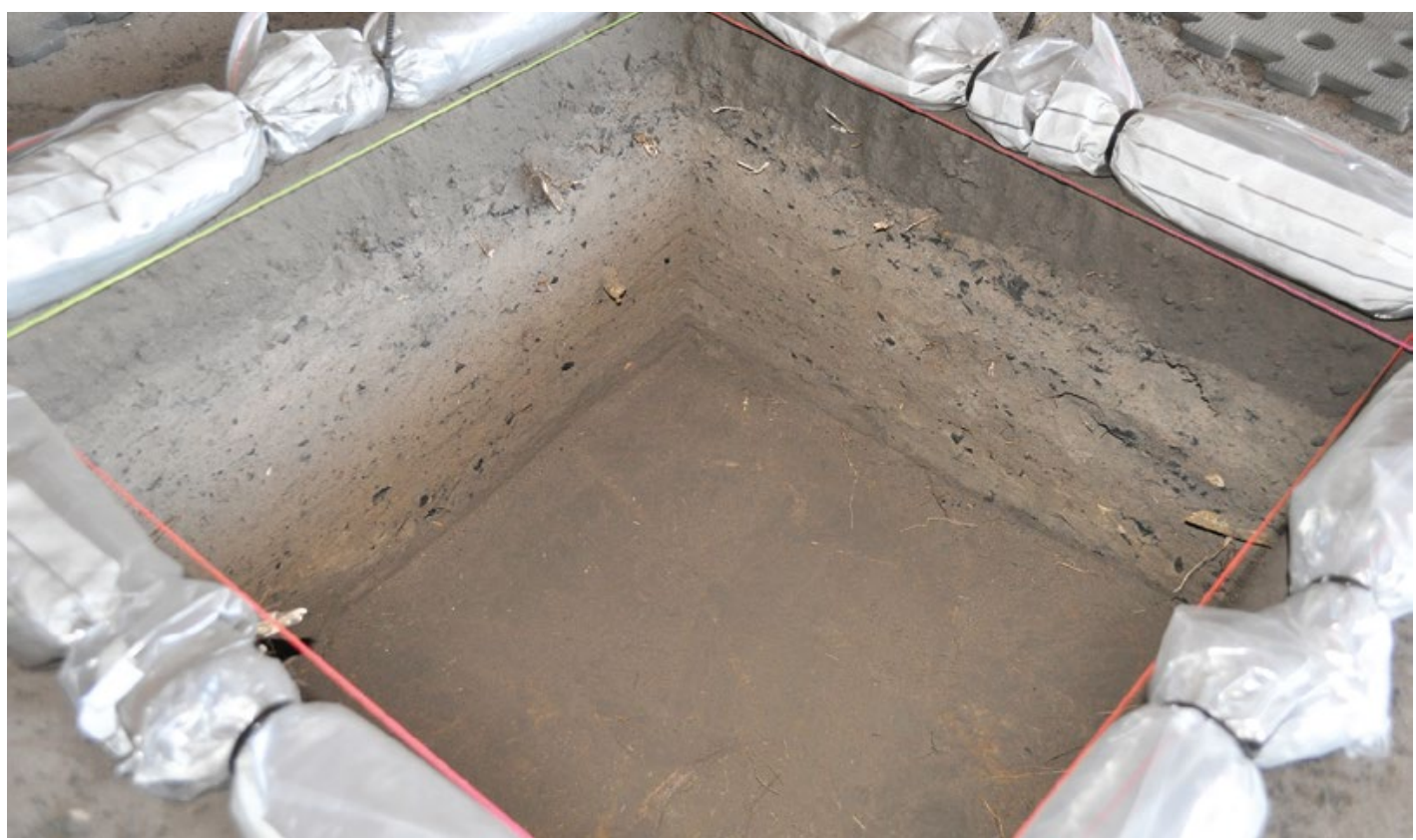

Figure 11.27 Square $P$ after completion of excavation showing south and west walls (the green string is the south side of the square). Note the flat rock surface at base.

Source: Photograph by Bruno David.

\section{Stratigraphy of Square P}

The Square P sediment sequence consists of the following SUs from the top downwards (Figure 11.28); SUs define the sediment layers, unlike XUs that relate to units of excavation. An XU is almost always thinner than the $\mathrm{SU}$ in which it occurs. Where neighbouring sediment layers are similarly composed, they are divided into sub-SUs, differentiated by a capital letter (e.g. SU1A, SU1B) rather than given their own SU number:

- SU1A: The loose, disturbed surface sediments of the current treadage zone, consisting of fine, ashy, loamy sand with abundant charcoal. Sediments, dry at the time of excavation, are homogeneous in colour, texture and content across the square and with depth. The changeover to SU1B is ill-defined. No plants grow on the ground surface at the top of SU1A. 
- SU1B: Similar in all respects to SU1A, only being differentiated by a slightly greater consolidation of sediments. Like SU1A, SU1B is loose and should be treated as a near-surface, disturbed deposit below the looser surface zone that is SU1A. A few dry leaves in vertical or angled positions are present. Sediments are homogeneous across the square and with depth. The changeover to SU2 is fairly marked but not sudden.

- SU2: Moderately consolidated and slightly compact fine, ashy, loamy sand with abundant charcoal and with animal bone. Sediments, dry at the time of excavation, are homogeneous in colour, texture and content across the square and with depth. Rootlets are present. Sediments are noticeably lighter in colour than SU1 above and SU3 below. The changeover to SU3A is gradual, typically over c. $3 \mathrm{~cm}$ vertical depth, sometimes slightly more.

- SU3A: In many ways similar to SU2, SU3A sediments are darker in colour with less abundant charcoal. Rootlets are present throughout the square but less abundant than in SU2. Sediments are homogeneous in colour, texture and content across the square and generally with depth, except that during excavation small, c. $1 \mathrm{~mm}$ to $2 \mathrm{~cm}$ thick patches of consolidated and compact, very fine, light-coloured powdery pigment coagulated around the dry, ashy, loamy sand that makes up the bulk of SU3A occurred at c. $26 \mathrm{~cm}$ depth in XU18, with a minor presence continuing down into XU19. These distinctive patches of coloured sediment are densely distributed across much of XU18 (Figure 11.29), rapidly petering out towards the northeastern quadrant of the square. These very numerous patches are, in plan view, typically c. $2 \mathrm{~cm}$ in diameter with diffuse convex edges that often overlap at their margins because they are so abundant. They are interpreted as drops of paint that fell on the ground during the painting of Panel E1, became mixed with the surface ashy, loamy sand and then dried in situ (see below). The absence of dried paint drops in the northeastern corner of the square matches well the edge of painted Panel E1 overhead on the ceiling (see Figure 11.4, which was accurately mapped to sub-centimetre accuracy by 3-D laser). The interface between SU3A and SU3B is marked in many parts of the square and easily distinguished during excavation; in other parts, in the central and northern sections, SU3A was intermixed with SU3B onto the basal rock.

- SU3B: This SU is the lowermost c. $4 \mathrm{~cm}$ of the sediment sequence across much of the square, although in some parts SU3B is intermixed with the basal levels of SU3A. Its sediments are less ashy and less charcoal-rich fine, loamy sand than those of SU3A. SU3B sediments are homogeneous in colour, texture and content across the square and with depth, and more humid than in higher SUs, although never 'wet'. Abundant, very fine rootlets grow against the surface of the rock at the very base of SU3B. The rock surface reached at the base of SU3B is flat across the square.

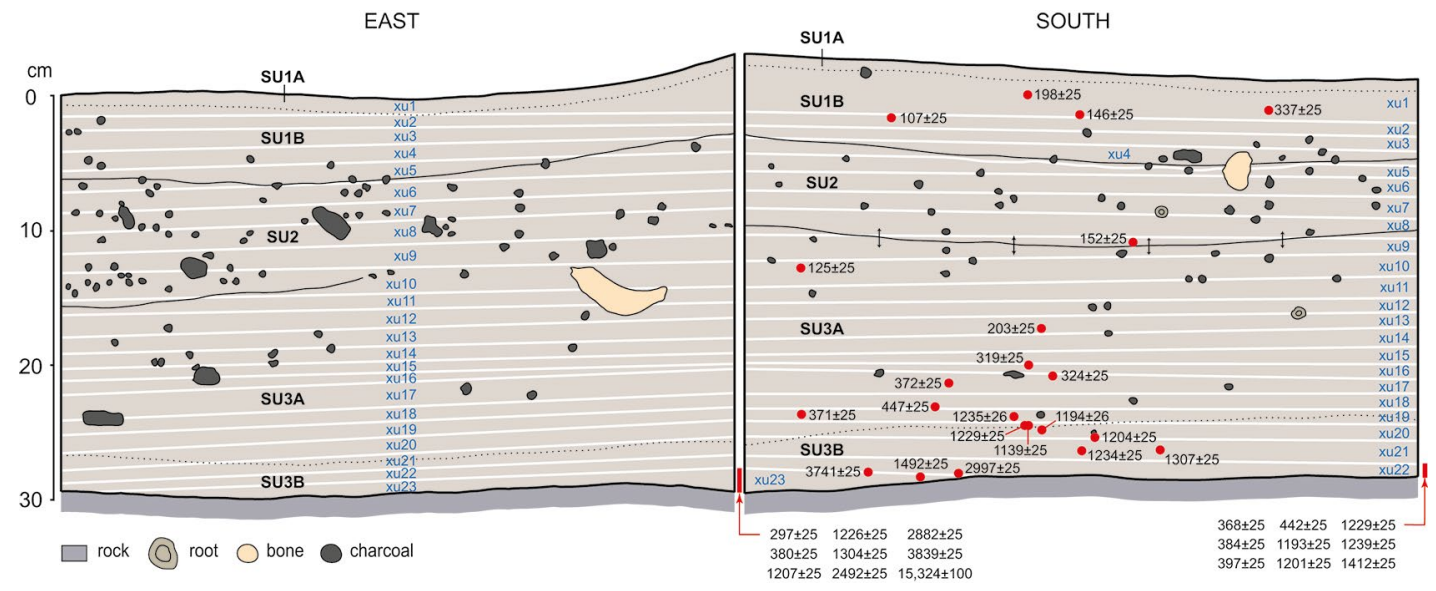

Figure 11.28 Square P east and south sections, with XUs and radiocarbon dates back-plotted.

Source: Illustration by Kara Rasmanis and Bruno David. 


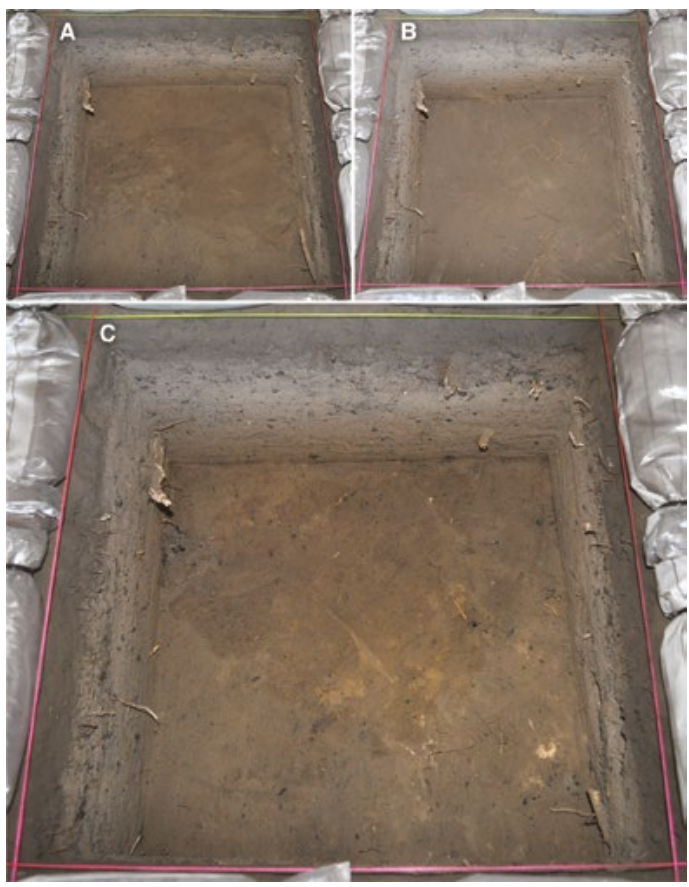

Figure 11.29 Square $P$ showing sediments at the base of A: XU16 (average basal depth $=22 \mathrm{~cm}$ below ground), a stratigraphic level above that of the dried paint drops; B: XU21 (average basal depth $=28 \mathrm{~cm}$ below ground), a stratigraphic level below that of the dried paint drops; C: XU18 (average basal depth $=24 \mathrm{~cm}$ below ground), at the stratigraphic level containing the dried paint drops, here visible as lighter-coloured patches.

Source: Photographs by Bruno David.

To better understand the origins and taphonomy of the Square P sediments and their cultural contents, analyses of $\mathrm{pH}$, percentage of organic matter and particle size were undertaken on bulk sediment samples by XU. Prior to analyses, all sediment samples were air-dried to constant weight at approximately $30^{\circ} \mathrm{C}$. There was no need to grind the samples as they were very sandy and noticeably well separated. All analyses were performed in duplicate.

\section{Particle size analyses of Square $\mathbf{P}$}

Each sample, $5 \mathrm{~g}$ of accurately weighed, airdried sediment considered representative of that $\mathrm{XU}$, was dispersed in 5 per cent tetra sodium pyrophosphate $\left(\mathrm{Na}_{4} \mathrm{P}_{2} \mathrm{O}_{7}\right)$, boiled for approximately 60 minutes and left overnight to disperse at room temperature. The samples were then wet-sieved in $600 \mu \mathrm{m}$-mesh. The $>600 \mu \mathrm{m}$ (coarse sand) particles retained in the sieve were transferred to pre-weighed petri dishes, air-dried to constant weight, and weighed. The $<600 \mu \mathrm{m}$ particles were then suspended in water and analysed with a Backman Culter LS 100 instrument.

The particle size distribution was classified using the Standard Association of Australia scheme (McDonald et al. 1998). The size fractions are defined as coarse sand $(>600 \mu \mathrm{m})$, medium sand $(600-212 \mu \mathrm{m})$, fine sand $(212$ $63 \mu \mathrm{m})$, silt $(2-63 \mu \mathrm{m})$, and clay $(<2 \mu \mathrm{m})$. The size fraction of the particles $>600 \mu \mathrm{m}$ was calculated as a weight percentage of the total sample, whereas the fractions of clay, silt and fine and medium sand size particles were calculated as volume percentage of the size fraction smaller than $600 \mu \mathrm{m}$.

\section{pH analyses of Square $\mathbf{P}$}

Soil $\mathrm{pH}$ was determined using the method described in the Soil Chemical Methods: Australasia handbook (Rayment and Lyons 2011). Measurement was based on a soil:water ratio of 1:5. The samples (1:5 water suspensions) were mechanically shaken (end-over-end shaker) for one hour. A Schott handlab Multi $12 \mathrm{pH}$ meter was standardised against buffer solutions of known $\mathrm{pH}$ to measure the $\mathrm{pH}$ of the samples.

\section{Organic matter in Square $\mathbf{P}$}

The content of organic matter was estimated by loss on ignition. The representative samples, c. $20 \mathrm{~g}$ of accurately weighed sediment, were oven-dried at $105^{\circ} \mathrm{C}$ to constant weight, weighed and then ignited in a muffle furnace at $550^{\circ} \mathrm{C}$ for two hours and re-weighed. The difference between the weight of ignited samples $\left(550^{\circ} \mathrm{C}\right)$ and oven-dry samples $\left(105^{\circ} \mathrm{C}\right)$ represents the weight of organic matter in the sample. The results are presented as a weight percentage of the oven-dry samples. 


\section{Results of analyses from Square $P$}

The results of the sediment analyses indicate that the Square $\mathrm{P}$ sediments are acidic $(\mathrm{pH}$ range: 3.83-4.55), loamy sand with high amounts of organic matter (4.0-8.3 per cent of weight by XU), consisting mainly of charcoal and ash (Table 11.5). The acidic nature of the sediments signal that buried bone is unlikely to have survived for very long.

Table 11.5 Square $\mathrm{P}$ : Sediment $\mathrm{pH}$, percentage of organic matter and particle size analysis by XU.

\begin{tabular}{|c|c|c|c|c|c|c|c|c|c|}
\hline \multirow[t]{2}{*}{$\mathrm{XU}$} & \multirow[t]{2}{*}{$\mathrm{pH}$} & \multirow{2}{*}{\begin{tabular}{|c|} 
Organic \\
matter \\
(\%weight)
\end{tabular}} & \multirow{2}{*}{$\begin{array}{c}\text { Particles } \\
>600 \mu m \\
\text { (\% weight) }\end{array}$} & \multicolumn{5}{|c|}{ Particle size distribution of particles $<600 \mu \mathrm{m}$ ( $\%$ volume) } & \multirow{2}{*}{$\begin{array}{c}\text { Soil } \\
\text { description }\end{array}$} \\
\hline & & & & $\begin{array}{c}\text { sand } \\
(600-63 \mu \mathrm{m})\end{array}$ & $\begin{array}{c}\text { medium } \\
\text { sand } \\
(600-212 \mu \mathrm{m})\end{array}$ & $\begin{array}{c}\text { fine sand } \\
(212-63 \mu \mathrm{m})\end{array}$ & $\begin{array}{c}\text { silt } \\
(63-2 \mu m)\end{array}$ & $\begin{array}{c}\text { clay } \\
(<2 \mu \mathrm{m})\end{array}$ & \\
\hline 1 & 4.51 & 7.32 & 7.1 & 74.6 & 41.8 & 32.8 & 22.9 & 2.5 & Loamy sand \\
\hline \multicolumn{10}{|l|}{2} \\
\hline 3 & 4.55 & 8.26 & 5.2 & 76.1 & 47.5 & 28.6 & 21.5 & 2.4 & Loamy sand \\
\hline \multicolumn{10}{|l|}{4} \\
\hline 5 & 4.55 & 8.19 & 5.3 & 76.2 & 42.9 & 33.3 & 21.9 & 1.9 & Loamy sand \\
\hline \multicolumn{10}{|l|}{6} \\
\hline 7 & 4.33 & 7.74 & 3.9 & 77.3 & 41.6 & 35.7 & 21.2 & 1.5 & Loamy sand \\
\hline \multicolumn{10}{|l|}{8} \\
\hline 9 & 4.31 & 6.31 & 5.7 & 76.3 & 41.3 & 35.0 & 22.0 & 1.7 & Loamy sand \\
\hline 10 & 4.13 & 5.78 & 4.3 & 73.7 & 40.3 & 33.4 & 24.3 & 2.0 & Loamy sand \\
\hline 11 & 3.96 & 5.15 & 5.3 & 77.2 & 44.9 & 32.3 & 20.9 & 1.9 & Loamy sand \\
\hline 12 & 3.94 & 5.23 & 3.1 & 77.5 & 46.1 & 31.4 & 20.4 & 2.1 & Loamy sand \\
\hline 13 & 3.86 & 5.51 & 3.5 & 75.3 & 43.1 & 32.2 & 22.8 & 1.9 & Loamy sand \\
\hline 14 & 3.85 & 5.23 & 2.9 & 79.9 & 47.5 & 32.4 & 18.5 & 1.6 & Loamy sand \\
\hline 15 & 3.85 & 5.19 & 2.8 & 78.9 & 45.0 & 33.9 & 19.3 & 1.8 & Loamy sand \\
\hline 16 & 3.83 & 4.98 & 3.3 & 77.5 & 43.3 & 34.2 & 20.5 & 2.0 & Loamy sand \\
\hline 17 & 3.87 & 4.76 & 3.1 & 78.1 & 49.0 & 29.1 & 20.1 & 1.8 & Loamy sand \\
\hline 18 & 3.86 & 4.03 & 2.9 & 74.1 & 41.2 & 32.9 & 23.5 & 2.4 & Loamy sand \\
\hline 19 & 3.91 & 5.65 & 4.6 & 71.9 & 38.5 & 33.4 & 25.6 & 2.5 & Loamy sand \\
\hline 20 & 3.98 & 5.35 & 2.9 & 76.4 & 46.6 & 29.8 & 21.4 & 2.2 & Loamy sand \\
\hline 22 & 3.98 & 4.34 & 2.9 & 78.2 & 43.4 & 34.8 & 19.5 & 2.3 & Loamy sand \\
\hline 23 & 3.96 & 4.17 & 3.2 & 86.0 & 55.4 & 30.6 & 12.3 & 1.7 & Sand \\
\hline 24 & 3.95 & 3.96 & 2.9 & 83.7 & 49.0 & 34.7 & 14.4 & 1.9 & Loamy sand \\
\hline
\end{tabular}

Source: Authors' data.

\section{Ground penetrating radar}

Ground penetrating radar (GPR) was used at Nawarla Gabarnmang to map the depth to bedrock and locate pieces of roof fall in the stratigraphic profile. A total of $28 \mathrm{GPR}$ lines were positioned in an approximately southeast to northwest orientation, with a spacing of $0.5 \mathrm{~m}$ between lines. The GPR data were obtained using a Mala X3M unit with a $250 \mathrm{Mhz}$ antenna using a sampling frequency of $10038 \mathrm{Mhz}$, time window of $102 \mathrm{~ns}$, trace interval of $0.02 \mathrm{~m}, 1024$ samples and four stacks. The data were processed and interpreted using ReflexW software using a suite of filters, including move start time, dewow, energy decay, background remove, bandpass and time cut. The methodology for processing GPR data is well summarised by Goodman and Piro (2013). The velocity of electromagnetic energy through sediment was estimated as $0.15 \mathrm{~m} / \mathrm{ns}$ for the site, based on comparison from similar sediments at other, nearby sites, in the absence of suitable 
hyperbola for velocity modelling coming directly from Nawarla Gabarnmang. This methodology, while necessary given the sub-surface conditions and the fixed geometry of the GPR transmitter and receiver, introduces a degree of uncertainty into our depth calculations.

\section{GPR Data}
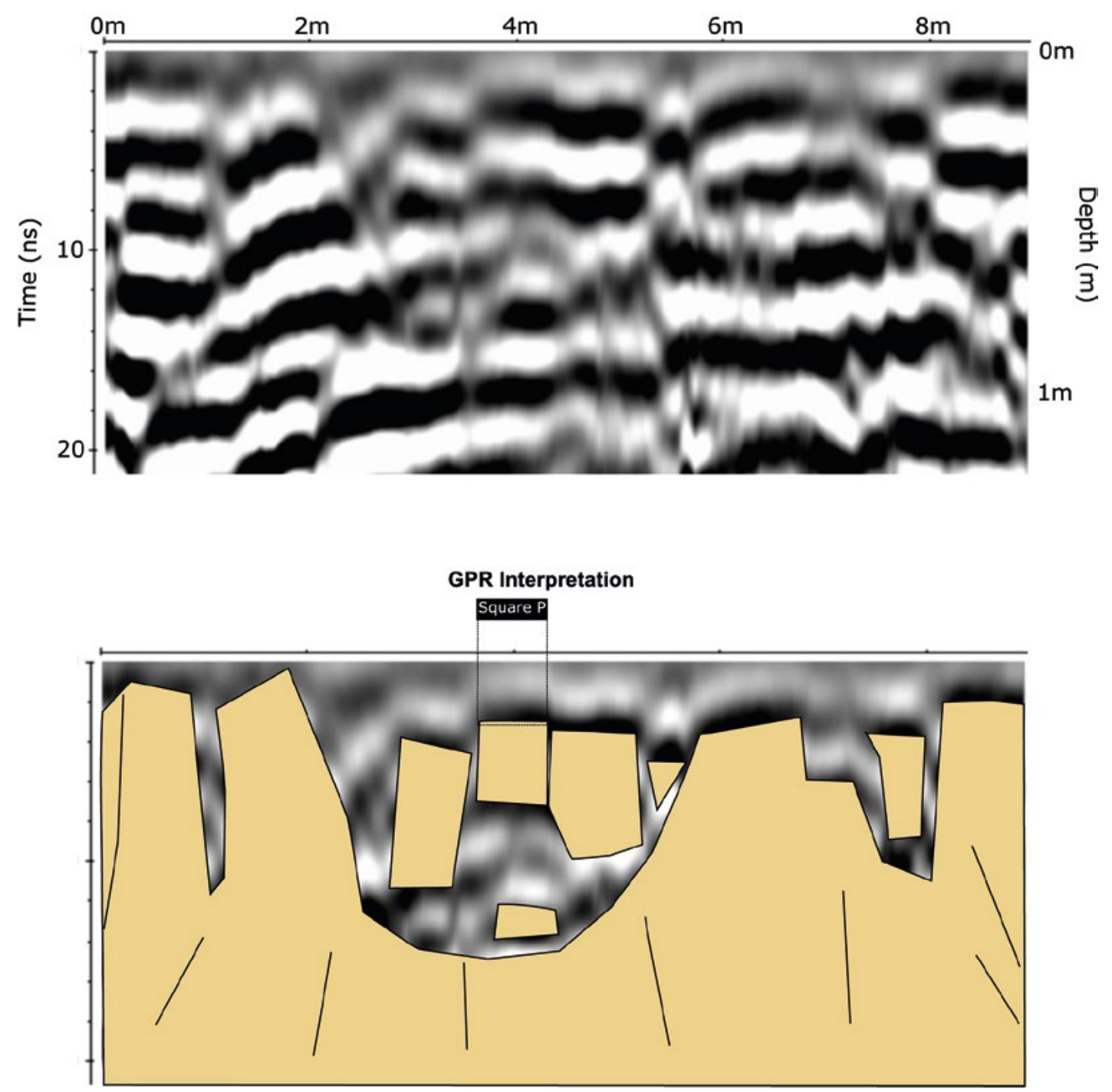

Figure 11.30 Profile view (top) and interpretation (bottom) of GPR data from the southeast to northwest ends of the rockshelter passing through Square $P$.

Source: Illustration by lan Moffat.

Interpretation of the GPR data (Figure 11.30) focused on a transect running across Square P, intended to map the geometry of the layer of rock that fell from the ceiling from the area of Panel E1. The results show that the slab of rock that forms the base of the excavation is c. $30 \mathrm{~cm}$ thick; it appears to sit over a deposit of unconsolidated sediment c. $30 \mathrm{~cm}$ thick. The bedrock surface appears to deepen significantly to a maximum depth of c. $1 \mathrm{~m}$ in the centre of the GPR line, rising nearly to the surface at the start and finish of the line. The base of Pillar 29 is indicated near the southeastern end of the line. The depths of features appear to be slightly underestimated, given that the surface of the rock slab appears by GPR at a depth of c. $25 \mathrm{~cm}$, whilst it was found at $30 \mathrm{~cm}$ in the excavation. 
A particular problem with interpreting these data is reliably defining the exact bedrock surface. This is due to the relatively low frequency of the antenna used; a $500 \mathrm{Mhz}$ or higher instrument would have been more appropriate for the depth of interest. The excavation, not having reached bedrock, does not provide a ground truth for just where this surface is. A further challenge to interpreting the data along the transect is the presence of blocks of roof-fall in localised places on the ground surface. These surface irregularities may have caused significant lateral discontinuities in the data, when the antenna bumped over the uneven ground surface during the survey.

Despite these challenges in interpreting the GPR data, the survey has demonstrated the potential of mapping the geometry of sub-surface features in rockshelter sites with this technique. In particular, the ability of GPR to image the geomorphology of the sub-surface bedrock, and so to validate whether an excavation ends on bedrock or on a slab of roof-fall, has important implications for siting excavations and determining whether they have found the maximum thickness of sediment within a site.

\section{Radiocarbon dates}

Forty accelerator mass spectrometry (AMS) radiocarbon dates on individual pieces of charcoal from Square P were obtained (Table 11.6). Throughout Square P, there is a high level of consistency in the calibrated radiocarbon ages within individual SUs, but poor depth-age sequencing within those SUs (Figure 11.28). That is, within a given SU the calibrated ages fit well within its delimited age range, but there is poor depth-age progression. There is good age differentiation between the SUs. It was not possible, therefore, to apply temporal constraints to the radiocarbon chronology within SUs, so we have identified four Radiocarbon Phases on the basis of age alone. To refine the chronological interpretation, the ${ }^{14} \mathrm{C}$ ages are grouped into four Radiocarbon Phases using the program Oxcal v4.2 (Bronk Ramsey 2009, 2013), and each phase is arranged within a sequence separated by a boundary that provides an estimated date of transition (Figure 11.31). All calibrated ages are based on the 68.3 per cent probability distributions.

The uppermost and most recent Radiocarbon Phase 4 consists of all the radiocarbon determinations with median ages of $180 \mathrm{cal} \mathrm{BP}$ or less, represented by all the radiocarbon dates from XU13 and above except for Wk-39278 (337 \pm 25 BP). All of these are in SU1A, SU1B, SU2 or in the SU2/SU3A interface. The single exception, the slightly older charcoal sample Wk39278 from the surface XU1, is probably a sample that originated from deeper levels in areas adjacent to Square P where trampling by feral water-buffalo has been documented, although the 'old wood' problem (e.g. Spriggs 1989; Wesley et al. 2016) cannot be discounted. In Square P, this treadage zone is limited to SU1A and SU1B.

Radiocarbon Phase 3, preceding Radiocarbon Phase 4, consists of the radiocarbon determinations with median ages from 390 to $510 \mathrm{cal} \mathrm{BP}$, found throughout SU3A and its interfaces with SU2 above and SU3B below (the single exception of Wk-39278 notwithstanding, as discussed above).

Radiocarbon Phase 2 consists of all the radiocarbon determinations with median ages from 1030 to $1370 \mathrm{cal} \mathrm{BP}$; these are all from SU3B or its interface with SU3A above it, indicating an intermixing of Radiocarbon Phases 2 and 3 (and 4, see below) at this interface.

Radiocarbon Phase 1 consists of all the radiocarbon determinations with median ages from 2580 to $4240 \mathrm{cal}$ BP. Radiocarbon Phase 1 covers a wide time range whose many gaps indicate multiple phases of activity condensed into the basal $1.1 \mathrm{~cm}$ of the excavation in XU22 or XU23, immediately against or very close to the basal rock surface in SU3B or its interface with SU3A above it where sediments from Radiocarbon Phases 2-4 are intermixed. 


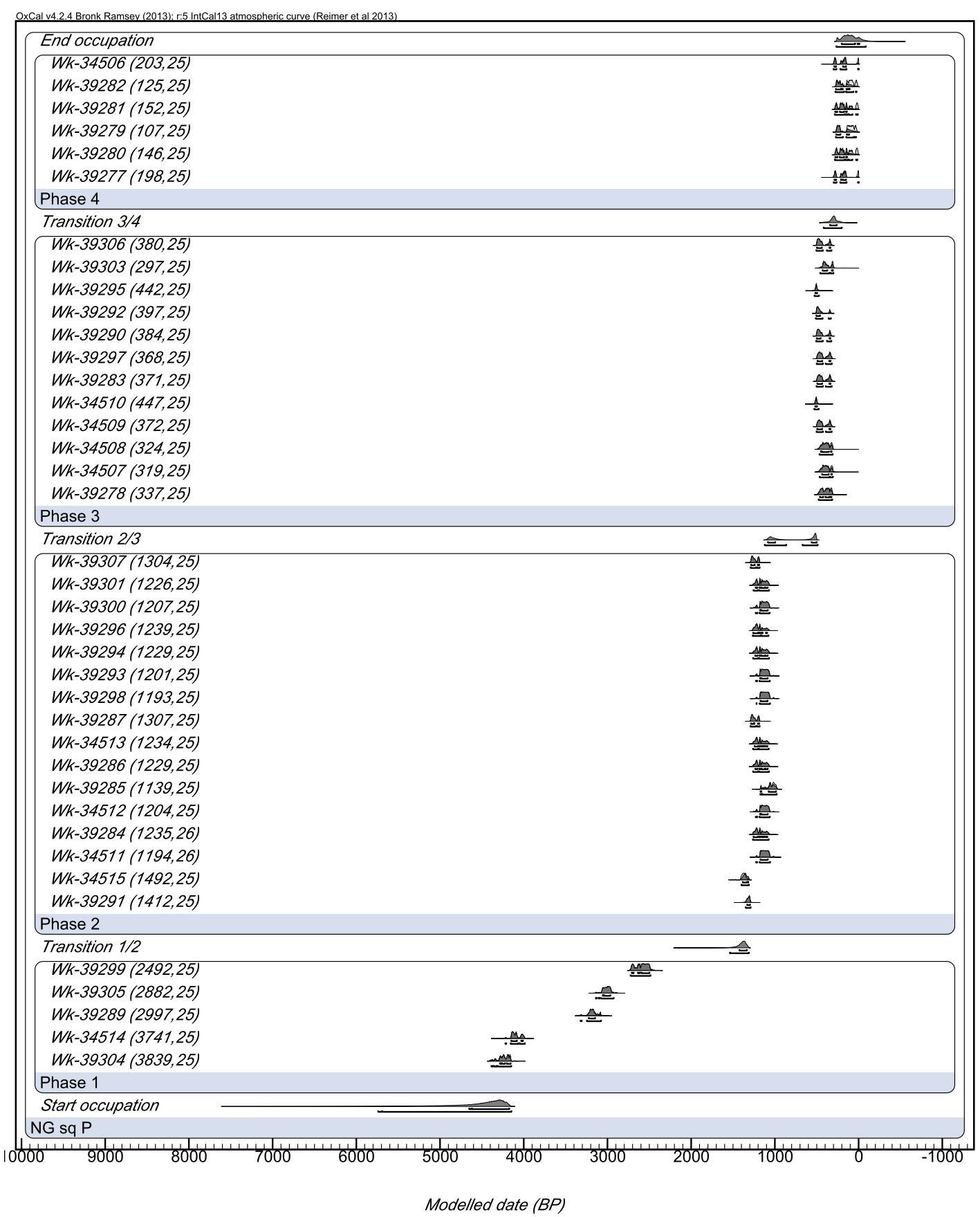

Figure 11.31 Bayesian age model for Square P produced with 0xCal v4.2 (see text for discussion).

Note: To magnify the diagram please see the PDF version at:press.anu.edu.au

Source: Illustration by Fiona Petchey.

This evaluation shows that the end of Radiocarbon Phase 4 began no earlier than 350-260 cal BP (1600-1690 AD), and may have taken place anytime between 210 and $-10 \mathrm{cal}$ BP (1740 and 1960 AD). It was closely preceded by Radiocarbon Phase 3, which began around 570-500 cal BP (1380-1450 AD). There is no evidence of activity between this era and the end of Radiocarbon Phase 2 (1090-990 cal BP), which may have been deposited as early as 1430-1330 cal BP. Radiocarbon Phase 1 represents a diffuse set of events starting around 4660-4170 cal BP. 
How is the single radiocarbon date of $15,324 \pm 100 \mathrm{BP}$ (Wk-39302), calibrating to 18,489 $18,713 \mathrm{cal} \mathrm{BP}$, with a median probability of $18,594 \mathrm{cal} \mathrm{BP}$, from basal XU23 to be understood? On the one hand, it could be charcoal redeposited through foot treadage or wind action onto the exposed upper surface of the rock slab that now lies at the base of Square P after it collapsed from the ceiling. As we have not yet excavated below that rock slab, we do not know the age of the ground surface on which it fell; we therefore do not know whether there is any missing temporal window between the underlying deposits, the time of ceiling collapse and the base of the excavated deposits in Square P. Archaeological excavations across much of Nawarla Gabarnmang find that late Holocene sediments immediately overlie late Pleistocene sediments in Squares D, E, F, I+L+M, Q and R, squares that are 9-14 m west and west-southwest of Square P. In Square A, $14 \mathrm{~m}$ southwest of Square P, late Holocene deposits immediately overlie early Holocene sediments. Only in contiguous Squares C, G, K and N, 13-15 m southwest of Square P, do late Holocene sediments overlie mid-Holocene sediments. In those excavation squares, at all levels above sterile basal sands where these are present, sediments are rich in cultural materials, including abundant charcoal throughout most of the late-Pleistocene to late-Holocene levels. We can infer from this that when the rock slab that now lies at the base of Square P fell from the ceiling (see below), the soft sediments then on or near the surface across most parts of the site were of late Pleistocene age and could easily have been carried by foot, or blown by wind onto nearby surfaces. The isolated radiocarbon determination of this age at the very base of Square P, from a tiny charcoal sample weighing $0.01 \mathrm{~g}$, suggests that this could be how the Pleistocene charcoal fragment on top of the slab could have gotten there. On the other hand, it may be in its 'correct' chronostratigraphic position, indicating that the slab fell around that time. Excavation below the slab may resolve this question.

Table 11.6 Square P: Radiocarbon determinations.

\begin{tabular}{|c|c|c|c|c|c|c|c|c|c|}
\hline $\mathrm{XU}$ & $\begin{array}{l}\text { Depth } \\
\text { (cm) }\end{array}$ & SU & $\begin{array}{c}\text { Wk- } \\
\text { laboratory } \\
\text { code }\end{array}$ & $\delta^{13} \mathrm{C} \%$ & $\begin{array}{l}\% \text { modern } \\
\text { carbon } \\
\left(F^{14} \mathrm{C} \%\right)\end{array}$ & $\begin{array}{c}{ }^{14} \text { C age } \\
\text { (years BP) }\end{array}$ & $\begin{array}{c}\text { Unmodelled } \\
\text { calibrated age } \\
\text { BP (68.3\% } \\
\text { probability) }\end{array}$ & $\begin{array}{c}\text { Unmodelled } \\
\text { calibrated age } \\
\text { BP ( } 95.4 \% \\
\text { probability) }\end{array}$ & $\begin{array}{l}\text { Median } \\
\text { calibrated } \\
\text { age BP }\end{array}$ \\
\hline 1 & 0.5 & $\begin{array}{c}1 \mathrm{a}+ \\
1 \mathrm{~b}\end{array}$ & 39277 & Not available & $97.6 \pm 0.3$ & $198 \pm 25$ & $\leq 290$ & $\leq 300$ & 180 \\
\hline 1 & 1.4 & $\begin{array}{c}1 \mathrm{a}+ \\
1 \mathrm{~b}\end{array}$ & 39278 & Not available & $95.9 \pm 0.3$ & $337 \pm 25$ & $460-310$ & $480-310$ & 390 \\
\hline 2 & 1.4 & $\begin{array}{c}1 \mathrm{a}+ \\
1 \mathrm{~b}\end{array}$ & 39280 & Not available & $98.2 \pm 0.3$ & $146 \pm 25$ & $280-0$ & $290-0$ & 150 \\
\hline 2 & 2.2 & $\begin{array}{c}1 \mathrm{a}+ \\
1 \mathrm{~b}\end{array}$ & 39279 & Not available & $98.7 \pm 0.3$ & $107 \pm 25$ & $260-30$ & $270-10$ & 110 \\
\hline 9 & 10.9 & $2+3 a$ & 39281 & Not available & $98.1 \pm 0.3$ & $152 \pm 25$ & 280-0 & $\leq 290$ & 170 \\
\hline 10 & 14.7 & $2+3 a$ & 39282 & Not available & $98.5 \pm 0.3$ & $125 \pm 25$ & $270-20$ & $280-10$ & 120 \\
\hline 13 & 17.3 & $2+3 a$ & 34506 & $-25.3 \pm 0.2$ & $97.5 \pm 0.3$ & $203 \pm 25$ & $\leq 300$ & $\leq 300$ & 170 \\
\hline 15 & 20.1 & $3 a$ & 34507 & $-26.1 \pm 0.2$ & $96.1 \pm 0.3$ & $319 \pm 25$ & $430-310$ & $470-300$ & 390 \\
\hline 16 & 21.1 & $3 a$ & 34508 & $-25.6 \pm 0.2$ & $96.1 \pm 0.3$ & $324 \pm 25$ & 440-310 & $470-300$ & 390 \\
\hline 17 & 21.3 & $3 a$ & 34509 & $-23.8 \pm 0.2$ & $95.5 \pm 0.3$ & $372 \pm 25$ & 500-330 & 510-310 & 440 \\
\hline 18 & 23.2 & $3 a$ & 34510 & $-25.7 \pm 0.2$ & $94.6 \pm 0.3$ & $447 \pm 25$ & $520-490$ & $530-480$ & 510 \\
\hline 19 & 25.0 & $\begin{array}{c}3 a+ \\
3 b \\
\end{array}$ & 39283 & Not available & $95.5 \pm 0.3$ & $371 \pm 25$ & 500-330 & 510-310 & 440 \\
\hline 19 & 24.5 & $\begin{array}{c}3 a+ \\
3 b\end{array}$ & 34511 & $-24.5 \pm 0.2$ & $86.2 \pm 0.3$ & $1194 \pm 26$ & 1170-1070 & $1230-1010$ & 1120 \\
\hline 19 & 24.2 & $\begin{array}{c}3 a+ \\
3 b\end{array}$ & 39284 & Not available & $85.8 \pm 0.3$ & $1235 \pm 26$ & $1260-1080$ & $1270-1070$ & 1180 \\
\hline 20 & 24.6 & $\begin{array}{c}3 a+ \\
3 b\end{array}$ & 34512 & $-24.7 \pm 0.2$ & $86.1 \pm 0.3$ & $1204 \pm 25$ & $1180-1080$ & $1230-1060$ & 1130 \\
\hline
\end{tabular}




\begin{tabular}{|c|c|c|c|c|c|c|c|c|c|}
\hline$X U$ & $\begin{array}{l}\text { Depth } \\
(\mathrm{cm})\end{array}$ & SU & $\begin{array}{c}\text { Wk- } \\
\text { laboratory } \\
\text { code }\end{array}$ & $\delta^{13} \mathrm{C} \% 0$ & $\begin{array}{l}\% \text { modern } \\
\text { carbon } \\
\left(\mathrm{F}^{14} \mathrm{C} \%\right)\end{array}$ & $\begin{array}{c}{ }^{14} \text { C age } \\
\text { (years BP) }\end{array}$ & $\begin{array}{c}\text { Unmodelled } \\
\text { calibrated age } \\
\text { BP }(68.3 \% \\
\text { probability) }\end{array}$ & $\begin{array}{c}\text { Unmodelled } \\
\text { calibrated age } \\
\text { BP ( } 95.4 \% \\
\text { probability) }\end{array}$ & $\begin{array}{l}\text { Median } \\
\text { calibrated } \\
\text { age BP }\end{array}$ \\
\hline 20 & 24.7 & $\begin{array}{c}3 a+ \\
3 b\end{array}$ & 39285 & Not available & $86.8 \pm 0.3$ & $1139 \pm 25$ & $1070-980$ & $1180-970$ & 1030 \\
\hline 20 & 24.9 & $\begin{array}{c}3 a+ \\
3 b\end{array}$ & 39286 & Not available & $85.8 \pm 0.3$ & $1229 \pm 25$ & $1240-1080$ & $1260-1060$ & 1160 \\
\hline 21 & 26.8 & $3 b$ & 34513 & $-25.7 \pm 0.2$ & $85.8 \pm 0.3$ & $1234 \pm 25$ & $1260-1080$ & $1270-1070$ & 1180 \\
\hline 21 & 26.3 & $3 b$ & 39287 & Not available & $85.0 \pm 0.3$ & $1307 \pm 25$ & $1290-1180$ & $1300-1220$ & 1250 \\
\hline 22 & $\begin{array}{l}28.0^{-} \\
28.7\end{array}$ & $\begin{array}{c}3 a+ \\
3 b\end{array}$ & 39297 & Not available & $95.5 \pm 0.3$ & $368 \pm 25$ & $490-330$ & 500-310 & 440 \\
\hline 22 & $\begin{array}{l}28.0- \\
28.7\end{array}$ & $\begin{array}{c}3 a+ \\
3 b\end{array}$ & 39290 & Not available & $95.3 \pm 0.3$ & $384 \pm 25$ & 500-330 & $510-320$ & 460 \\
\hline 22 & $\begin{array}{l}28.0- \\
28.7\end{array}$ & $\begin{array}{c}3 a+ \\
3 b\end{array}$ & 39292 & Not available & $95.2 \pm 0.3$ & $397 \pm 25$ & $510-340$ & $520-330$ & 480 \\
\hline 22 & $\begin{array}{l}28.0^{-} \\
28.7\end{array}$ & $\begin{array}{c}3 a+ \\
3 b\end{array}$ & 39295 & Not available & $94.6 \pm 0.3$ & $442 \pm 25$ & $520-490$ & $530-470$ & 510 \\
\hline 22 & $\begin{array}{l}28.0- \\
28.7\end{array}$ & $\begin{array}{c}3 a+ \\
3 b\end{array}$ & 39298 & Not available & $86.2 \pm 0.3$ & $1193 \pm 25$ & $1170-1070$ & $1230-1050$ & 1120 \\
\hline 22 & $\begin{array}{l}28.0- \\
28.7\end{array}$ & $\begin{array}{c}3 a+ \\
3 b\end{array}$ & 39293 & Not available & $86.1 \pm 0.3$ & $1201 \pm 25$ & $1180-1080$ & $1230-1060$ & 1130 \\
\hline 22 & $\begin{array}{l}28.0^{-} \\
28.7\end{array}$ & $\begin{array}{c}3 a+ \\
3 b\end{array}$ & 39294 & Not available & $85.8 \pm 0.3$ & $1229 \pm 25$ & $1240-1080$ & $1260-1060$ & 1160 \\
\hline 22 & $\begin{array}{l}28.0^{-} \\
28.7\end{array}$ & $\begin{array}{c}3 a+ \\
3 b\end{array}$ & 39296 & Not available & $85.7 \pm 0.3$ & $1239 \pm 25$ & $1260-1090$ & $1270-1070$ & 1200 \\
\hline 22 & $\begin{array}{l}28.0^{-} \\
28.7\end{array}$ & $\begin{array}{c}3 a+ \\
3 b\end{array}$ & 39291 & Not available & $83.9 \pm 0.3$ & $1412 \pm 25$ & $1340-1290$ & $1350-1280$ & 1320 \\
\hline 22 & 28.8 & $3 b$ & 39289 & Not available & $68.9 \pm 0.2$ & $2997 \pm 25$ & $3230-3080$ & $3220-3070$ & 3180 \\
\hline 22 & 28.7 & $3 b$ & 34514 & $-25.6 \pm 0.2$ & $62.8 \pm 0.2$ & $3741 \pm 25$ & $4150-4000$ & $4230-3980$ & 4100 \\
\hline 23 & $\begin{array}{c}28.7- \\
29.1 \\
\end{array}$ & $\begin{array}{c}3 a+ \\
3 b\end{array}$ & 39303 & Not available & $96.4 \pm 0.3$ & $297 \pm 25$ & $430-300$ & $460-290$ & 390 \\
\hline 23 & $\begin{array}{l}28.7- \\
29.1\end{array}$ & $\begin{array}{c}3 a+ \\
3 b\end{array}$ & 39306 & Not available & $95.4 \pm 0.3$ & $380 \pm 25$ & $500-330$ & $510-320$ & 460 \\
\hline 23 & $\begin{array}{l}28.7- \\
29.1\end{array}$ & $\begin{array}{c}3 a+ \\
3 b\end{array}$ & 39300 & Not available & $86.1 \pm 0.3$ & $1207 \pm 25$ & $1180-1080$ & $1230-1060$ & 1130 \\
\hline 23 & $\begin{array}{l}28.7- \\
29.1\end{array}$ & $\begin{array}{c}3 a+ \\
3 b\end{array}$ & 39301 & Not available & $85.8 \pm 0.3$ & $1226 \pm 25$ & $1230-1080$ & $1260-1060$ & 1150 \\
\hline 23 & $\begin{array}{c}28.7- \\
29.1 \\
\end{array}$ & $\begin{array}{c}3 a+ \\
3 b\end{array}$ & 39307 & Not available & $85.0 \pm 0.3$ & $1304 \pm 25$ & $1290-1180$ & $1290-1180$ & 1250 \\
\hline 23 & 29.2 & $3 b$ & 34515 & $-25.2 \pm 0.2$ & $83.1 \pm 0.3$ & $1492 \pm 25$ & $1400-1340$ & $1480-1460$ & 1370 \\
\hline 23 & $\begin{array}{l}28.7- \\
29.1\end{array}$ & $\begin{array}{c}3 a+ \\
3 b\end{array}$ & 39299 & Not available & $73.3 \pm 0.2$ & $2492 \pm 25$ & $2710-2490$ & $2730-2480$ & 2580 \\
\hline 23 & $\begin{array}{l}28.7- \\
29.1\end{array}$ & $\begin{array}{c}3 a+ \\
3 b\end{array}$ & 39305 & Not available & $69.9 \pm 0.2$ & $2882 \pm 25$ & $3060-2960$ & $3140-2920$ & 3010 \\
\hline 23 & $\begin{array}{l}28.7- \\
29.1 \\
\end{array}$ & $\begin{array}{c}3 a+ \\
3 b\end{array}$ & 39304 & Not available & $62.0 \pm 0.2$ & $3839 \pm 25$ & $4300-4150$ & $4410-4150$ & 4240 \\
\hline 23 & $\begin{array}{l}28.7- \\
29.1\end{array}$ & $\begin{array}{c}3 a+ \\
3 b\end{array}$ & 39302 & Not available & $14.8 \pm 0.2$ & $\begin{array}{c}15,324 \pm \\
100\end{array}$ & $18,720-18,480$ & $18,800-18,360$ & 18,590 \\
\hline
\end{tabular}

All ${ }^{14} \mathrm{C}$ ages are AMS on single pieces of charcoal. Calibrations undertaken using 0xCal 4.2 (IntCal13) (Reimer et al. 2013). Source: Authors' data. 


\section{Geomorphological history of area around Square $\mathbf{P}$}

Square $\mathrm{P}$ is located on the central-eastern side of the site, where widely spaced pillars create an open space beneath a large, more or less flat ceiling (Figure 11.4). Immediately to the east, this open space is delimited by the set of closely spaced Pillars 29-36, while to the west are the moderately spaced Pillars 25-28. In this central-eastern part of the site that contains Square P, the large ceiling measures $8 \mathrm{~m}$ wide by $12 \mathrm{~m}$ long. Elsewhere, from ground level to ceiling, the open space is interrupted by numerous pillars. It is on the ceiling of this large, open space that we find the most visually spectacular art panels at the site, including Panel E1.

Although Square P was shallow (29 cm deep) compared to the other excavation squares at Nawarla Gabarnmang, it contained rich archaeological deposits of stone artefacts, faunal remains and earth pigments dating to the past c. 4240 years, a similar period of time as that found in Square B $5 \mathrm{~m}$ to the west. The accumulated sediments in both these squares signal a recent history relative to the long sequences revealed in Squares $\mathrm{A}, \mathrm{D}+\mathrm{H}, \mathrm{F}+\mathrm{I}+\mathrm{L}+\mathrm{M}$ and $\mathrm{E}+\mathrm{J}+\mathrm{O}+\mathrm{Q}+\mathrm{R}$, which are all deeper (60-85 cm depth) and have an antiquity close to 50,000 years (David et al. completed manuscript).

This study of Square $\mathrm{P}$ and its immediate surroundings prompts two questions:

- Does the rock floor at the base of the square represent bedrock, or is it the upper surface of a collapsed ceiling slab?

- Why are there no pillars in this part of the site?

To answer these questions, we turned to the archaeology, geomorphology and the 3-D laser map of the site (cf. David et al. 2011, 2013, completed manuscript; Delannoy et al. 2013; Geneste et al. 2010, 2012; see also Chapter 10).

\section{Origin of the rock at the base of Square $P$}

To explore whether the rock surface at the base of Square P is bedrock or the upper surface of a fallen ceiling slab, we looked at the configuration and geomorphology of the other excavated squares across the site. Confirmed bedrock was reached in a number of squares $(A, D+H, E+J$, $\mathrm{F}+\mathrm{I}+\mathrm{L}+\mathrm{M})$. These squares, all positioned close to pillars, are where the quarzitic bedrock is dissected by geologically ancient narrow crevices along fissure lines. These crevices rapidly taper to a depth of c. $20-35 \mathrm{~cm}$ below the bedrock surface (Figure 11.32). Square P is different in that it is some distance from extant pillars, the surface of the rock at its base is flat and there are no signs of a crevice or fissure in the basal rock. Initial indications are thus that the rock base of Square P is not the bedrock, but a fallen (or positioned) slab. Further investigation enabled a firmer determination. 

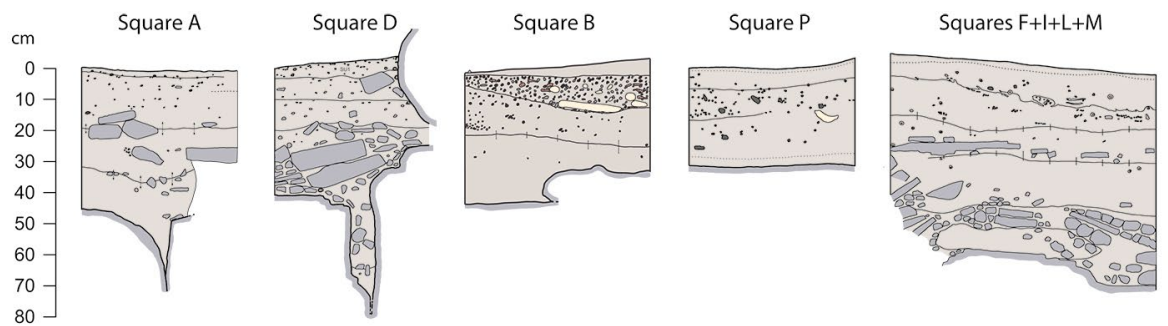

Squares $J+E$
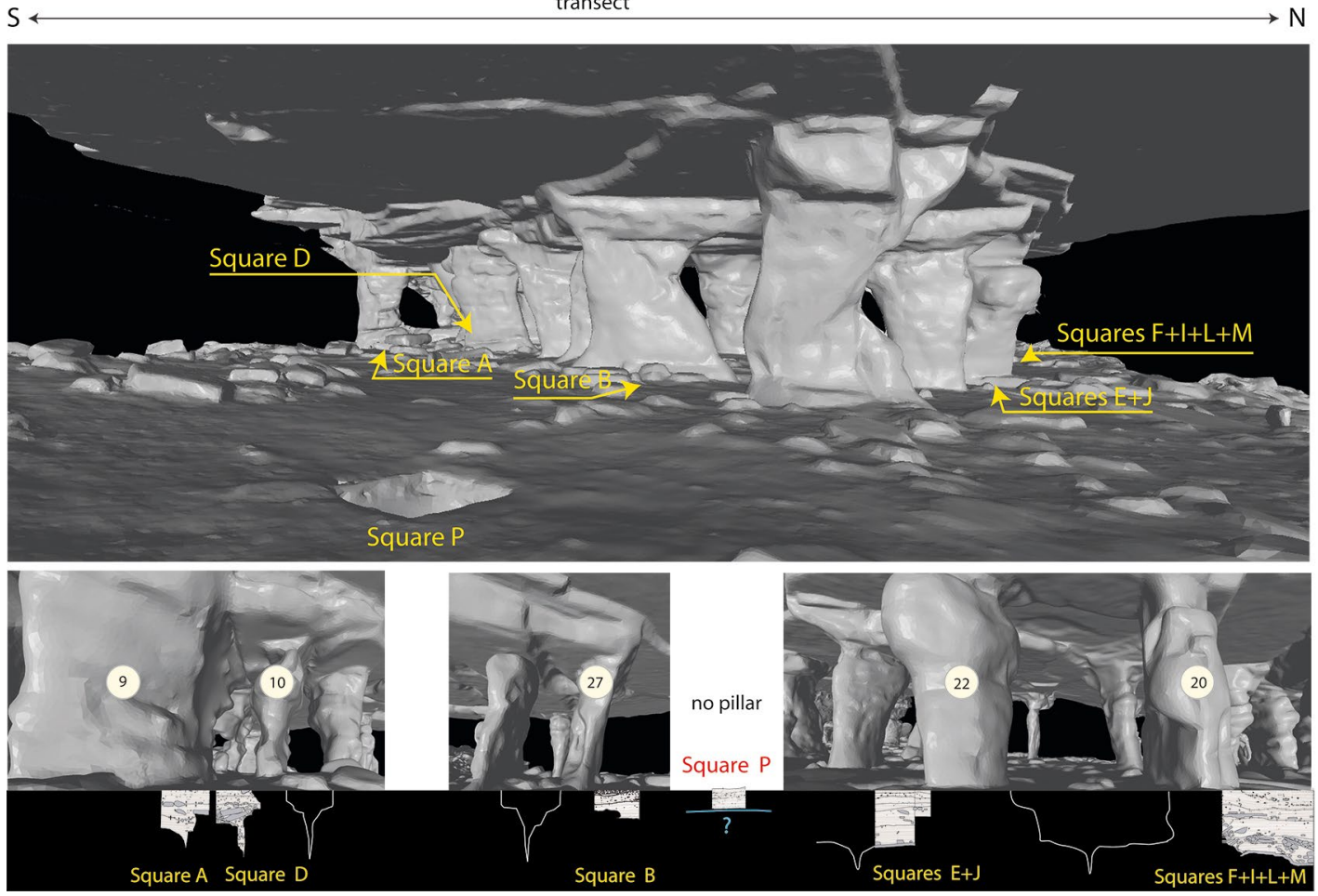

Figure 11.32 Section drawings of excavation squares, showing the relative depth of pits. Source: Illustration by Jean-Jacques Delannoy, Bruno David and Kara Rasmanis.
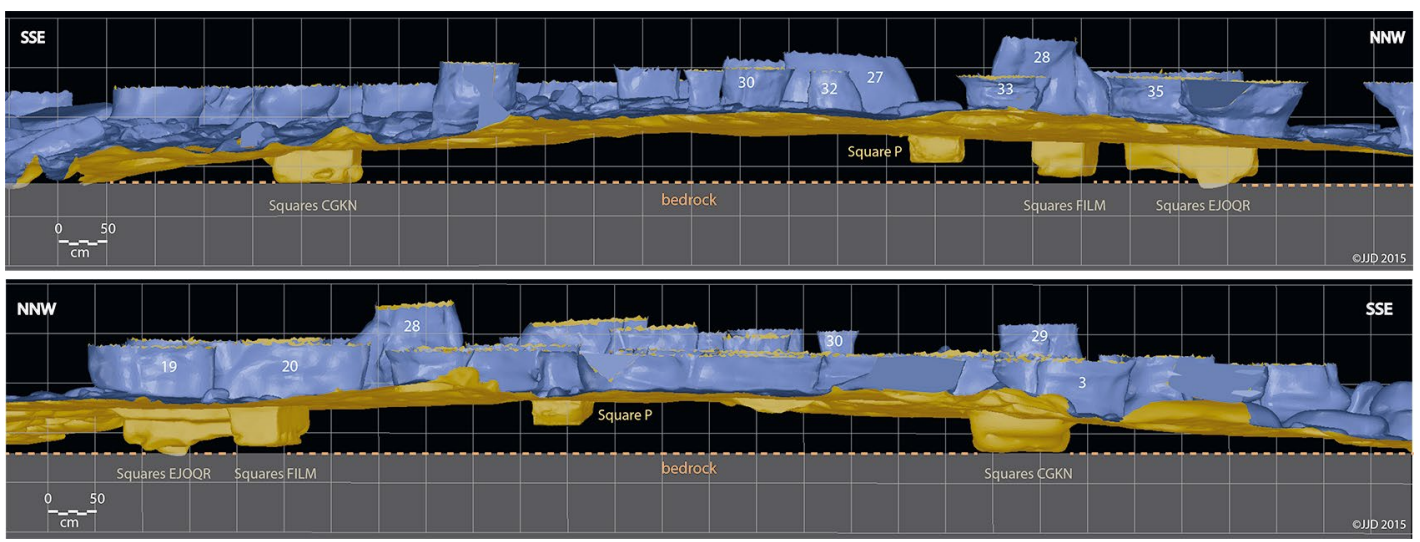

Figure 11.33 3-D projections of excavation squares, from the laser mapping of the site.

These two projections extrapolate via the 3-D model the alignment of the current ground level to reveal sub-surface (in yellow) and above-ground details (the base of the pillars, shown in blue). Here the base of Square $P$ is perched above the expected bedrock level, as extrapolated from the bedrock levels revealed in Squares $(+G+K+N, E+J+Q+R$ and $F+++L+M$. The slightly domed configuration of the ground (more elevated at the centre than along the edges) is also apparent.

Source: Illustration by Jean-Jacques Delannoy. 

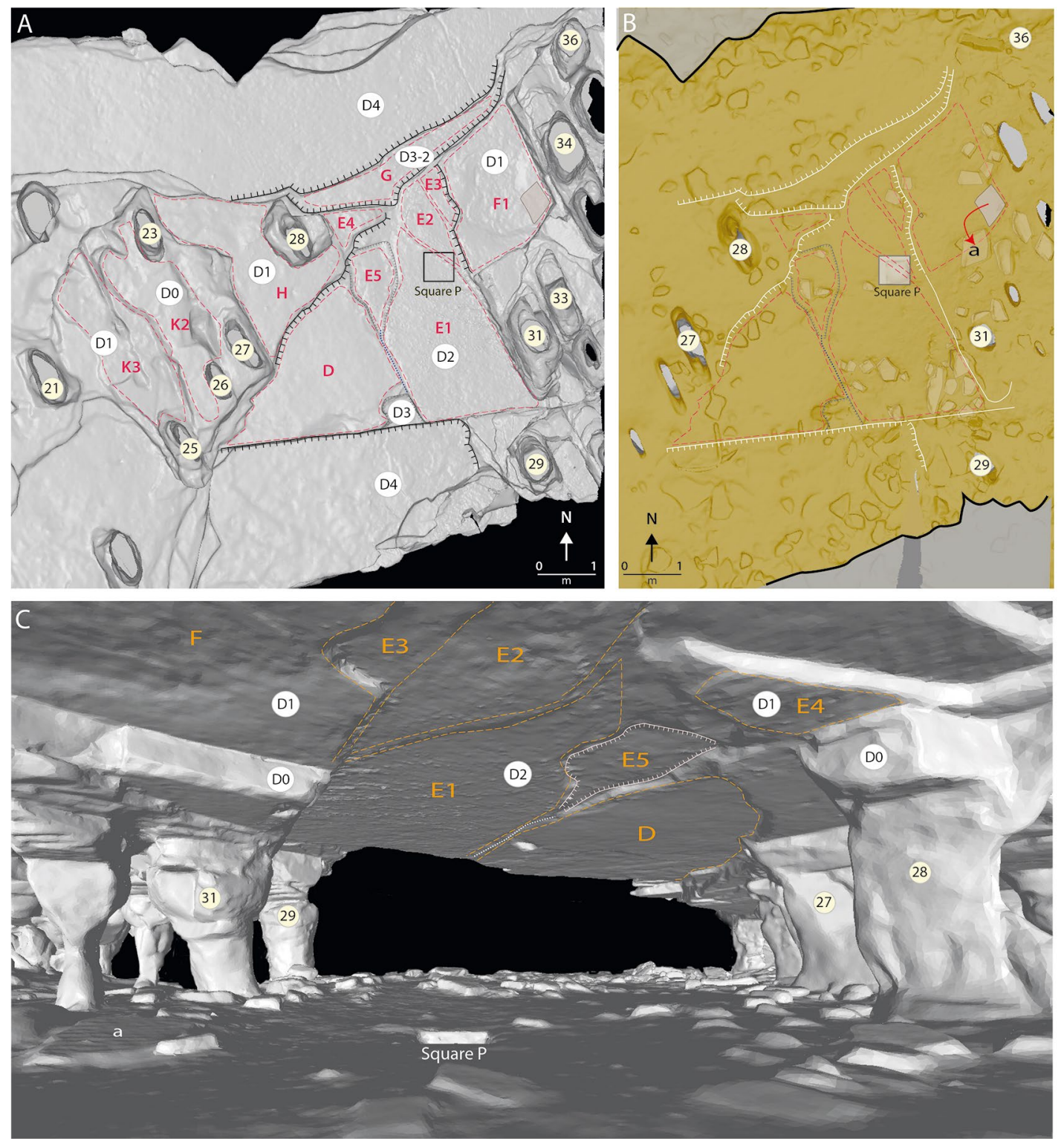

Figure 11.34 View of the ceiling $(A)$ and ground $(B)$ levels around Square $P$, as evident from the 3-D model.

A: Ceiling view showing the various rock art panels (red lines and lettering); the edges of the ceiling rock strata (D0-D4); and the extant Pillars 21-36. B: Ground view showing the individual blocks of rock currently present at ground level; the anthropically moved block (red arrow, showing movement from original to current positions); the extant pillars (numbered); and the major features of the current ceiling ledges representing the edges of the exposed rock strata (white), and rock art panel (red). C: The area around Square P, looking south-southwestward.

Source: Illustration by Jean-Jacques Delannoy.

At first look, the spatial relationship between the area of Square P and the location of past pillars is unclear, as some pillars across the site have been removed by people (Delannoy et al. 2013; see Chapter 10). So the base of Square $P$ may correspond with the location of a now-removed ancient pillar whose base would have been at a high point of the bedrock. We addressed this question in two ways. We began by examining the depth of the bedrock across the excavated squares. As these are located along the northern (Squares $\mathrm{F}+\mathrm{I}+\mathrm{L}+\mathrm{M}$ and $\mathrm{E}+\mathrm{J}+\mathrm{O}+\mathrm{Q}+\mathrm{R}$ ) and southern (Squares $\mathrm{A}, \mathrm{D}+\mathrm{H}$ and $\mathrm{C}+\mathrm{G}+\mathrm{K}+\mathrm{N}$ ) sides of the site, they enable a north-south transect to be drawn for bedrock across the site (Figure 11.33). Figure 11.33 places these excavated squares and their 
bedrock base in their correct spatial alignment: the blue areas represent the present surface topography together with the lower parts of the extant pillars; the brown areas represent the sub-surface sediments as extrapolated by the 3-D model from laser scanning of both the site and numerous excavated squares (those excavations were open when the laser scanning was done). The bedrock is approximately at the same elevation: see the dashed line identifying the level of the bedrock base in Squares $\mathrm{C}+\mathrm{G}+\mathrm{K}+\mathrm{N}, \mathrm{F}+\mathrm{I}+\mathrm{L}+\mathrm{M}, \mathrm{E}+\mathrm{J}+\mathrm{O}+\mathrm{Q}+\mathrm{R}$; Squares $\mathrm{A}, \mathrm{B}$ and $\mathrm{D}+\mathrm{H}$, excavated in 2010-2011, were already back-filled when the laser scanning was done in 2012, and therefore do not appear on Figure 11.33. Figure 11.33 clearly shows the rock at the base of Square P is higher than the bedrock in the other squares. Three possibilities can thus be entertained: 1) the bedrock is more elevated at the centre of the site, as represented by Square P; 2) the base of Square P represents the base of an ancient, now-collapsed pillar; or 3) the base of Square P represents the upper surface of an ancient collapsed ceiling slab.

The first option is ruled out by observing the dip of the bedrock around the pillars and on the ceiling rock strata. Figure 11.34 (viewed in 3-D) shows well the sub-horizontal alignment of the geological strata to the right (west) of Square $P$.

To explore the second option, we analysed the positions of pillars and ceiling fissure lines using the 3-D model (Figure 11.35). This analysis utilises the current distribution of pillars across the site, as well as the densely pillared, slightly elevated area that delimits the open 'courtyard' on the southern side of the site.

Figure 11.35 shows two projections.

Projection 1 (Figure 11.35A) is the ceiling as observed from ground level. Here we can clearly see that the pillars are aligned along two intersecting axes (SSE-NNW and ENEWSW); also shown are the currently exposed rock strata on the ceiling. The SSE-NNW axis represents fissures that resulted from regional tectonic activity; the ENE-WSW fissures are more localised stress fractures that formed after the voids between pillars had been created at Nawarla Gabarnmang. We again note the sparse distribution of pillars on the eastern part of the site where Square P is located.
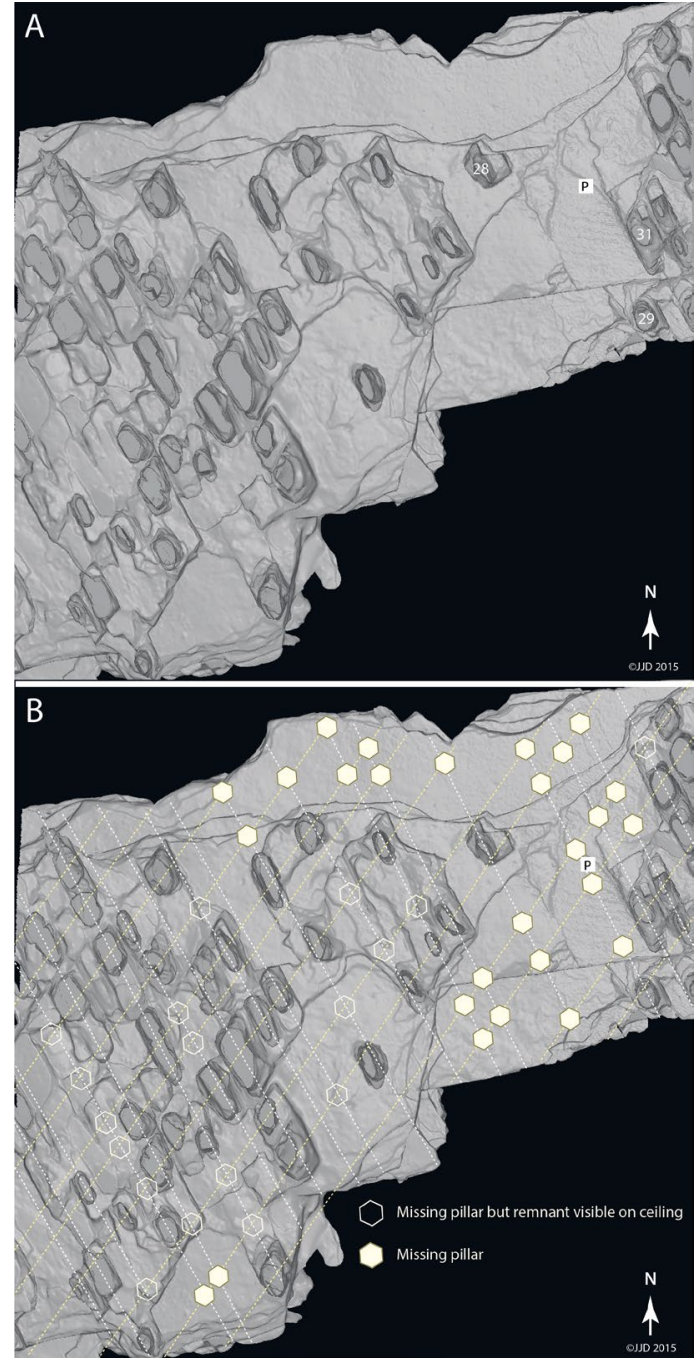

Figure 11.35 Ceiling view of the central-eastern and western parts of Nawarla Gabarnmang, showing the location of Square $P$.

A: Current ceiling and pillars: The pillars can be seen as darker areas. B: 'Original' ceiling: Missing pillars are identified from remnant traces on the ceiling, and their expected occurrences along the intersecting alignments (yellow and white lines) of the extant pillars.

Source: Illustration by Jean-Jacques Delannoy. 
Projection 2 (Figure 11.35B) shows the axes of the pillars with their parallel and criss-crossing alignments (white lines: SSE-NNW; yellow lines: ENE-WSW). The natural fissures exposed in the bedrock at the base of the excavations, aligned with matching ceiling fissures overhead, parallel those criss-crossing pillar alignments (the corridors between the dashes). The extant pillars are positioned where the two pillar axes meet. This on-site mapping coupled with the 3-D model allows us to identify the tops of the missing pillars (Figure 11.36): these remnant pillars on the ceiling are located where the alignments of the pillars cross. We can thus locate the pillars that once existed in the eastern and northern side of the site, where the largest sections of painted ceiling occur.

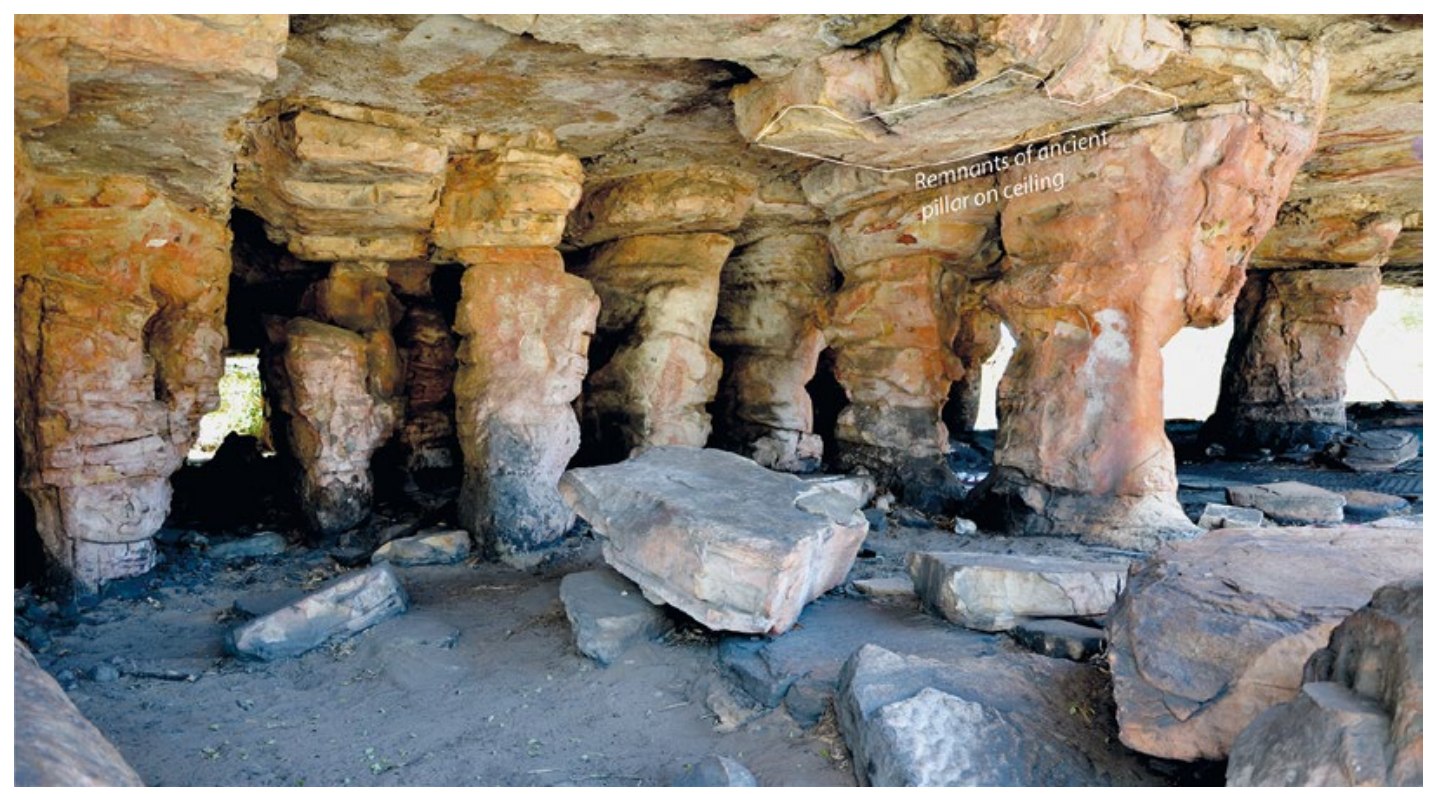

Figure 11.36 Southwest section of rockshelter, showing remnants of a missing pillar.

Source: Photograph by Jean-Jacques Delannoy.

To see whether the sparseness of pillars in the eastern side of the site was due to preferential weathering and erosion (lateral variation of geological facies that would have caused the eastern pillars to be less resistant), we have projected the NNW-SSE alignment of the pillars on the edge of the densely pillared, slightly elevated area to the south of the site (Figure 11.37). This projection, and the dense packing of pillars on the southern side, shows that these align along the same axis as the pillars under the rockshelter. The two 3-D views shown in Figure 11.38 confirm this. Figure 11.38A is a north-south view from the northern entrance of the site, with the rockshelter shown in grey, the 'courtyard' to the south shown in green, the rock outcrop further to the south shown in light yellow and the background (southern) pillars under the overhang of the rockshelter shown in pink. This figure clearly shows the continuous alignment of the pillars and of the voids between them. Figure $11.38 \mathrm{~B}$ is a north-south view from the northern edge of the rockshelter (numbered pillars and Square P), through the central courtyard (green) and the northern edge of the densely pillared, slightly elevated area to the south of the site (light yellow). On this latter edge, the alignment of the site's pillars can be seen: for example, Pillar 28 of the rockshelter aligns with the 28 th pillar of the slightly elevated area to the south, and that sequence of pillar alignments progresses in good order across space. 


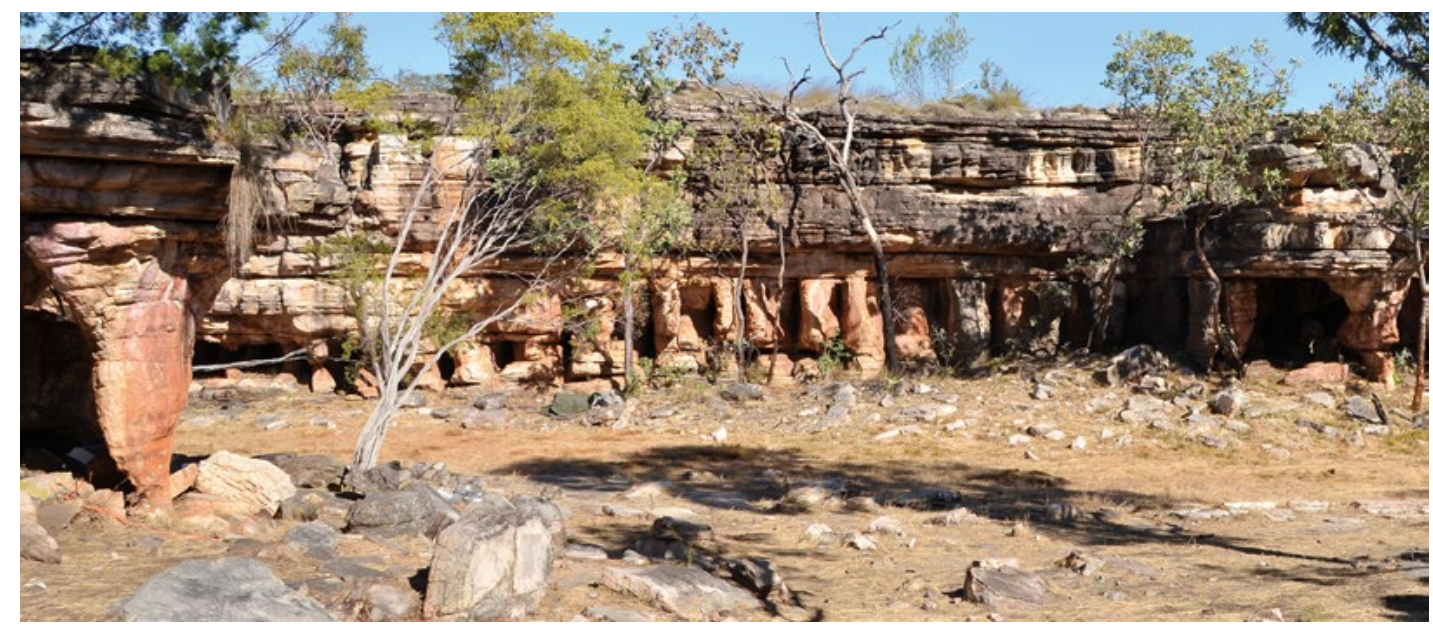

Figure 11.37 Edge of the densely pillared, slightly elevated area to the south of the shelter.

The spacing between the pillars differs noticeably from that inside the main shelter. This difference is not due to geological causes, as the same pillar and inter-pillar alignments project across the two areas (see Figure 11.35), along with the action of comparable weathering processes. The difference is due to the actions of people, who have altered the geological matrix in the shelter (and commenced also to remove pillars in the western part of the southern rock outcrop shown at the extreme right-hand side of the photograph).

Source: Photograph by Jean-jacques Delannoy.

These results allow us to conclude:

- The low density of pillars in the eastern part of the site is not due to differential weathering and erosion. The edge of the slightly elevated area to the south of the rockshelter demonstrates the regular presence of pillars along the same alignments as within the rockshelter. The same logic should thus also apply to the eastern part of the site where pillars are absent.

- The rock base in Square P does not correspond with the base of an ancient pillar, as the location of the square does not correspond with the alignment of the pillars (see Figure 11.35); instead, it is positioned along the NNE-SSW alignment of fissure lines in the bedrock. Those fissure lines are evident as narrow crevices in the bedrock that now lies underground and has been revealed in the excavations at the base of Squares $\mathrm{A}, \mathrm{D}+\mathrm{H}$ and $\mathrm{F}+\mathrm{I}+\mathrm{L}+\mathrm{M}$, and as corresponding fissures along the ceiling overhead.

Overall, the spatial configuration of the bedrock (Figure 11.33) and the distribution and alignment of extant and ancient pillars (Figure 11.35) enable us to be sure the rock base in Square $\mathrm{P}$ is neither an elevated part of the bedrock nor the base of a pillar. But it is consistent with a rock slab fallen from the ceiling. The location of the high points revealed by GPR mapping (Figure 11.30; see above) corresponds to the alignment of the pillars, so those high points can be interpreted as the bases of disappeared pillars. The GPR cross-section also confirms that Square $\mathrm{P}$ is located to the right of a deepening of the bedrock, consistent with the formation of a crevice caused by the weathering and evacuation of weathered products along fissure lines over long geological time frames.

This convergence of geological, GPR and 3-D modelling evidence lead us to conclude that the rock at the base of Square $\mathrm{P}$ is the upper surface of a collapsed portion of the ceiling rock rather than the actual bedrock of the shelter. 

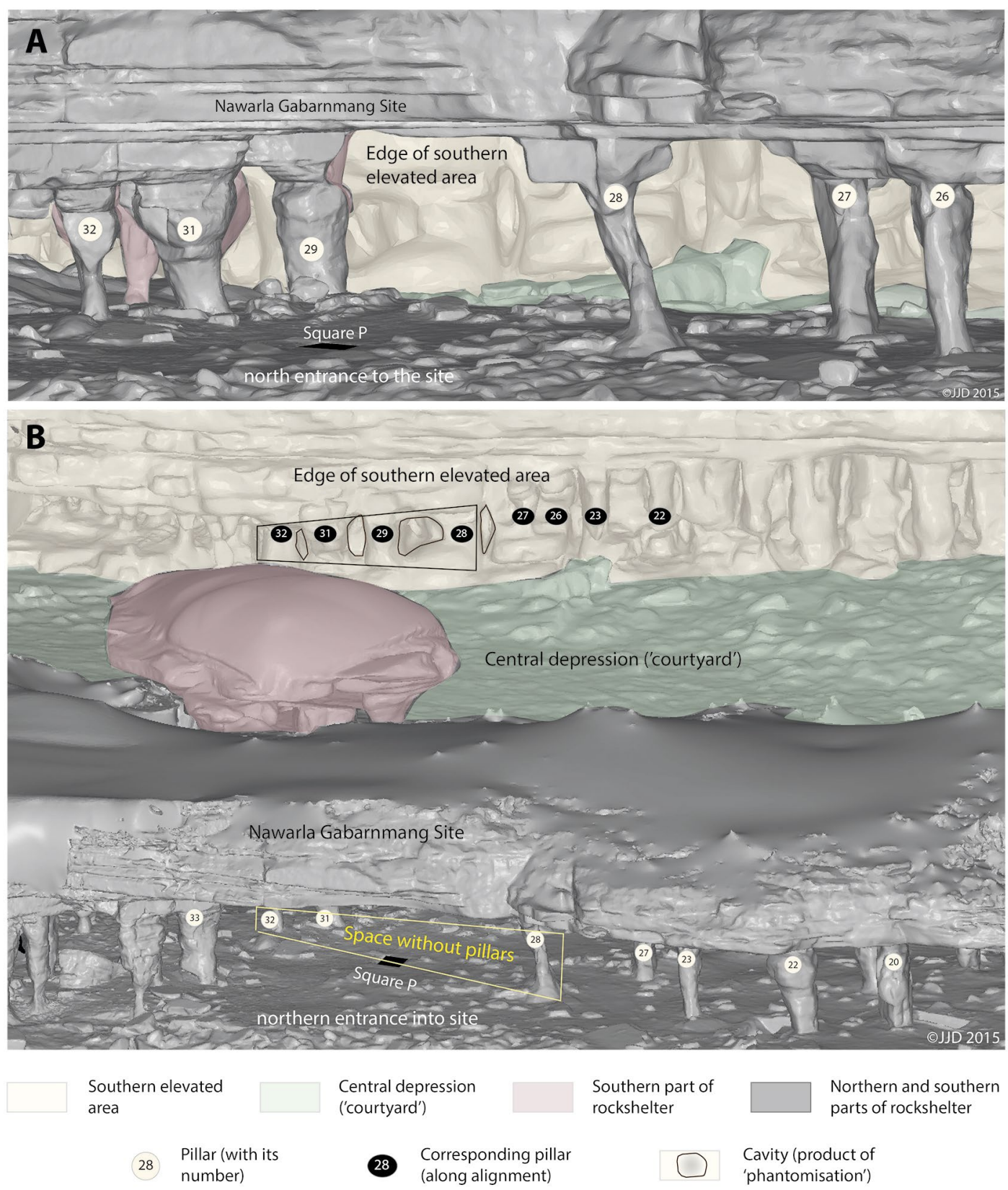

Figure 11.38 Projected view of the Nawarla Gabarnmang shelter and the densely pillared edge of the slightly elevated area to the south.

A: View from the northern entrance into the shelter, looking through the site across the 'courtyard' onto the dense pillars further to the south. The pillars align across the shelter onto the edge of the slightly elevated area to the south of the 'courtyard'. B: Angled view allowing us to compare the pillars within the shelter with those at the edge of the slightly elevated area (the alignment of the pillars follows the alignment of geological structures and fissure lines).

Source: Illustration by Jean-Jacques Delannoy. 


\section{Morphogenic reconstitution of Nawarla Gabarnmang to the east of Square $\mathbf{P}$}

The preceding analysis has highlighted the paucity of pillars in the eastern sector, which created an expansive, flat ceiling space on which art Panels D-E1-E2-E3-F1 were made (Figure 11.34). This extant art could only have been made after the current ceiling rock surface was formed.

Figure 11.34 shows various views of the Square $P$ area. Figure 11.34A is a view of the ceiling with its art panels, exposed geological strata, and the extant pillars. Figure $11.34 \mathrm{~B}$ is a ground view showing the blocks exposed on the surface, and the edges of extant rock strata. Figure 11.34C shows the flatness of the ceiling, which is related to the sub-horizontality of the quartzitic strata (with strata D1 and D2 as the base layers) and to the resistance of those strata to weathering and erosion. In this part of the site, rock art predominantly occurs on stratum D2, less often on stratum D1. Along more northern and southern parts of the site, rock art is also found on a large surface of stratum D4 (not shown on Figure 11.34C).

These views show that no art phase on Panel E1 above Square P could have been done until strata D0 and D1 had fallen from the ceiling. The remnant ledges on the edges of strata D0 and D1 clearly have a rectilinear geometry, indicating where the missing strata have collapsed. This collapse took place when there were no pillars to give structural support. Here, the geometry of the remnant broken edges does not align with geological points of weakness; i.e. the broken edges do not align with the network of fissures. This is particularly visible on Figure 11.34, where the northern and southern edges of the overhang (transition slabs D3-2 and D4; see Figure 11.34A) are not aligned along these fissure lines (shown as white and yellow dashes in Figure 11.35B), but rather cut across them. This non-alignment of ceiling surface edges relative to the natural fissure lines results from ceiling slab collapse caused by an absence of structural support and ensuing mechanical stress, rather than from mechanical failure along zones of weakness. The ledge separating the rock art-bearing Panels G-E4-H from Panels F1-E1-E2E3-E5 corresponds to an area of weakness (fissure line) running in an ENE-WSW direction. The eastern rectilinear ledge of rock stratum D2 (Panel E1) and the fissure that runs through stratum D2 (between Panels E1 and D) are aligned with lines of weakness oriented SSE-NNW (Figure 11.34).

These ceiling strata ledges correspond to the edges of slab collapses. Analysis of the two collapsed strata D0 and D1, and their respective ledges, indicates that these collapses, whose exact timing we do not know, certainly did not all happen at the same time. In the area of Square P, we know that stratum D1, which caused the exposure of stratum D2, became exposed on the ceiling sometime before $3839 \pm 25 \mathrm{BP}(4150-4410 \mathrm{cal} \mathrm{BP}$; see Table 11.6, Figure 11.28), as indicated by the minimum age for the collapse of the slab at the base of Square P. If the flat surface of the ceiling above Square P can be matched to the separation plane (the sub-horizontal joint) between strata D1 and D2, then we could conclude that the flat surface of the ceiling probably relates to a lack of pillars in this part of the site. In other parts of the site, ceilings with extant pillars are corbelled, and between pillars their flat surfaces are much smaller (e.g. the space between Pillars 21-23 and Pillars 25-27 that house art Panels K2-K3; see Figure 11.34A). If the flat surface of the ceiling above Square P relates to an absence of pillars in this part of the site before the collapse of stratum D1, then the question must be asked: What caused those pillars to disappear? This question is the more significant because the ground around Square P is relatively flat and its few large blocks suggest an absence of accumulated collapsed rocks below ground. The blocks 
of stone in this part of the site are mostly small and tend to sit on the ground surface, unlike other parts of the site where large and partly buried blocks emanate above ground level. These small and tabular surface blocks cannot account for the roof collapse, or for the mass of rock from the missing pillars.

The west side of the site (not mapped in Figure 11.34; see Chapter 10) demonstrates two important features. First, the collapse of pillars creates an uneven, densely cluttered floor surface. Second, from this we can conclude that some blocks from collapsed pillars in areas with flat surfaces were physically removed from the shelter; there is ample evidence of this in the large quantities of anthropically removed blocks, immediately outside the northern dripline in particular (see Delannoy et al. 2013). The absence of accumulated blocks, and the flatness of the ground surface in the area of Square P, indicate that many blocks from the collapsed pillars were removed before the collapse of stratum D1, at least in the area north of a line linking Pillars 28-31. Although the area south of this line lies under the same ceiling stratum (D2) as the area immediately to the north, the ground surface there is more chaotic and includes numerous blocks from stratum D1.

These observations allow us to conclude (see Figure 11.39):

1. Fallen blocks from 12 now-missing pillars were removed from the large, open central part of the site by people, whatever the cause(s) of those pillar collapses. Both the pillar collapses and the removal of their blocks pre-date the fall of stratum D1.

2. The absence of pillars from the large, open central part of the site led to the collapse of the entire stratum D1 from the ceiling in the space between Pillars 28, 27, 31 and 34. This collapse must have taken place before c. $4240 \mathrm{cal} \mathrm{BP}$, possibly during terminal Pleistocene times, as indicated by the minimum age of the stratum D1 collapse evident at the base of Square P.

3. Strata D2-D3 subsequently collapsed along the northern and southern edges of the site, exposing new flat surfaces upon which large panels of rock art were then created, Panel J1 in the north and Panel C2 in the south (see Figure 11.4). The collapse of the strata D2-D3 should have created a higher ground level in this part, but the reverse occurred: the ground level is slightly lower than in the central, open part of the site (Figure 11.33). This lowering of the ground level, and the blocks immediately outside the northern overhang in particular, result from removal of blocks under the overhang to beyond the dripline. This anthropogenic change to the site took place before the fall of stratum D1, i.e. before c. $4240 \mathrm{cal} \mathrm{BP}$. It is evidence of the social modification of a very large rockshelter through aménagement and inhabitation (cf. Delannoy et al. 2013; Thomas 2008; see also Chapter 10).

4. Today, we see numerous horizontal slabs of rock on the present ground surface. Local Jawoyn Elders call these 'pillows' (see Delannoy et al. 2013). Examination of one (slab 'a' on Figures $11.34 \mathrm{~B}$ and $11.34 \mathrm{C}$ ) indicates that it is not in its original position; it has come from the localised collapse of a section of stratum D0 near Pillar 34; its repositioning onto the ceiling was digitally tested with the 3-D model. After it fell from the ceiling, it was moved by people to its current location (red arrow on Figure 11.34B). 


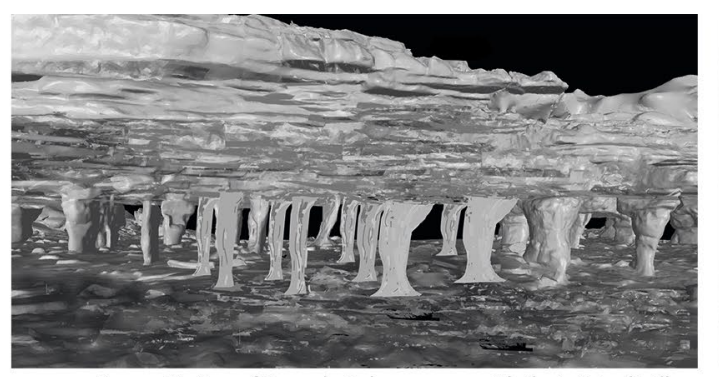

Reconstitution of Nawarla Gabarnmang, with the 'original' pillars

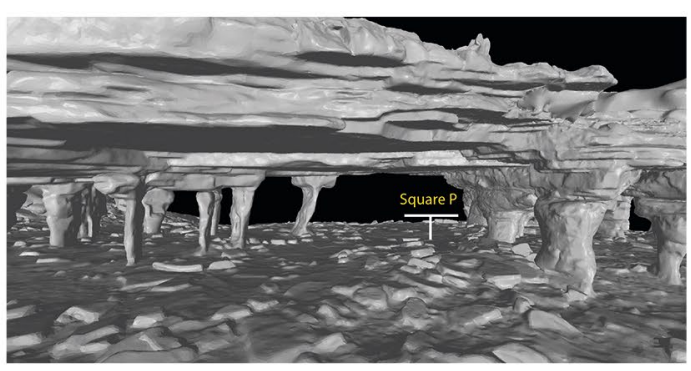

Distribution of extant pillars at Nawarla Gabarnmang

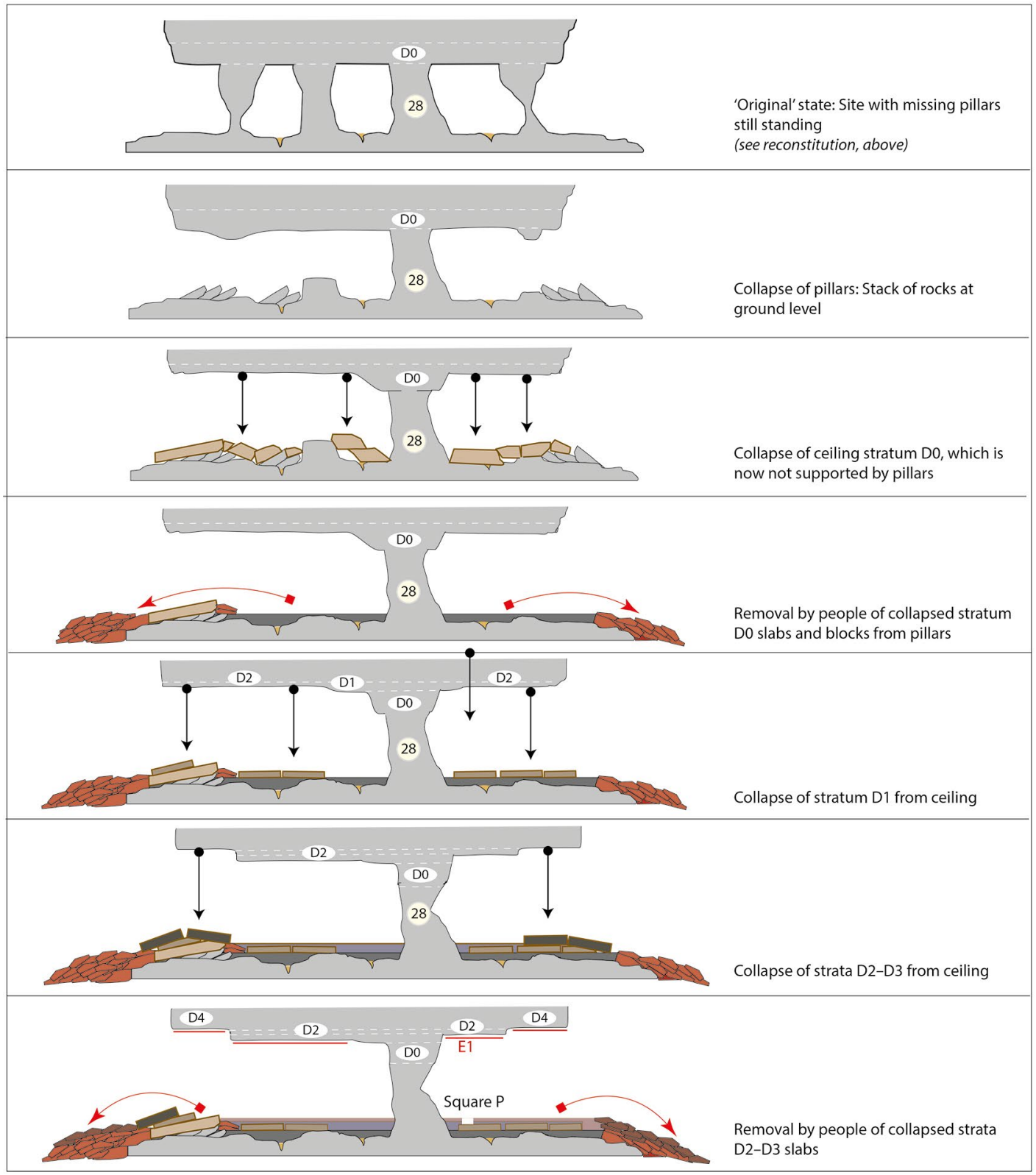

Figure 11.39 Geomorphological reconstitution of the area around Square P.

The two views from the 3-D model at the top of the figure show the 'original' (reconstituted) and current configurations of this part of the shelter, as seen from the southern entrance into the site. The illustrations below these two figures show the evolution of the site's physical matrix, as revealed by geomorphological and archaeological evidence.

Source: Illustration by Jean-Jacques Delannoy. 


\section{Cultural materials in Square P: Stone artefacts}

Having determined the site's extant configuration in the area around Square P, let us now explore its buried cultural materials. Our major aim is to understand better the sequence of paintings on Panel E1 overhead, and their cultural context.

A total of 793 definite stone artefacts weighing $304.8 \mathrm{~g}$ were recovered from Square P, nearly half from the uppermost XU1 to XU8 (Table 11.7; Figure 11.40). Stone artefacts weigh on average $0.38 \mathrm{~g}$, and the vast majority ( 89.4 per cent, $\mathrm{n}=708$ ) measure $<10 \mathrm{~mm}$ in maximum length. They appear to represent the by-products of on-site artefact manufacturing or retouching, an issue to be addressed in detail elsewhere.

Table 11.7 Square P: Distribution of excavated cultural materials.

\begin{tabular}{|c|c|c|c|c|c|}
\hline \multirow[t]{2}{*}{$X U$} & \multirow[t]{2}{*}{ SU } & \multirow{2}{*}{$\begin{array}{c}\text { Charcoal } \\
(\mathrm{g})\end{array}$} & \multicolumn{2}{|c|}{ Stone artefacts } & \multirow{2}{*}{$\begin{array}{c}\text { Bone + teeth } \\
(g)\end{array}$} \\
\hline & & & $(\#)$ & (g) & \\
\hline 1 & $1 a+1 b$ & 140.11 & 54 & 3.28 & 7.90 \\
\hline 2 & $1 a+1 b$ & 117.20 & 57 & 6.95 & 5.54 \\
\hline 3 & $1 b+2$ & 138.14 & 56 & 195.91 & 27.12 \\
\hline 4 & $1 b+2$ & 111.20 & 38 & 4.95 & 14.02 \\
\hline 5 & $1 b+2$ & 137.63 & 38 & 1.69 & 19.35 \\
\hline 6 & $1 b+2$ & 191.26 & 52 & 29.40 & 5.71 \\
\hline 7 & 2 & 219.65 & 46 & 15.45 & 9.27 \\
\hline 8 & $2+3 a$ & 186.09 & 54 & 1.90 & 12.57 \\
\hline 9 & $2+3 a$ & 90.92 & 27 & 4.61 & 0.48 \\
\hline 10 & $2+3 a$ & 111.79 & 35 & 3.59 & 2.13 \\
\hline 11 & $2+3 a$ & 130.37 & 27 & 3.42 & 3.99 \\
\hline 12 & $2+3 a$ & 110.25 & 31 & 2.12 & 1.60 \\
\hline 13 & $2+3 a$ & 84.58 & 36 & 4.87 & 1.41 \\
\hline 14 & $3 a$ & 57.43 & 34 & 1.60 & 0.03 \\
\hline 15 & $3 a$ & 65.24 & 25 & 4.99 & 0.45 \\
\hline 16 & $3 a$ & 42.41 & 29 & 1.26 & 0.04 \\
\hline 17 & $3 a$ & 55.77 & 29 & 0.79 & 0.05 \\
\hline 18 & $3 a$ & 38.59 & 17 & 1.40 & 0.02 \\
\hline 19 & $3 a+3 b$ & 36.47 & 22 & 2.13 & 0.47 \\
\hline 20 & $3 a+3 b$ & 50.92 & 43 & 4.11 & 0.06 \\
\hline 21 & $3 a+3 b$ & 29.16 & 32 & 6.98 & \\
\hline 22 & $3 a+3 b$ & 2.32 & 10 & 3.39 & 0.04 \\
\hline 23 & $3 a+3 b$ & 0.31 & 1 & 0.02 & \\
\hline Total & & 2147.81 & 793 & 304.81 & 112.25 \\
\hline
\end{tabular}

Source: Authors' data.

Stone artefacts were made from five major types of raw material (Table 11.8; Figure 11.41): quartzite overwhelmingly predominates, followed by chert, quartz, siltstone and igneous rock. Three igneous flakes exhibit ground dorsal surfaces originating from ground-edge axes. Their occurrence in XU1 and XU9 suggests that axe maintenance was done in the area of Square P. 


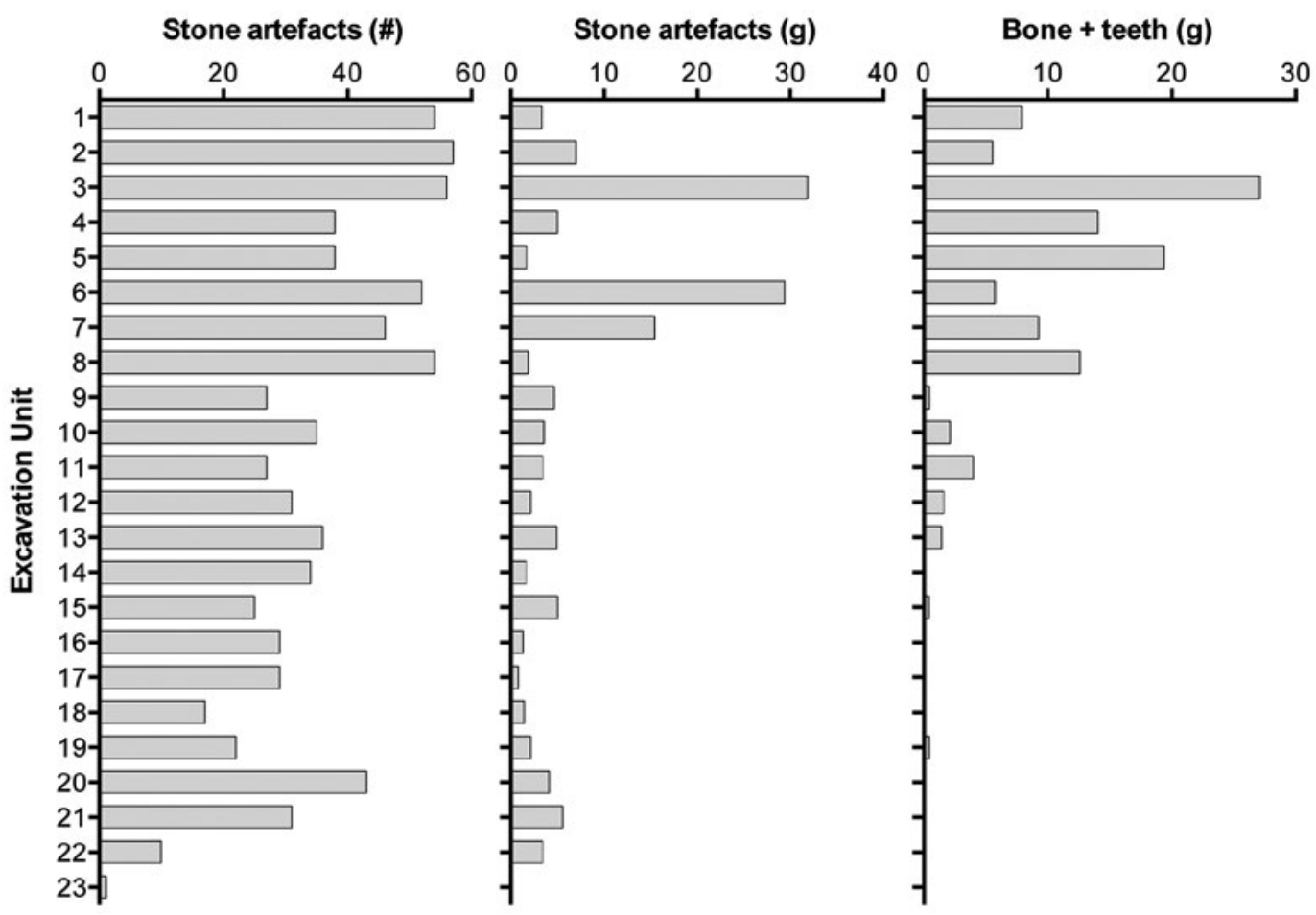

Figure 11.40 Square P: Distribution of stone artefacts and bone + teeth (excluding a particularly large stone artefact weighing $164.0 \mathrm{~g}$ from XU3, to enable better visualisation of the overall distribution down the XU profile).

Source: Illustration by Jerome Mialanes.

Table 11.8 Square P: Incidence of stone artefacts by raw material.

\begin{tabular}{|l|r|r|r|r|}
\hline Raw material & $\#$ & $\%$ & $\mathbf{9}$ & $\%$ \\
\hline Quartzite & 744 & 93.8 & 293.1 & 96.1 \\
\hline Chert & 26 & 3.3 & 3.7 & 1.2 \\
\hline Quartz & 14 & 1.8 & 4.7 & 1.6 \\
\hline Siltstone & 6 & 0.8 & 3.0 & 1.0 \\
\hline Igneous & 3 & 0.4 & 0.3 & 0.1 \\
\hline
\end{tabular}

Source: Authors' data.

A total of 10 modified artefacts other than the ground-edge axe fragments, all tools or tool fragments, were recovered from the topmost 12 XUs of Square P; all are made on quartzite (Figure 11.42). They include three unifacial, two bifacial and one unclassifiable point, as defined by Brindley and Clarkson (2015) (Figure 11.43). The unclassifiable point does not possess evidence of retouching, but its pointed distal end coupled with the presence of multiple fractures diagnostic of high velocity impact suggest that it is the tip of a projectile point (the complete left margin of the artefact has been removed by a burinating fracture along a length of $7.3 \mathrm{~mm}$; tip crushing extends onto the dorsal face; the distal end of the dorsal face has a $2.7 \mathrm{~mm}$ long fracture scar with a step termination; the end of the ventral face has a fracture scar $0.7 \mathrm{~mm}$ long with a step termination). Macro-fracture types diagnostic of high-velocity impacts, sometimes in the form of negative and sometimes as positive fracture lips 1 to $2 \mathrm{~mm}$ long with step terminations (Brindley and Clarkson 2015; Geneste and Plisson 1990, 1993; Normand et al. 2008; O'Farrell 2004), are also present on two of the five definite excavated points and suggest that they were also used as projectile points. A fuller analysis of the Square P stone artefacts in relation to those of all the excavated squares from Nawarla Gabarnmang will be presented elsewhere. 

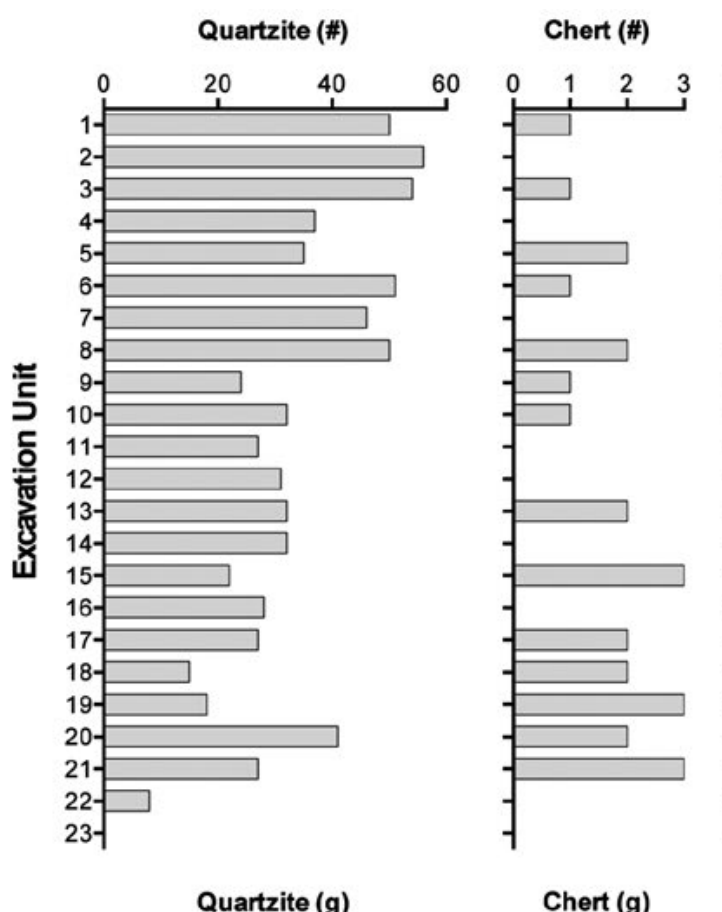

Quartz (\#)

Siltstone (\#)

Igneous (\#)
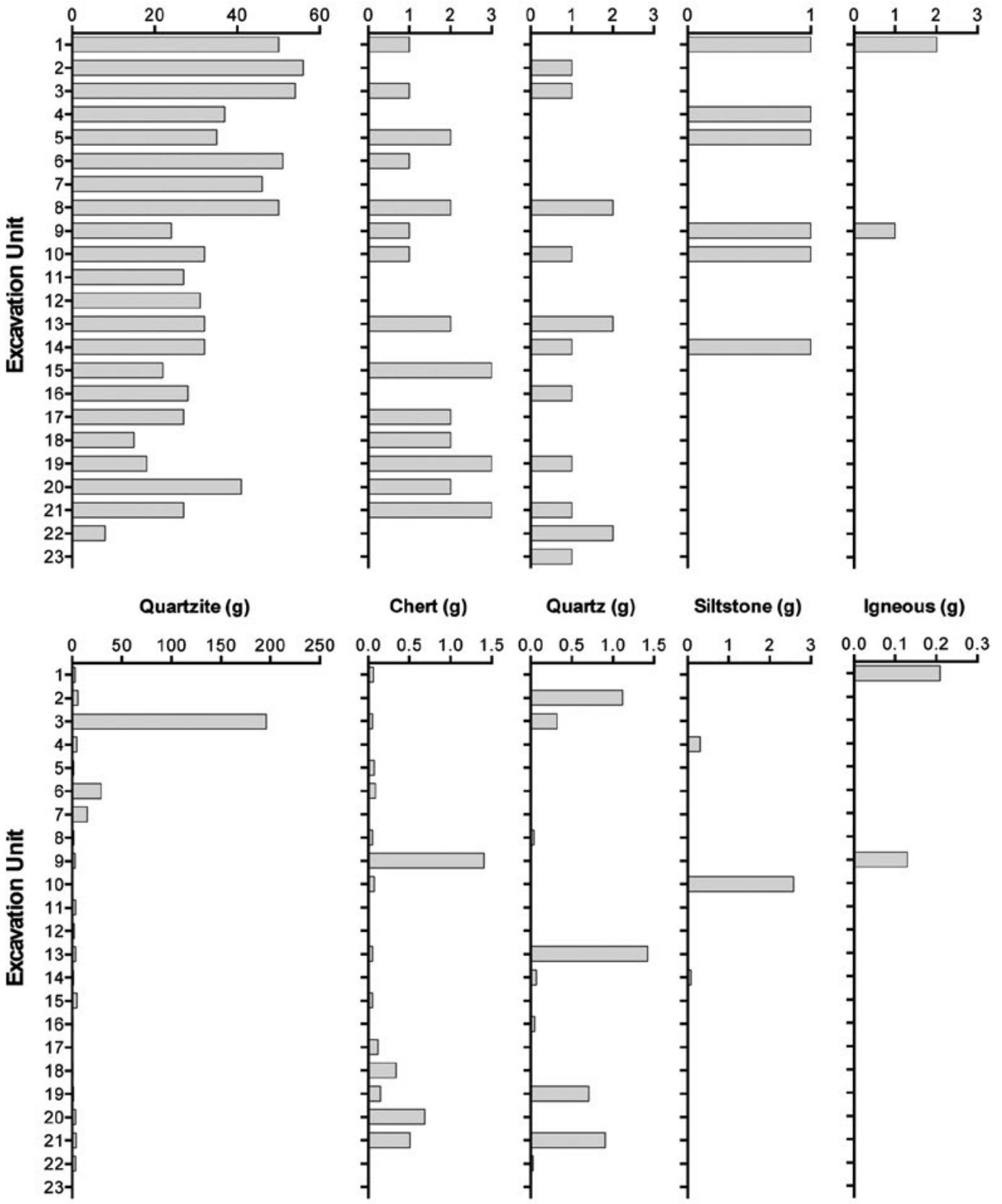

Figure 11.41 Square P: Raw material distribution by number and by weight.

Source: Illustration by Jerome Mialanes. 


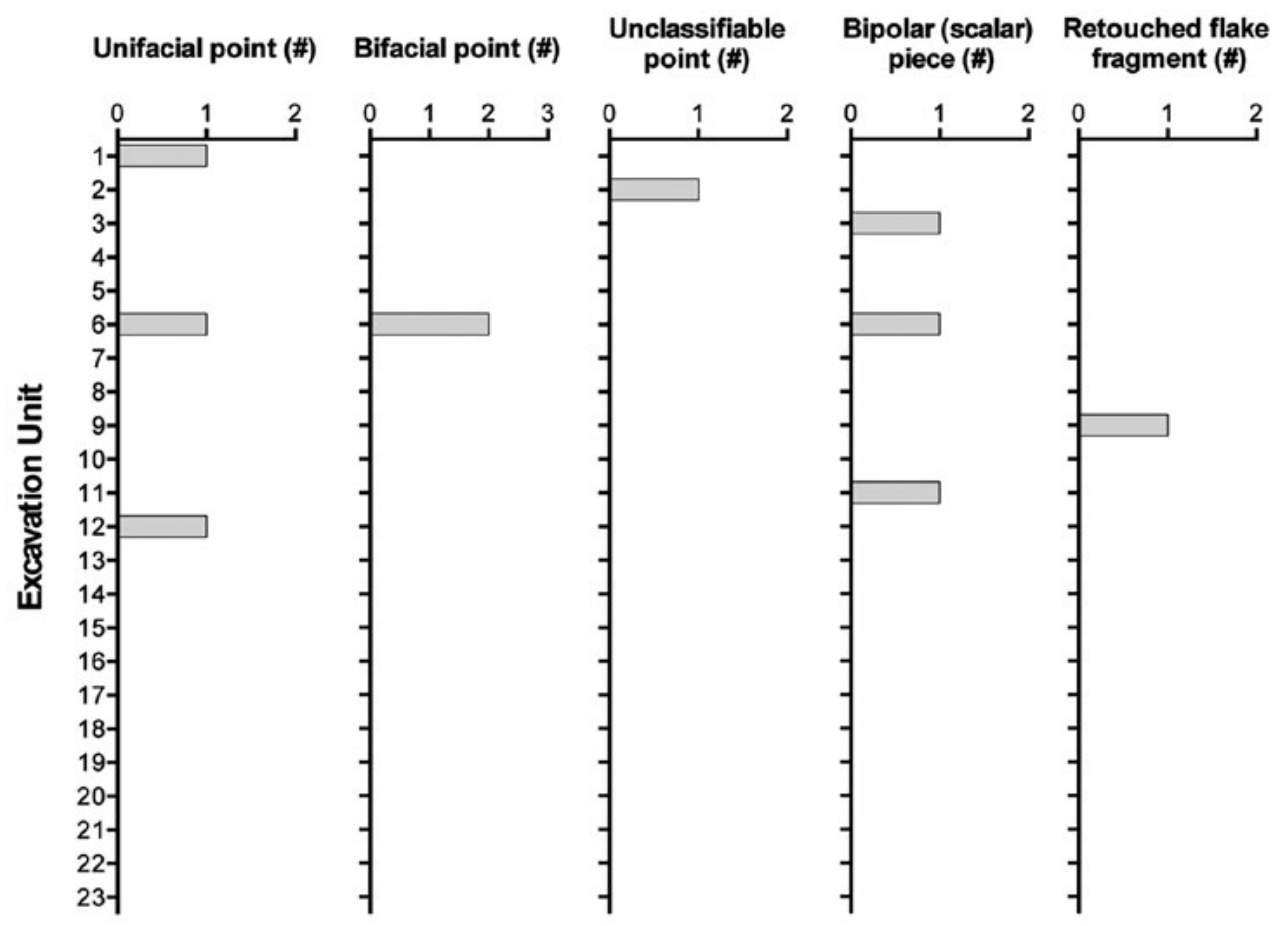

Figure 11.42 Square P: Distribution of stone artefact types by number. Source: Illustration by Jerome Mialanes.

A
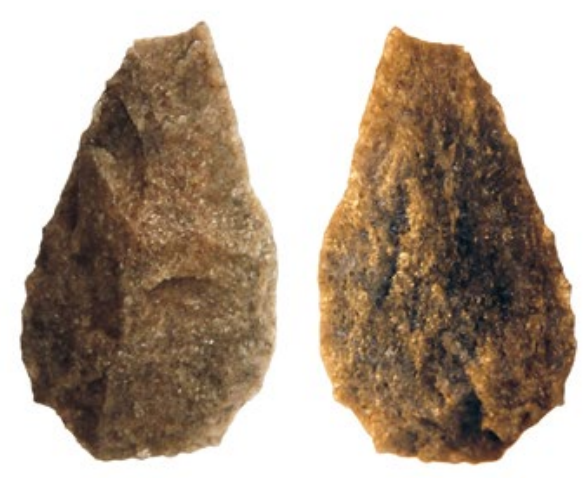

B

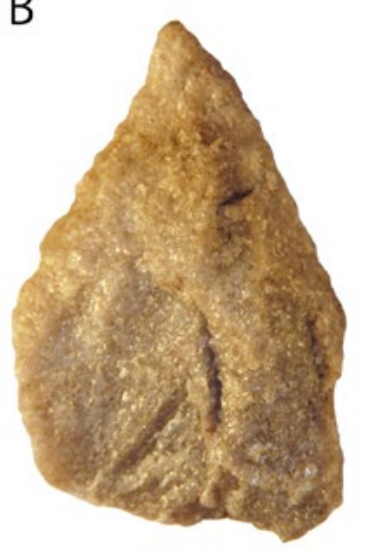

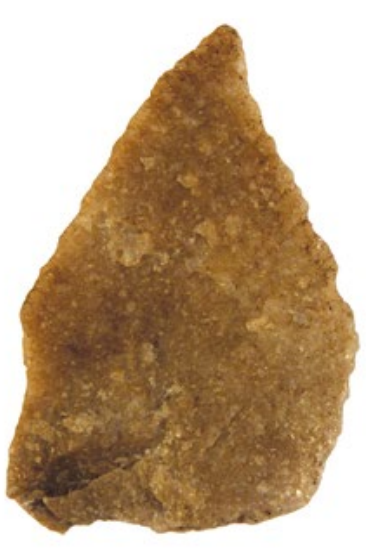

E

$\mathrm{F}$

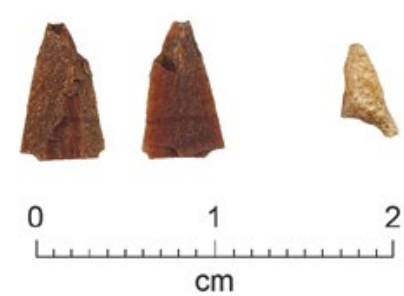

Figure 11.43 Square P: Formal stone tool types.

A: Bifacial point XU6(3); B: Bifacial point XU6(2); C: Unifacial point XU12(1); D: Unifacial point XU1(2); E: Unclassifiable point XU2(1); F: Unifacial point XU6(1).

Source: Photographs by Catherine Cretin and Mila Folgado. 


\section{Cultural materials in Square P: Faunal remains}

The faunal assemblage from Square P consists of a moderate quantity of fragmentary bones and teeth (Table 11.7), some mammalian faecal material and a tiny quantity of freshwater bivalve shell.

Well-preserved macropodid (wallaby or kangaroo) faecal pellets were recovered from XU2 and XU3. Other faecal material from XU1 and XU3 adheres to unburnt bone fragments and contains abundant mammal hair. These are interpreted as fragments of dog faeces. One example from XU1 contains part of a caudal vertebra of a macropodoid, while another also from XU1 contains a complete thoracic vertebra of an agamid (dragon lizard). Another example from XU3 contains a small sliver of unburnt cortical bone, probably from a medium-sized mammal.

Shell fragments, all from XU4-XU5, have a total weight of $0.03 \mathrm{~g}$. The fragments are extremely fragile and breaking up into laminar sheets.

The highest concentrations of bones and teeth were recovered from XU1-XU8, with a reduced quantity in XU9-XU13, and only occasional small fragments in XU14-XU22 (Table 11.7; Figure 11.40). The bulk of the assemblage thus dates from Radiocarbon Phase 4, i.e. since c. 180 cal BP. The oldest recovered remains from XU22 might be as old as the end of Radiocarbon Phase 2 (c. 990-1090 cal BP), but are more likely associated with the start of Radiocarbon Phase $3(500-570 \mathrm{cal} \mathrm{BP})$.

The most recent bones and teeth from XU1-XU3 are exceptionally and uniformly well-preserved, and show a relatively low prevalence of burning (Figure 11.44). Most remains from XU4-XU6 are similarly well-preserved; however, a few unburnt fragments show extensive corrosion along root channels and/or areas of surface damage interpreted as consumption by termites. Damage of both kinds becomes increasingly more prevalent from XU7 to XU15. Below XU15, virtually all of the recovered bone is heavily burnt to the point of being fully calcined (Figure 11.44); these fragments are visibly corroded and, with the exception of a few fragments of tooth crown, are taxonomically uninformative. The changes in the physical condition of the faunal remains through the deposit point to an aggressive preservation environment in which bones and even teeth are degraded to the point of non-recovery even by fine-scale excavation methods within a period of centuries. The principal degradation processes in this environment are likely to be microbial attack, much of it associated with rootlet contact and penetration, the acidity of sediments and direct consumption by termites (Hedges 2002; Jans et al. 2004). Fungal attack may also be prevalent, but this tends to work on the internal structure of bone and be less visible macroscopically.

The total sample contained 48 individual fragments for which it was possible to make a taxonomic determination to family level or below (Table 11.9). This includes a minimum of seven mammal species, including a species of quoll (Dasyurus sp.), an unidentified bandicoot (Peramelidae or Thyaclomyidae), the northern brushtail possum (Trichosurus vulpecula arnhemensis), a small rodent (the grassland melomys - Melomys burtoni) and at least three species of macropodid distinguishable by size. Small macropodid remains are probably from a rock wallaby (Peradorcas concinna) and/or a species of nail-tail wallaby (Onychogalea sp.). A medium-sized taxon is almost certainly the agile wallaby (Macropus agilis). Larger remains might be from the black wallaroo (M. bernardus), the antilopine wallaroo (M. antilopinus) and/or the euro (M. robustus). None are identified with certainty as diagnostic elements are absent. The agamid lizard remains include one dentary from XU6 positively determined as a frilled lizard (Chlamydosaurus kingii). A small crocodile, probably less than $1 \mathrm{~m}$ in total length, is represented by a small fragment of maxilla in $\mathrm{XU} 2$. A single calcined teleost fish vertebra comes from XU10. 


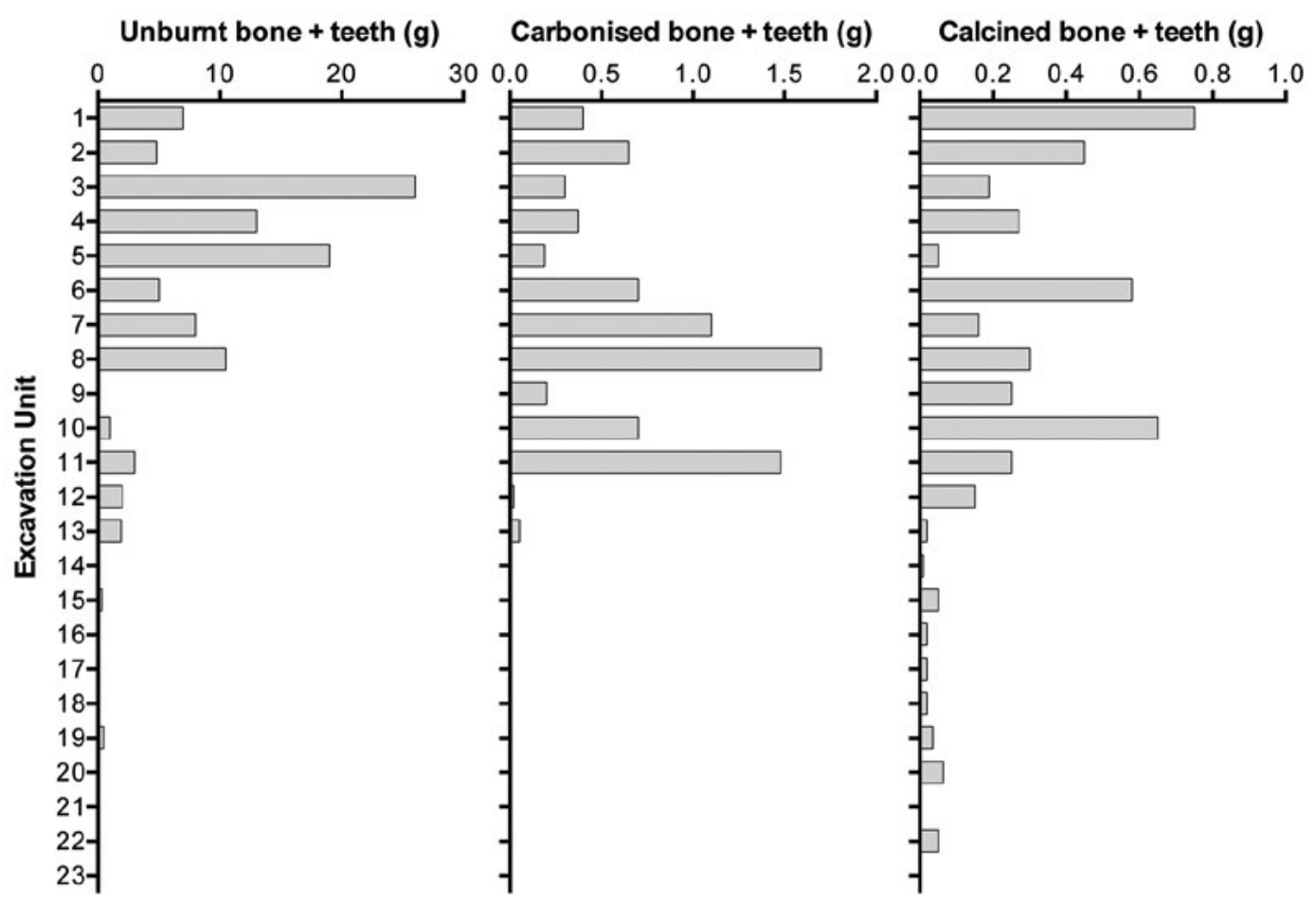

Figure 11.44 Square P: Burning composition (by weight) of recovered bones and teeth through the stratigraphic profile.

Carbonised = burnt but with retained carbon; calcined = all carbon has been pyrolised .

Source: Illustration by Jerome Mialanes.

Medium-sized macropodid (M. agilis) remains make up nearly 50 per cent of the total sample of identified fragments, with small macropodids and the brushtail possum accounting for 13 per cent and 17 per cent, respectively. The agile wallaby, which inhabits grassland/savannah habitats, appears to have been favoured during Radiocarbon Phase 4 times from c. $180 \mathrm{cal}$ BP. Brushtail possums are found in most habitats, including savannah and rocky gorges and breakaways.

Noteworthy in the assemblage from Square P is the high incidence of human modifications to bone fragments: the application of red ochre to bone surfaces; the occurrence of clusters of fine scratches and shaving marks (presumably made with stone artefacts); and modification by grinding. Examples of both ochre application and scratches/shaving marks occur in most XUs from XU1 to XU5; older examples are perhaps not recognised due to root and termite damage to the bone surfaces. Only one example of grinding was observed, on a small, unburnt cortical bone fragment from XU2. Bone from other parts of the site displays the same kinds of modifications. A detailed account of the entire assemblage is in preparation. 
11. Dating painted Panel E1 at Nawarla Gabarnmang, central-western Arnhem Land plateau

\begin{tabular}{|c|c|c|c|c|c|c|c|c|c|c|c|c|c|c|c|c|c|c|c|}
\hline 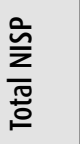 & $r$ & 0 & $\operatorname{Ln}$ & in & $m$ & $\operatorname{Ln} \mid r$ & $\sim \nabla$ & $m$ & $m c$ & $\circ \mathrm{m}$ & 0 & 0 & $0-$ & -- & 0 & 0.0 & 00 & 0 & $\stackrel{\infty}{q}$ \\
\hline 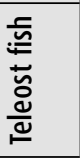 & & & & & & & & & - & & & & & & & & & & - \\
\hline 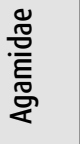 & - & & & & & - & & & & - & & & & & & & & & $m$ \\
\hline 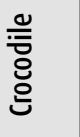 & & - & & & & & & & & & & & & & & & & & $\tau$ \\
\hline 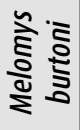 & & - & & & & & & & & & & & & & & & & & - \\
\hline
\end{tabular}

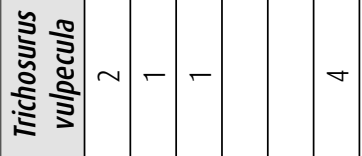

$\infty$

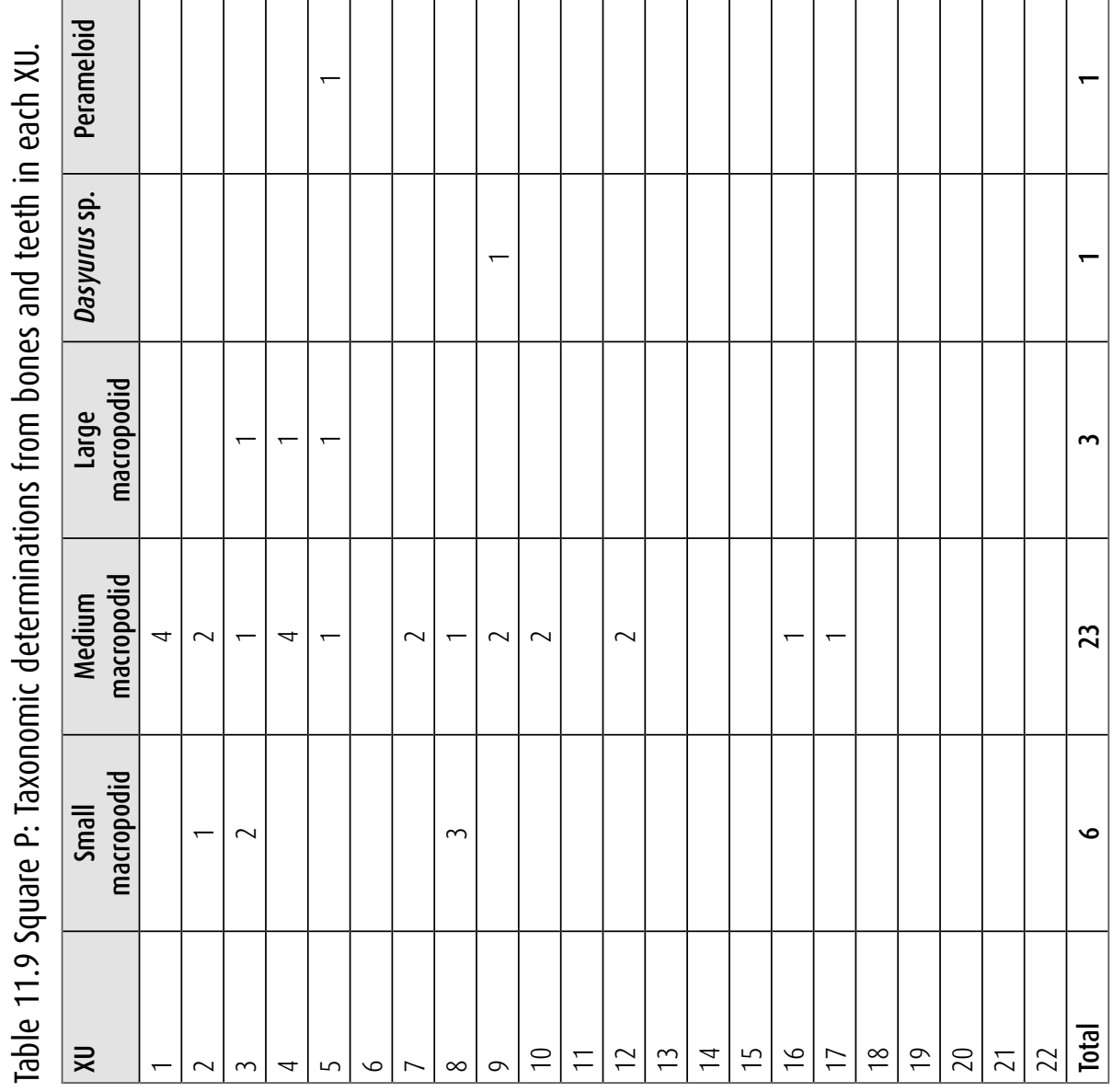

$\stackrel{\tilde{\hat{n}}}{\underline{\Sigma}}$

$\approx$ 峞

离

훙

हे

崩 商

旁言 


\section{Cultural materials in Square P: Excavated pigments}

Numerous small pieces of pigment were excavated from Square P. They occur as three different types:

1. Paint drops that fell from the ceiling and/or brushes as paintings were made immediately above the square. These fell as wet drops of paint, coagulated on the sandy surface when it was at the depth of XU18, impregnating the ashy loamy sand sometimes down to the level of XU19, and dried in situ. These now-dried paint drops were sampled during excavation as slightly accreted concentrations of pigment mixed with incorporated ashy loamy sand.

2. Tiny solid pigment pieces $(2-3 \mathrm{~mm}$ long, the $2 \mathrm{~mm}$ minimum size representing the mesh size of the sieves used in the excavation) to small (up to $1.7 \mathrm{~cm}$ long) fragments of pigment.

3. Small painted rocks (from $4 \mathrm{~mm}$ to $6 \mathrm{~mm}$ long), each consisting of a thin quartzite spall covered by a thin reddish layer of pigment on a single surface.

Both paint drops and solid pigment pieces were investigated by macroscopic observation and by microanalytical techniques (e.g. scanning electron microscope coupled with energy-dispersive $\mathrm{X}$-Ray spectroscopy [SEM-EDX]; X-ray fluorescence [XRF]) coupled with structural techniques (e.g. Raman microspectroscopy; X-ray diffraction [XRD]). A sample of pieces was analysed with a LEO Stereoscan 440 SEM with a Brucker SDD X-FLASH 4030 EDX, in high-vacuum mode at $20 \mathrm{kV}$. The elemental composition of the excavated pieces was analysed with a Bruker S1 Titan 500 portable X-Ray Fluorescence (pXRF) analyser equipped with a rhodium tube, a SDD detector and a $5 \mathrm{~mm}$ collimator (acquisition parameters: for $10 \mathrm{keV}, 30 \mathrm{~s}$ live-time count and for $30 \mathrm{keV}, 30 \mathrm{~s}$ live-time count). XRF analysis revealed major chemical components. XRD and Raman microspectroscopy were used to determine chemical structures. XRD patterns were measured by a diffractometer with an INEL XRG-3000 generator, an INEL CPS 120 curved detector (within an angular range of $0^{\circ}$ to $120^{\circ}$, in $2 \theta$ ), equipped with an anticathode in Cobalt $\left(K_{\mathrm{Co}}=1.78897 \AA\right)$ and a monochromator plan in Silicon. The Raman spectra were obtained with a green laser at $514 \mathrm{~nm}$ with a Jobin-Yvon-Horiba T640000 equipped with a microscope (at $\times 10$, $\times 50$ and $\times 100$ magnification).

\section{Paint drops}

As each paint drop sample contained a combination of fine pigment powder and ashy loamy sand, the powder was hand-separated under a binocular microscope. The powder samples are unambiguously dried paint drops because of 1) their physical characteristics as slightly accreted powder patches embedded in the ashy loamy sand; 2) their sudden appearance on an ancient ground surface beginning at c. $26 \mathrm{~cm}$ depth in XU18; 3) the sub-rounded plan shape of the individual accreted sample patches; and 4) the rapidly decreasing volumes of the individual patches with depth.

Six phials of light-coloured (Munsell: 7.5YR 4/3 brown [4 samples] to 7.5YR 6/4 light brown [2 samples]) pigmented sediment were analysed from XU18, representing paint drops excavated as dry pigment powder accreted around the ashy loamy sand. These pigment-rich sediments contrast with the homogeneous and unpigmented, very dark brown (7.5YR 3/1) to dark-brown (7.5YR 3/2) ashy loamy sand that surrounds them in SU3A (these Munsell colours were measured on sediments from each of the surrounding XU16, XU17 and XU20, where dried paint drops are absent).

SEM-EDX analysis indicates that the ashy loamy sand from XU18 is largely made up of Si, Al, $\mathrm{Fe}, \mathrm{P}, \mathrm{Ca}$ and $\mathrm{Ti}$, with $\mathrm{K}, \mathrm{Na}$ and $\mathrm{Mg}$ also present as minor elements. Five of the six dried paint samples show a composition similar to the ashy loamy sand; the sixth (XU18 in situ sample \#4), one of the two light-brown samples, was different. It contained a higher incidence of $\mathrm{Al}$ than the other samples, and a crystalline morphology consisting of plates (e.g. Figure 11.45). 


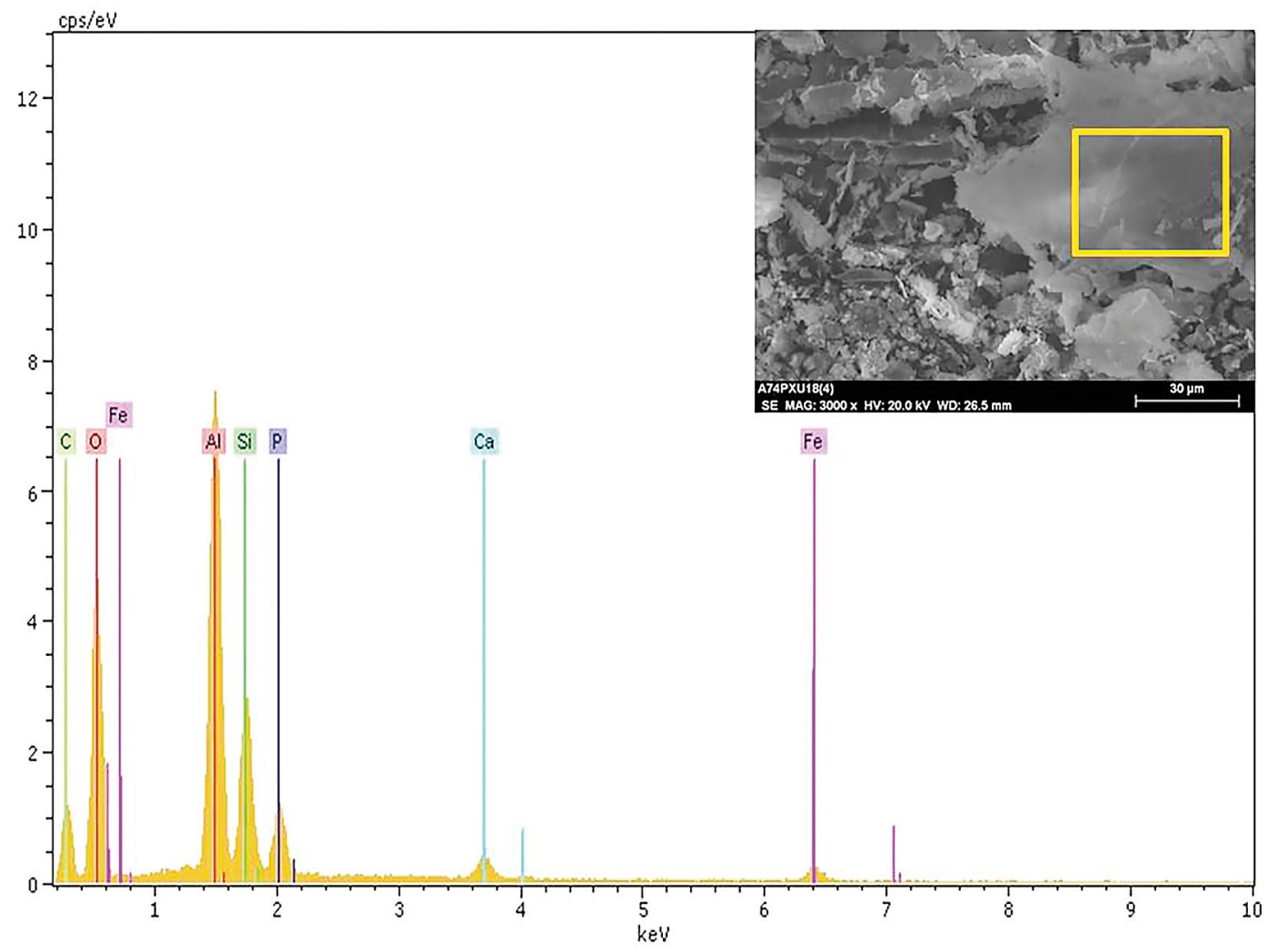

Figure 11.45 EDX spectrum of light-coloured pigment powder from XU18 in situ sample \#4.

Source: Illustration by Emilie Chalmin.

The elemental composition of that different light-brown pigment powder is distinctive from both the ashy loamy sand in which it is embedded, and from the other dried paint drop samples: it exhibits high $\mathrm{Ca}$ and $\mathrm{P}$ values (2 per cent as $\mathrm{CaO}$ and 7 per cent as $\mathrm{P}_{2} \mathrm{O}_{5}$ ), with minor $\mathrm{Si}, \mathrm{Al}$, $\mathrm{Na}, \mathrm{Mg}, \mathrm{S}, \mathrm{Cl}$ and $\mathrm{K}$, and a fluffy pellet morphology.

For the paint drop samples, the only structure identified through XRD is quartz. Nevertheless, it is not possible to determine if the quartz really comes from the paint or if its presence is due to contamination from the surrounding sediment. The structure of the light-coloured powder was more difficult to identify due to its weak crystallinity.

The two light-brown patches of pigmented ashy loamy sand sampled from XU18 mainly consist of alumino-silicates. One of these patches also contains apatite $(\mathrm{Ca} 5(\mathrm{PO} 4) 3(\mathrm{OH}, \mathrm{F}, \mathrm{Cl})$ ). The presence of apatite could suggest that the pigment was mixed with crushed bone in the making of a paint paste. However, apatite is rarely found in the dried paint drops of Square P, whereas it should be represented in numerous samples if the pigment had been systematically mixed with crushed bone. We thus conclude that the apatite found amidst the dried paint drop sample from XU18 more likely comes from a tiny fragment of heavily degraded bone that happened to lie in the ground at this level and that was included in the phial during sampling. A tiny, light-coloured fragment of heavily degraded bone was also separately sampled from XU20, and subsequently identified in the laboratory as apatite, confirming the presence of degraded bone in these sediments (see also the faunal remains section, above). 


\section{Solid pigment pieces}

One hundred and ninety-seven solid pieces of pigment (red, orange, brown, yellow, yellowand-red, white) were excavated from Square P. They are all tiny to very small. None have the morphology of fallen flakes of paint; rather, they all appear to be by-products of the on-site processing of originally larger lumps of pigment.
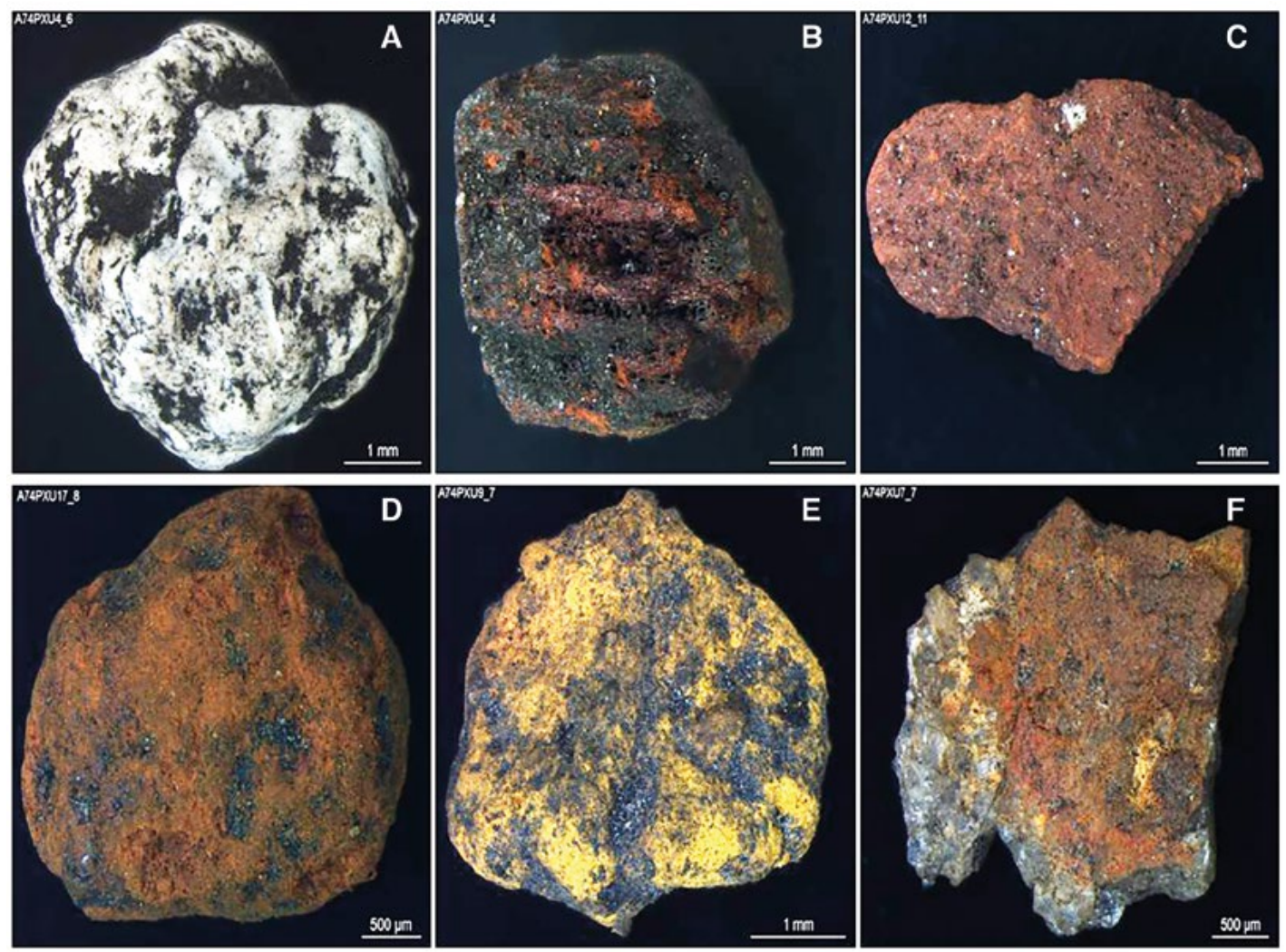

Figure 11.46 Square P: Examples of excavated solid coloured pieces showing the range of morphological characteristics, Nawarla Gabarnmang.

Note: The surface traces of black on individual pieces are ashy sediments from the archaeological layers from which they were excavated.

Source: Photographs by Géraldine Castets.

All pieces, regardless of their colouration, have a dull, earthy lustre. The three solid white pieces from XU4 and XU15 have a compact powder texture that produces a white streak (Figure 11.46A). In contrast, 11 pieces, some red, some orange, have strongly porous textures and a high iron content (Figure 11.46B). The great majority of pieces -183 tiny to small red, orange, yellow, and yellow-and-red lumps - contain iron oxides that would produce reddish or yellowish streaks when rubbed (Figure 11.46C, 11.46D and 11.46E). Some have a compact powdery texture, whereas others have a few cracks on their surfaces. Four of the 60 red pieces reveal a metallic lustre characteristic of a 'pure' iron mineral.

All the solid pieces other than the white ones contain iron $(\mathrm{Fe})$ in varied proportions, the iron causing their colouration. According to the results of the elemental analyses (Figure 11.47), iron is not associated with any other major chemical element ( $\mathrm{Si}, \mathrm{Al}, \mathrm{Ca}$ and $\mathrm{P}$ ). It reveals that the iron apparently only occurs in the form of oxide. It is difficult to classify the samples into a set of distinct chemical groups, as there is considerable overlap in the chemistries of individual samples. 


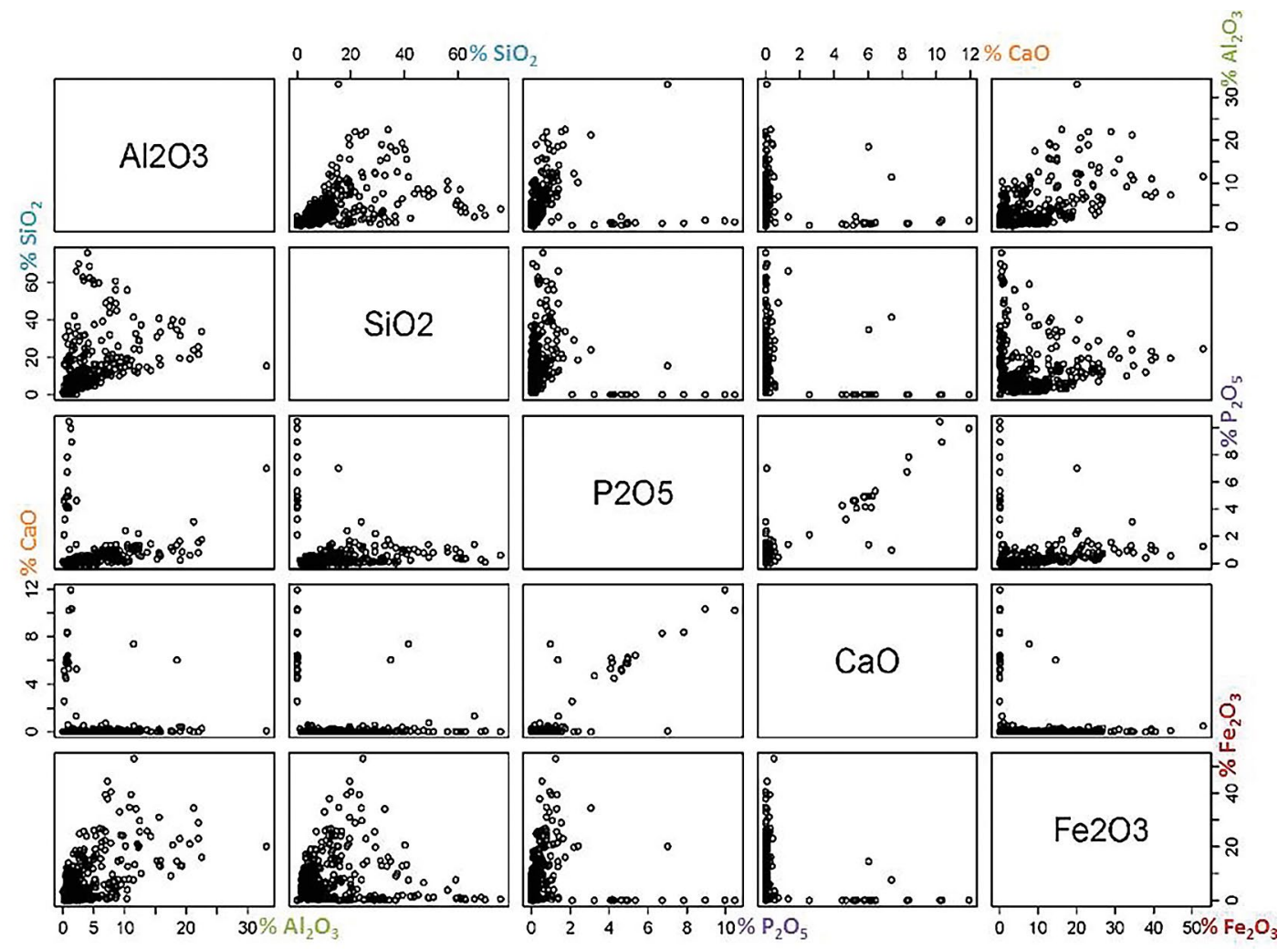

Figure 11.47 2-plot diagram representing the major element contents of solid pieces (in \% of oxide mass). Each circle represents a solid piece. The contribution of each oxide $\left(\mathrm{Al}_{2} \mathrm{O}_{3^{\prime}} \mathrm{SiO}_{2^{\prime}} \mathrm{P}_{2} \mathrm{O}_{5^{\prime}} \mathrm{CaO}, \mathrm{Fe}_{2} \mathrm{O}_{3}\right)$ is indicated for each sample by reading the per cent values along the horizontal and vertical axes.

Source: Illustration by Emilie Chalmin.

Alumino-silicates (presence of $\mathrm{Si}$ and $\mathrm{Al}$ ) are only detected by XRF (which identifies the elements) and not by XRD (which reveals the structure of compounds). Two different Si:Al ratios are revealed by XRF quantitative analysis - 1:1 and 2:1 - indicating clays such as kaolinite and muscovite respectively. Weakly crystallised clay minerals may also be present.

Some tiny red pieces $<2 \mathrm{~mm}$ long excavated from XU14 were ground into powder to allow further analyses. A maghemite $\left(\gamma-\mathrm{Fe}_{2} \mathrm{O}_{3}\right) /$ magnetite $\left(\mathrm{Fe}_{3} \mathrm{O}_{4}\right)$ structure has been identified by XRD for one of these powdered pieces (Figure 11.48), whereas goethite $(\mathrm{FeOOH})$ has been detected on a solid yellow piece that also came from XU14. However, in these samples, the iron oxides are always mixed with abundant quartz grains from the deposit that makes the identification of the minor compounds difficult.

Raman microspectroscopy clearly identifies the presence of haematite $\left(\mathrm{Fe}_{2} \mathrm{O}_{3}\right)$ on several red pieces from XU14. A number of white particles, each a few micrometres long, embedded in the red matrix of sample A74PXU14R from XU14, were identified as rutile $\left(\mathrm{TiO}_{2}\right)$ (Figure 11.49).

The structural characterisation of several solid pieces of pigment confirms the presence of multiple compounds within individual pieces. Some of the iron oxides are well crystallised, others less so. The poorly crystallised oxides and clays are not always clearly identified. 


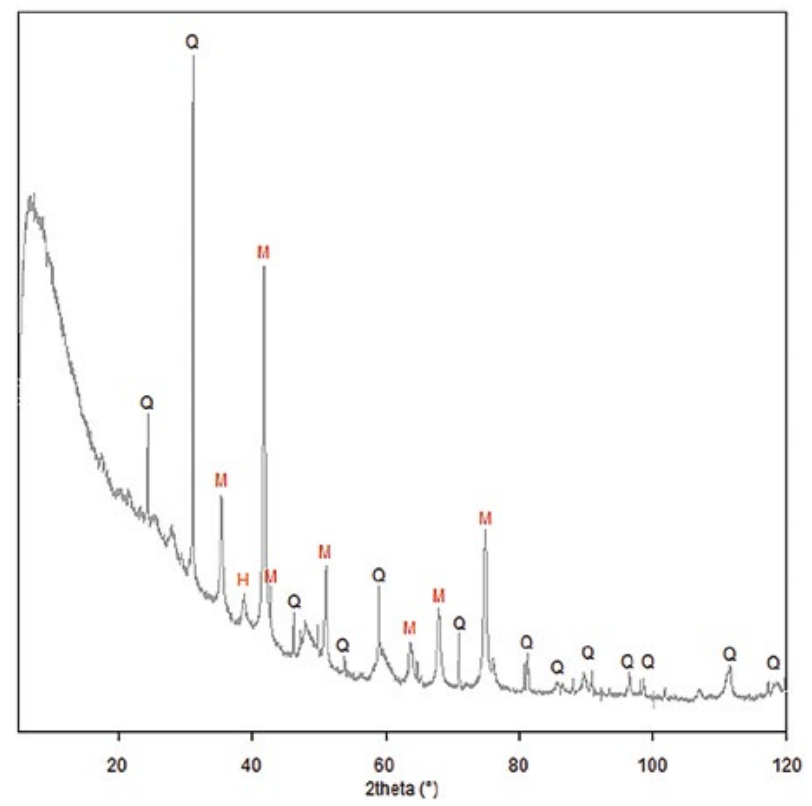

Figure 11.48 XRD pattern of a sample of red pigment from XU14 (laboratory sample code: A74PXU14_powder).

Q: Quartz; M: Maghemite/magnetite; H: Haematite.

Source: Illustration by Emilie Chalmin.

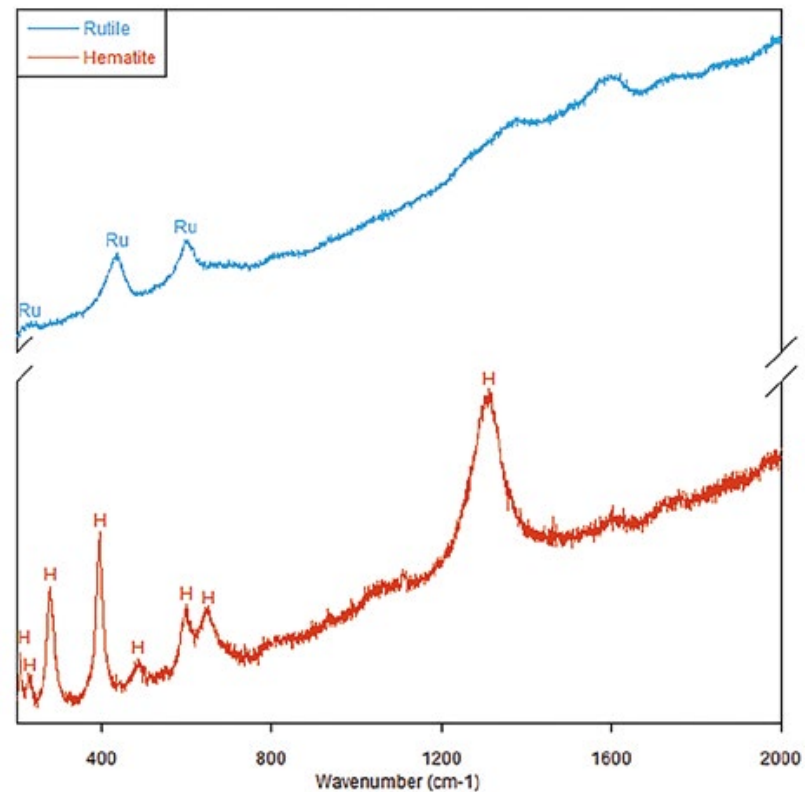

Figure 11.49 Raman spectra of a red piece with tiny white specks from XU14 (laboratory code: A74PXU14R).

H: Haematite; Ru: Rutile.

Source: Illustration by Emilie Chalmin. 


\section{Painted rocks}

Nine samples are small fragments of rock with red or orange pigment adhering on one surface only (Figure 11.46F). In all cases, the rock matrix is quartzitic sandstone. The continuous coloured layer covering the rock is largely iron oxide. The composition of these pigment layers is compatible with the similarly coloured solid pieces of pigment, but it could also be due to weathering of the rock surface prior to its falling, presumably from the ceiling. The pigmented surface could not have attained its colouring after burial as 1) only one face is coloured in each case; and 2) alteration of the rock would have required exposure to air if it was a natural byproduct of surface weathering.

\section{Discussion of the excavated pigments}

The excavated dried paint drops were overwhelmingly found in XU18 during excavation, with a minor presence in XU19. These paint drops fell onto an old, ashy loamy sand surface as paintings were made overhead. That much of the surface area was covered by now-dried paint drops in XU18 suggests a major painting event between 390-510 cal BP (Radiocarbon Phase 3), the time when the level of XU18 was the floor in this part of the site. The light colour of the paint drops indicates that this painting event made light-coloured, off-white paintings rather than yellow or red paintings. We identify this painting event with Panel E1 art Phases IV, V (see Figures 11.12-11.14) or Phase VI (see Figure 11.15), the three phases when numerous paintings in light-coloured pigments were made immediately overhead.

Solid pieces of pigment are found pretty much continuously through the stratigraphic sequence (Figure 11.50). The quantity of such solid pieces varies with depth, although no clear patterning is evident in the chrono-stratigraphic distribution of particular colours. The solid pieces of pigment may relate to rock art or to other kinds of painting activity, such as the coating of bone with red ochre that is evident in Square P and elsewhere at Nawarla Gabarnmang. We cannot determine whether or not these solid pieces of pigment relate to the Panel E1 art, although they do suggest repeated painting activity at Nawarla Gabarnmang given their high frequencies throughout the Square P sediment sequence.

Small, probably exfoliated pieces of painted rock were recovered from XU3 (4 pieces), XU6 (1 piece), XU7 (2 pieces) and XU15 (2 pieces). These are too small to indicate which items of rock art they came from, and only suggest minimum ages of 390-510 cal BP (the age of the ground levels onto which the small painted rock fragments fell) for the earliest artistic activities in this part of the site.

Chemical analysis has confirmed that the yellow solid pieces consist of goethite. The orange and red pieces owe their colours to the presence of iron oxides in the form of haematite and/or maghemite/magnetite. Maghemite can form naturally by weathering or by low-temperature oxidation of spinels containing ferrous iron, commonly magnetite. Its presence can also reveal heating in direct contact with organic materials (at moderate temperatures of $<350^{\circ} \mathrm{C}$, reachable in small open fires). The presence of red and orange pieces enriched in maghemite at Nawarla Gabarnmang Square P may indicate that these pieces of ochre have been in contact with wood and/or animal fats in a fireplace (see Cornell and Schwertmann 2003; Grogan et al. 2003; Salomon et al. 2015; Schwertmann and Cornell 2000). This evidence of probable heating of ochres at Nawarla Gabarnmang may indicate purposeful heat alteration of lumps of ochre for the production of paint pastes, or accidental heating in the presence of campfires. 


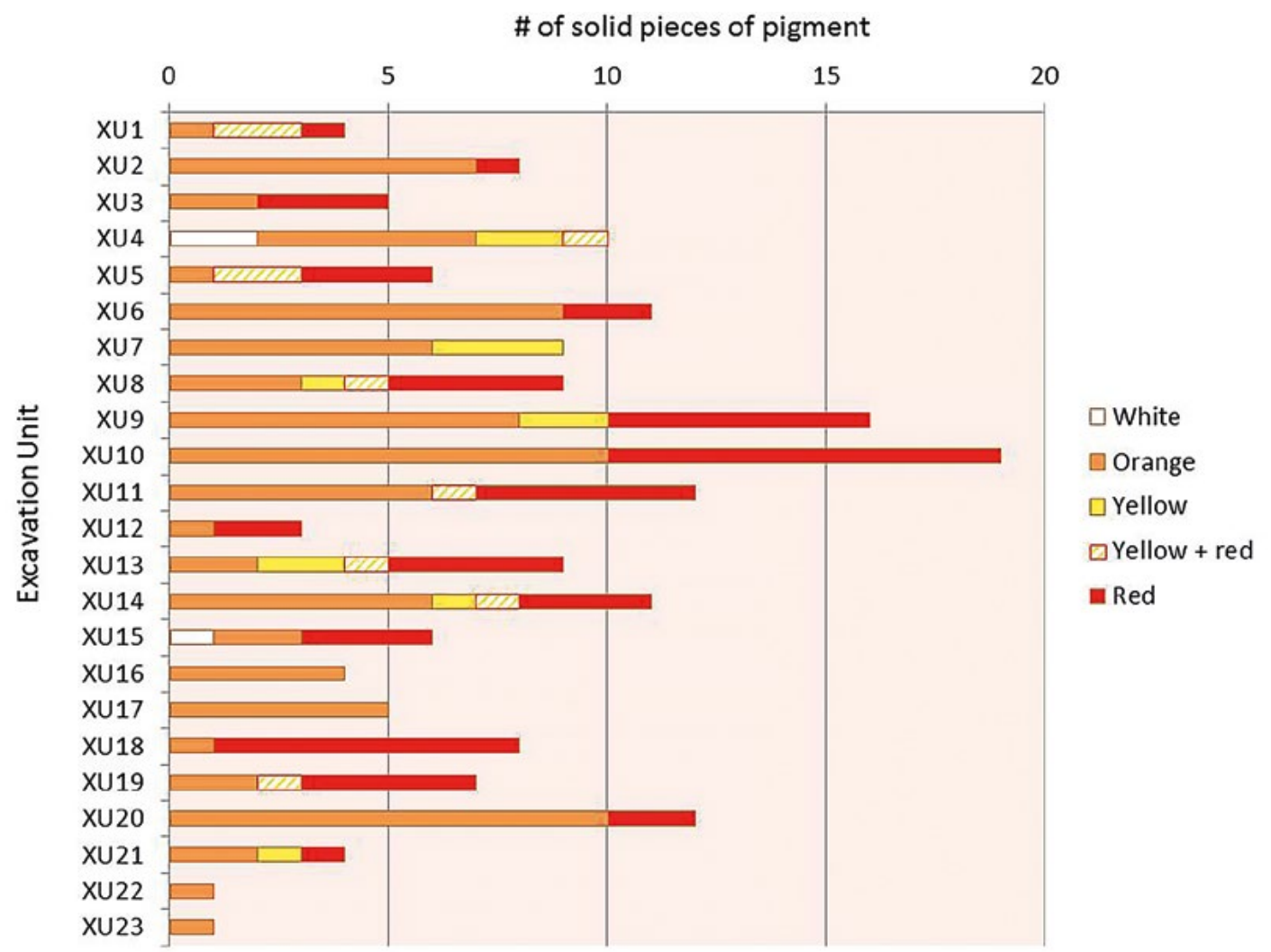

Figure 11.50 Square P: Number of solid pieces of pigment by colour, by XU.

Source: Illustration by Emilie Chalmin.

\section{Conclusion}

Our varied studies allow a series of clear conclusions about the painted rock art on Panel E1 at Narwala Gabarnmang:

1. The large, flat ceiling area encompassing art Panel E1 was caused by roof fall following the removal of supporting pillars sometime before c. $4240 \mathrm{cal} \mathrm{BP}$, and possibly in late Pleistocene times.

2. The rock base of Square $P$ is not bedrock, but a large slab of roof fall (stratum D1) that must date to c. $4240 \mathrm{cal} \mathrm{BP}$ or older.

3. As the extant art on the ceiling surface at Panel E1 can only have been produced after the collapse of stratum D1 from the ceiling, it must be more recent than c. 18,594 cal BP, and possibly is more recent than c. $4240 \mathrm{cal} \mathrm{BP}$.

4. The evidence from stratified ochre in Square $P$, paint drops and small painted rocks indicates a major painting event during Radiocarbon Phase 3; this suggests that the bulk of the art in Panel E1 was produced 390-510 cal BP.

5. The light colour of the paint drops indicates white or off-white or light tan coloured pigments, rather than yellows or reds; so it is most likely to be associated with the most recent period of rock art production (artistic Phases IV, V or VI).

With an occupation history approaching 50,000 years and rock art dating to at least 27,000 years ago (David et al. completed manuscript, 2013, 2014), Nawarla Gabarnmang has a welldocumented chronology of long occupation and art production. The multi-faceted analysis of 
Panel E1 and excavation of Square P directly below it have allowed a further chronological refinement relating to the production of art at the site, clearly indicating that, although the paintings on Panel E1 are relatively recent, art production took place repeatedly over long periods of time at Nawarla Gabarnmang.

\section{Acknowledgements}

We thank Margaret Katherine and family, Wes Miller, Ray Whear, the late Peter Bolgay and the Jawoyn Association Aboriginal Corporation for asking us to undertake archaeological research at Nawarla Gabarnmang. Thanks to Elisa Boche, Magen O'Farrell, Daniel James (Monash University), Jacqueline Matthews (University of Western Australia) and Chris Urwin (Monash University) for helping with the excavations. Thanks to Valérie Reita and Denis Testemale (Institut Néel) for undertaking the Raman micro-spectroscopy; Pauline Martinetto for access to the X-Ray diffractometer (Institut Néel); and the University Grenoble Alpes for financial support to undertake the chemical analysis (NAÏADE, PEPS interdisciplinary project 2013). We thank the Australian Research Council for Linkage grant LP1 10200927 and Discovery grants, QEII and Discovery Outstanding Research Award (DORA) Fellowships DP0877782 and DP130102514. Thanks to Kara Rasmanis for drafting parts of Figure 11.4, Catherine Cretin for photographing and Mila Folgado for presentation of the artefacts on Figure 11.43.

\section{References}

Brindley, J. and C. Clarkson 2015. Beyond a suggestive morphology: Were Wardaman stone points exclusively spear armatures? Australian Archaeology 80:81-92. doi.org/10.1080/03122417.2015.116 82061

Bronk Ramsey, C. 2009. Bayesian analysis of radiocarbon dates. Radiocarbon 51(1):337-360. doi.org/ $10.1017 /$ S0033822200033865

Bronk Ramsey, C. 2013. OxCal Program v4.2.2. Radiocarbon Accelerator Unit, University of Oxford, Oxford.

Carson, L.J., P.W. Haines, A. Brakel, B.A. Pietsch and P.A. Ferenczi 1999. Milingimbi SD53-2, 1:250 000 Geological Map Series Explanatory Notes. Northern Territory Geological Survey, Government Printer of the Northern Territory, Darwin.

Chippindale, C. and P.S.C. Taçon 1993. Two old painted panels from Kakadu: Variation and sequence in Arnhem Land rock art. In J. Steinbring, A. Watchman, P. Faulstich and P.S.C. Taçon (eds), Time and Space: Dating and Spatial Considerations in Rock Art Research, pp. 32-56. Occasional AURA Publication 8. Australian Rock Art Research Association, Melbourne.

Cornell, R.M. and U. Schwertmann 2003. The Iron Oxides: Structure, Properties, Reactions, Occurrences, and Uses. Wiley-VCH, Weinheim. doi.org/10.1002/3527602097

David, B., J.-J. Delannoy, R. Roberts, Z. Jacobs, B. Brook, J.-M. Geneste, F. Petchey, J. Mialanes, T. Richards, B. Barker, M.I. Bird, C. Clarkson, E. Boche, S. Hoerlé and M. Katherine completed manuscript. Human colonisation of Sahul prior to fifty-one thousand years ago. 
David, B., J-M. Geneste, R.L. Whear, J-J. Delannoy, M. Katherine, R.G. Gunn, C. Clarkson, H. Plisson, P. Lee, F. Petchey, C. Rowe, B. Barker, L. Lamb, W. Miller, S. Hoerle, D. James, E. Boche, K. Aplin, I.J. McNiven, T. Richards, A. Fairbairn and J. Matthews 2011. Nawarla Gabarnmang, a 45,185 \pm 910 cal BP site in Jawoyn Country, southwest Arnhem Land plateau. Australian Archaeology 73:73-77.

David, B., B. Barker, F. Petchey, J.-J. Delannoy, J-M. Geneste, C. Rowe, M. Eccleston, L. Lamb and R. Whear 2013. A 28,000 year old excavated painted rock from Nawarla Gabarnmang, northern Australia. Journal of Archaeological Science 40:2493-2501. doi.org/10.1016/j.jas.2012.08.015

David, B., B. Barker, J.-J. Delannoy, J-M. Geneste, F. Petchey and L. Lamb 2014. A Pleistocene charcoal drawing or painting from northern Australia. INORA 69:18-22.

Delannoy, J.-J., B. David, J.-M. Geneste, M. Katherine, B. Barker, R.L. Whear and R.G. Gunn 2013. The social construction of caves and rockshelters: Chauvet Cave (France) and Nawarla Gabarnmang (Australia). Antiquity 87:12-29. doi.org/10.1017/S0003598X00048596

Elkin, A.P. 1952. Cave-painting in southern Arnhem Land. Oceania 22(4):245-255. doi.org/10.1002/ j.1834-4461.1952.tb00181.x

Geneste, J.-M. and H. Plisson 1990. Technologie fonctionnelle des pointes à cran solutréennes: L'apport des nouvelles données de la Grotte de Combe Saunière (Dordogne). In J.K. Kozlowski (ed.), Feuilles de Pierre: Les Industries à Pointes Foliacées du Paléolithique Supérieur Européen, pp. 293-332. Études et Recherches Archéologiques de l'Université de Liège 42, Liège.

Geneste, J.-M. and H. Plisson 1993. Hunting technologies and human behavior: Lithic analysis of Solutrean shouldered points. In H. Knecht, A. Pike-Tay and R. White (eds), Before Lascaux: The Complex Record of the Early Upper Paleolithic, pp. 117-137. CRC Press, Boca Raton.

Geneste, J.-M., B. David, H. Plisson, C. Clarkson, J-J. Delannoy, F. Petchey and R. Whear 2010. Earliest evidence for ground-edge axes: $35,400 \pm 410$ cal BP from Jawoyn country, Arnhem Land. Australian Archaeology 71:66-69. doi.org/10.1080/03122417.2010.11689385

Geneste, J-M, B. David, H. Plisson, J-J. Delannoy and F. Petchey 2012. The origins of ground-edge axes: New findings from Nawarla Gabarnmang, Arnhem Land (Australia) and global implications for the evolution of fully modern humans. Cambridge Archaeological Journal 22:1-17. doi.org/10.1017/ S0959774312000017

Goodman, D. and S. Piro 2013. GPR Remote Sensing in Archaeology. Springer-Verlag, Berlin. doi.org/ 10.1007/978-3-642-31857-3

Grogan, K.L., R.J. Gilkes and B.G. Lottermoser 2003. Maghemite formation in burnt plant litter at East Trinity, North Queensland, Australia. Clays and Clay Minerals 51(4):390-396. doi.org/10.1346/ CCMN.2003.0510404

Gunn, R.G. 1992. Bulajang: A reappraisal of the archaeology of an Aboriginal cult. In J. McDonald and I.P. Haskovec (eds), State of the Art, pp. 174-194. AURA Publication 6. Australian Rock Art Research Association, Melbourne.

Gunn, R.G. 2016. Art of the Ancestors: Spatial and Temporal Patterning in the Rock Art of Nawarla Gabarnmang, A Major Jawoyn Cultural Site on the Arnhem Land Plateau. Unpublished PhD thesis. Monash University, Clayton.

Gunn, R.G., R.L. Whear and L.C. Douglas 2012. Dating the present at Nawarla Gabarnmang: Time and function in the art of a major Jawoyn rock art and occupation site in western Arnhem Land. Australian Archaeology 75:55-65. doi.org/10.1080/03122417.2012.11681950 
Harris, E.C. 1989. Principles of Archaeological Stratigraphy. Academic Press, London.

Hedges, R.E.M. 2002. Bone diagenesis: An overview of processes. Archaeometry 44:319-328. doi.org/10.1111/1475-4754.00064

Ingold, T. 2000. The Perception of the Environment: Essays on Livelihood, Dwelling and Skill. Routledge, London. doi.org/10.4324/9780203466025

Jans, M.M.E., C.M. Nielsen-Marsh, C.I. Smith, M.J. Collins and H. Kars 2004. Characterisation of microbial attack on archaeological bone. Journal of Archaeological Science 31:87-95. doi.org/ 10.1016/j.jas.2003.07.007

McDonald, R.C., R.F. Isbell, J.G. Speight, J. Walker and M.S. Hopkins 1998. Australian Soils and Land Survey Field Handbook. CSIRO, Canberra.

Normand C., M. O’Farrell and J. Rios Garaizar 2008. The function(s) of archaic Aurignacian bladelets: Data and thoughts based on examples from Isturitz Cave (Pyrénées-Atlantiques, France). Palethnologie 1:6-44.

O'Farrell M. 2004. Les pointes de la Gravette de Corbiac (Dordogne) et considérations sur la chasse au Paléolithique supérieur ancien. In P. Bodu and C. Constantin (eds), Approches Fonctionnelles en Préhistoire. XXVeme Congrès Préhistorique de France, pp. 121-138. Société Préhistorique Française, Nanterre.

Quinif, Y. 2010. Fantômes de Roche et Fantômisation. Essai sur un Nouveau Paradigme de Karstogénèse. Karstologia Mémoires, Volume 18. Association Française de Karstologie, Mons.

Rayment, G.E and D.J. Lyons 2011. Soil Chemical Methods: Australasia. CSIRO Publishing, Melbourne.

Reimer, P.J., E. Bard, A. Bayliss, J.W. Beck, P.G. Blackwell, C. Bronk Ramsey, C.E. Buck, H. Cheng, R.L. Edwards, M. Friedrich, P.M. Grootes, T.P. Guilderson, H. Haflidason, I. Hajdas, C. Hatté, T.J. Heaton, D.L. Hoffmann, A.G. Hogg, K.A. Hughen, K.F. Kaiser, B. Kromer, S.W. Manning, M. Niu R.W. Reimer, D.A. Richards, E.M. Scott, J.R. Southon, R.A. Staff, C.S.M. Turney and J. van der Plicht 2013. IntCal13 and Marine13 radiocarbon age calibration curves, 0-50 000 years cal BP. Radiocarbon 55 (4):1869-1887. doi.org/10.2458/azu_js_rc.55.16947

Russell, T. 2012. No one said it would be easy. Ordering San paintings using the Harris Matrix: Dangerously fallacious? A reply to David Pearce. South African Archaeological Bulletin 67(196):26-272.

Salomon, H., C. Vignaud, S. Lahlil and N. Menguy 2015. Solutrean and Magdalenian ferruginous rocks heat-treatment accidental and/or deliberate action? Journal of Archaeological Science 55:100112. doi.org/10.1016/j.jas.2014.12.024

Schwertmann U. and R.M. Cornell 2000. Iron oxides in the Laboratory: Preparation and Characterization. Wiley-VCH, New York. doi.org/10.1002/9783527613229

Spriggs, M. 1989. The dating of the Island Southeast Asian Neolithic: An attempt at chronometric hygiene and linguistic correlation. Antiquity 63:587-613. doi.org/10.1017/S0003598X00076560

Thomas, J. 2008. Archaeology, landscape, and dwelling. In B. David and J. Thomas (eds), Handbook of Landscape Archaeology, pp. 300-306. Left Cost Press, Walnut Creek.

Wesley, D., S. O'Connor and J. Fenner 2016. Re-evaluating the timing of the Indonesian industry in northwestern Arnhem Land. Archaeology in Oceania. doi.org/10.1002/arco.5091 
This text is taken from The Archaeology of Rock Art in Western Arnhem Land, Australia, edited by Bruno David, Paul Taçon, Jean-Jacques Delannoy and Jean-Michel Geneste, published 2017 by ANU Press, The Australian National University, Canberra, Australia.

dx.doi.org/10.22459/TA47.11.2017.11 